GÖTtinger Zentrum

Für Biodiversitätsforschung Und ÖKOlogie

- Göttingen Centre for Biodiversity and Ecology -

\title{
Tritrophic Interactions between Populus tremula, Leaf Beetles and their Natural Enemies - FROM THE FIELD TO THE LABORATORY
}

\author{
Dissertation zur Erlangung des Doktorgrades der \\ Mathematisch-Naturwissenschaftlichen Fakultät der \\ Georg-August-Universität Göttingen
}

\author{
vorgelegt von \\ Diplom-Biologe \\ Paul-Albin Maximilian von Fragstein und Niemsdorff \\ geboren in \\ Stuttgart
}

Göttingen, Juli 2011 
Referent: Prof. Dr. Teja Tscharntke

Korreferent: Prof. Dr. Stefan Schütz

Tag der mündlichen Prüfung: 13.09.2011 
In Erinnerung an Michael Ksinsik 


\section{Contents}

Chapter 1 - General Introduction: Tritrophic interactions between Populus tremula, leaf beetles and their natural enemies - from the field to the laboratory 1

Introduction 2

$\begin{array}{lr}\text { Study design \& organisms } & 6\end{array}$

Research objectives and chapter outline 12

$\begin{array}{ll}\text { References } & 14\end{array}$

CHAPTER 2 - Relating genetic variation of ecologically important tree traits to associated organisms in full-sib aspen families $\quad 24$

Abstract 25

$\begin{array}{ll}\text { Introduction } & 26\end{array}$

$\begin{array}{lr}\text { Material and methods } & 27\end{array}$

Results $\quad 32$

$\begin{array}{ll}\text { Discussion } & 39\end{array}$

$\begin{array}{ll}\text { Conclusion } & 41\end{array}$

Acknowledgements $\quad 41$

References $\quad 42$

$\begin{array}{ll}\text { Appendix } & 48\end{array}$

ChAPTER 3 - Variable responses of leaf beetle adults and larvae and their predators to morphological and genetic differences of Populus tremula trees 55

$\begin{array}{ll}\text { Abstract } & 56\end{array}$

$\begin{array}{ll}\text { Introduction } & 57\end{array}$

Material and methods $\quad 59$

$\begin{array}{ll}\text { Results } & 64\end{array}$

$\begin{array}{ll}\text { Discussion } & 73\end{array}$

Acknowledgements $\quad 76$

$\begin{array}{ll}\text { References } & 77\end{array}$

$\begin{array}{ll}\text { Appendix } & 85\end{array}$ 
CHAPTER 4 - The allomone of leaf beetle larvae (salicylaldehyde) attracts experienced $\begin{array}{ll}\text { Harmonia axyridis and other predators } & 87\end{array}$

$\begin{array}{ll}\text { Abstract } & 88\end{array}$

$\begin{array}{lr}\text { Introduction } & 89\end{array}$

$\begin{array}{lr}\text { Material and methods } & 90\end{array}$

Results $\quad 92$

$\begin{array}{ll}\text { Discussion } & 95\end{array}$

$\begin{array}{lr}\text { Acknowledgements } & 97\end{array}$

$\begin{array}{lr}\text { References } & 98\end{array}$

Chapter 5 - Porous defense in a tritrophic system: odor perception reflects prey specialization of potter wasps (Hymenoptera: Eumeninae) 104

$\begin{array}{ll}\text { Abstract } & 105\end{array}$

$\begin{array}{lr}\text { Introduction } & 106\end{array}$

$\begin{array}{lr}\text { Material and methods } & 109\end{array}$

$\begin{array}{ll}\text { Results } & 113\end{array}$

$\begin{array}{ll}\text { Discussion } & 116\end{array}$

$\begin{array}{ll}\text { Acknowledgements } & 118\end{array}$

$\begin{array}{ll}\text { References } & 119\end{array}$

$\begin{array}{ll}\text { Appendix } & 127\end{array}$

$\begin{array}{lr}\text { Chapter } 6 \text { - Synthesis } & 128\end{array}$

$\begin{array}{ll}\text { Synthesis } & 129\end{array}$

$\begin{array}{ll}\text { References } & 134\end{array}$

$\begin{array}{ll}\text { SUMMARY } & 136\end{array}$

$\begin{array}{ll}\text { SUMMARY } & 137\end{array}$

$\begin{array}{ll}\text { ZUSAMMENFASSUNG } & 139\end{array}$

ACKNOWLEDGEMENTS

$\begin{array}{ll}\text { Curriculum Vitae } & 143\end{array}$

$\begin{array}{ll}\text { Publications } & 144\end{array}$ 


$$
\mid \begin{array}{r}
\text { Chapter } \\
1
\end{array}
$$

\section{General Introduction:}

Tritrophic Interactions between Populus tremula, Leaf Beetles and their Natural Enemies

- From the Field to the Laboratory

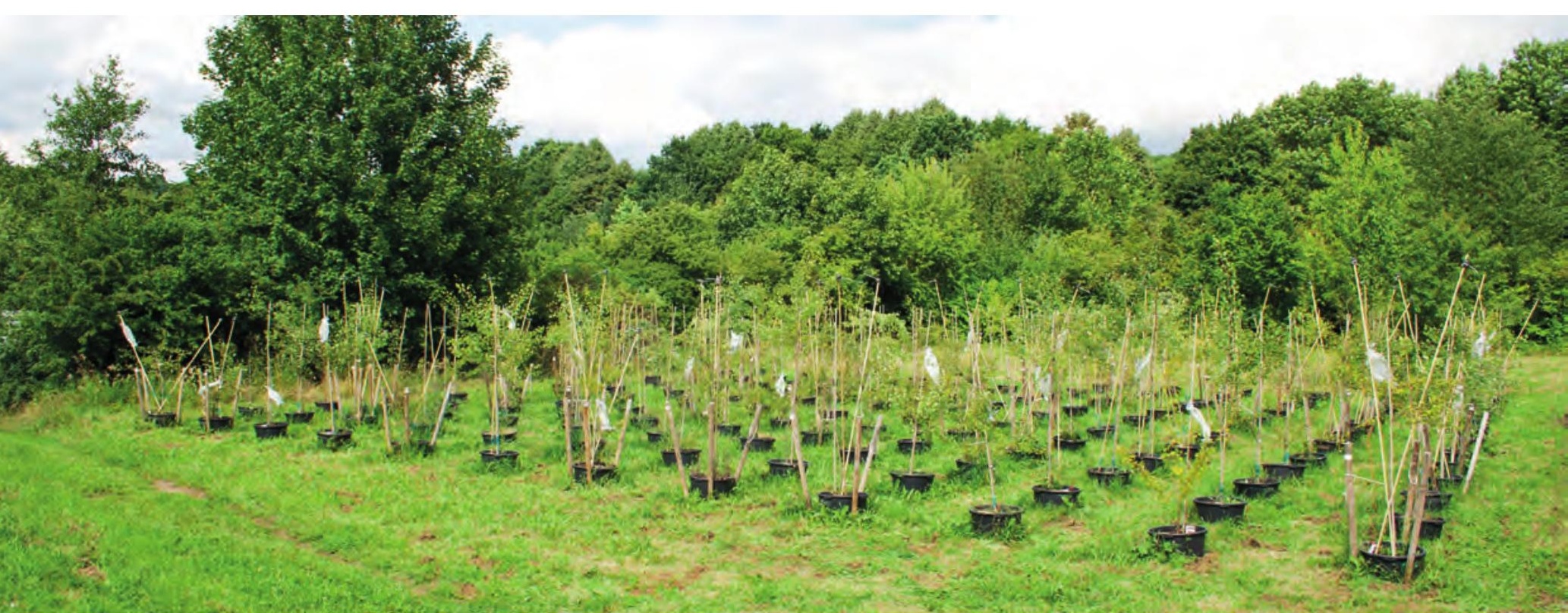




\section{INTRODUCTION}

A drastic increase of global energy consumption is expected for the following years. The global goal (Kyoto protocol) is to replace fossil fuel by renewable energy sources (Lasch et al., 2010), thus the cultivation of renewable energy gains in importance, e.g. with trees as a living store of biomass (Hinchee et al., 2009). In this context short rotation plantations with fast-growing tree species and rotation times of less than 30 years (Makeschin, 1999) got increasingly into focus of current ecology research but have been already aresearch subject of applied sciences since the 1970s. Short rotation cropping systems can help to meet the requirements of future wood demands and can also sequester carbon as a contribution to the reduction of greenhouse gases (Dickmann, 2006). However, today these cropping systems are not able to supply the actual wood demand, as the plantations provide only $12 \%$ of the total amount of wood consumed, whereas the rest of $88 \%$ is still taken from wild forests (Fenning and Gershenzon, 2002). The Food and Agriculture Organization of the United Nations (FAO) expected an increase of demand for wood from today $1.7 \%$ annually up to $20 \%$ in the following decades. To meet these requirements 9.4 million hectares of forest cover will be destroyed every year (FAO, 2008). The exploitation of native forests at current rates will lead to a massive depletion of this resource. Moreover, the destruction of native forests will result in an irretrievable loss of habitats and in the endangering of wildlife (Fox, 2000, Fenning and Gershenzon, 2002). Therefore, high-yielding short rotation cropping systems on former arable land are a worthwile alternative to the exploitation of natural habitats.

\section{Poplar short rotation forestry}

In short rotation plantations mainly Salix and Populus species are cultivated which exhibit economically important characteristics such as fast growth-rates (Zsuffa et al., 1996), efficient nitrogen storage (Pregitzer et al., 1990), high photosynthetic capacity (Barigah et al., 1994), high tolerance and resistance against damage by herbivores (Bassman et al., 1982), and global propagation (Yu, 2001, Dickmann and Kuzovkina, 2008). Such tree species are commonly used to obtain pulp, chipboard and energy (Bradshaw et al., 2000).

Additionally, Populus species have become a favorite subject in ecology conservation, environmental sciences, molecular studies - with the first completely sequenced tree genome 
(Tuskan et al., 2006) -, physiology and biotechnology (Bradshaw et al., 2000) due to their important role in several ecosystems. Populus species provide habitat for wildlife (Sage, 1998), act as keystone species with a high level of genetic diversity at the population level (David et al., 2001), and are involved in complex community level interactions. For example Madritch et al. (2007, 2009) showed the linkage between genetic diversity and variation in belowground processes in trembling aspen, and Whitham et al. (2006) discussed the importance of genetic diversity in evolutionary processes in natural forests.

Poplars are pioneer species and common plant invaders in the early succession on disturbed sites. They are widespread trees species in boreal, temperate, montane as well as tropical forests (Dickmann and Kuzovkina, 2008) and include about 30 species in the northern hemisphere (Eckenwalder, 1996). In natural sites aspen create habitats for a fauna including many endangered species and therefore provide important ecosystem services (Kouki et al., 2004).

Agricultural and short rotation forestry production is focused on maximum yield which is achieved by extended cultures of selectively breed, but ecologically less adapted crop and tree varieties. This type of management causes the instability and pest susceptibility of such cropping systems (Gruppe et al., 1999). In willow plantations the blue willow leaf beetle Phratora vulgatissima prefers trees cropped in monoculture (Peacock et al., 1999). With regard to cropping systems two principal hypotheses are known as drivers for lower herbivore densities: 1) the "enemies hypothesis": predators and parasites are more effective in complex systems than in simple ones; and 2) the "resource concentration hypothesis": specialist herbivores are able to find, stay, and reproduce more easily in simple systems, i.e. monocultures of their host plants (Root, 1973, Risch, 1981, Russell, 1989). Lacking natural resistance against pathogens and insect pests is compensated by intensive use of pesticides (Gruppe et al., 1999). The application of insecticides in short rotation plantations is reported to increase the biomass growth (Gruppe et al., 1999). However, Bassman et al. (1982) estimated that defoliation of poplars up to $75 \%$ results in only a negligible negative growth impact. A reduction of feeding damage by herbivores can be achieved by the diversification of plant cropping (Stamps and Linit, 1998). Planting of diverse poplar and willow species together in a plantation can reduce the feeding damage by herbivorous insects due to the 
fact that diversity in cropping systems can alter the behaviour of herbivorous invertebrates (Vandermeer, 1989).

\section{Multitrophic interactions}

A huge variety of abiotic and biotic factors affect the abundance of herbivores and the impact of natural enemies, e.g. fluctuations in weather or availability and quality of food. Thus, plants (as the food resource) exert a bottom-up influence on herbivorous insects and their natural enemies by their distribution, availability, their architecture and by primary as well as secondary metabolites (Ehrlich and Raven, 1964, Price et al., 1980, Bottrell et al., 1998, Bernays and Chapman, 2000, Legrand and Barbosa, 2003, Schoonhoven et al., 2005). There are direct and indirect ways of such bottom-up influences of plants. Plant morphological traits including plant size (Neuvonen and Niemelä, 1981, Lawton, 1983), plant biomass (resource abundance) (Hunter, 1992, Marques et al., 2000), leaf surface characteristics such as pubescence, aspects of plant color and shape and phenological differences as well as plant allelochemicals act directly as well as indirectly (Kagata et al., 2005) on herbivores and natural enemies. Also, plant population traits such as variation in plant density and plant diversity have a direct impact on arthropod communities. Indirect effects are mainly driven by infochemicals, e.g. herbivore-induced plant volatiles (HIPVs) (Bottrell et al., 1998, Dicke and Baldwin, 2010). Multitrophic interactions are often shaped by such herbivore-induced plant volatiles (HIPVs) released by infested plants, as well as by herbivore sequestered plant allelochemicals, e.g. salicyladehyde sequestered by salicin using leaf beetle larvae, and by prey volatiles such as pheromones and de novo synthesized allomones (Fig. 1).

Infochemical use is known for a range of herbivores (Rojas, 1999, Kalberer et al., 2001, Halischke et al., 2008) and of the herbivores' enemies (Takabayashi and Dicke, 1996, Steidle and van Loon, 2003, Dicke and Baldwin, 2010) including parasites (Dougherty et al., 1999), parasitoids (Rutledge, 1996, Quicke, 1997) and predators including beetles (Herms et al., 1991, Yoneya et al., 2009), true bugs (Weissbecker et al., 2000) and wasps (Hendrichs et al., 1994, Punzo and Ludwig, 2005). These infochemicals are used for host finding and location and thus link two trophic levels, the first and second level (plant - herbivore) as well as the second and third level (prey - predator) (Fig. 1). 
Specialists

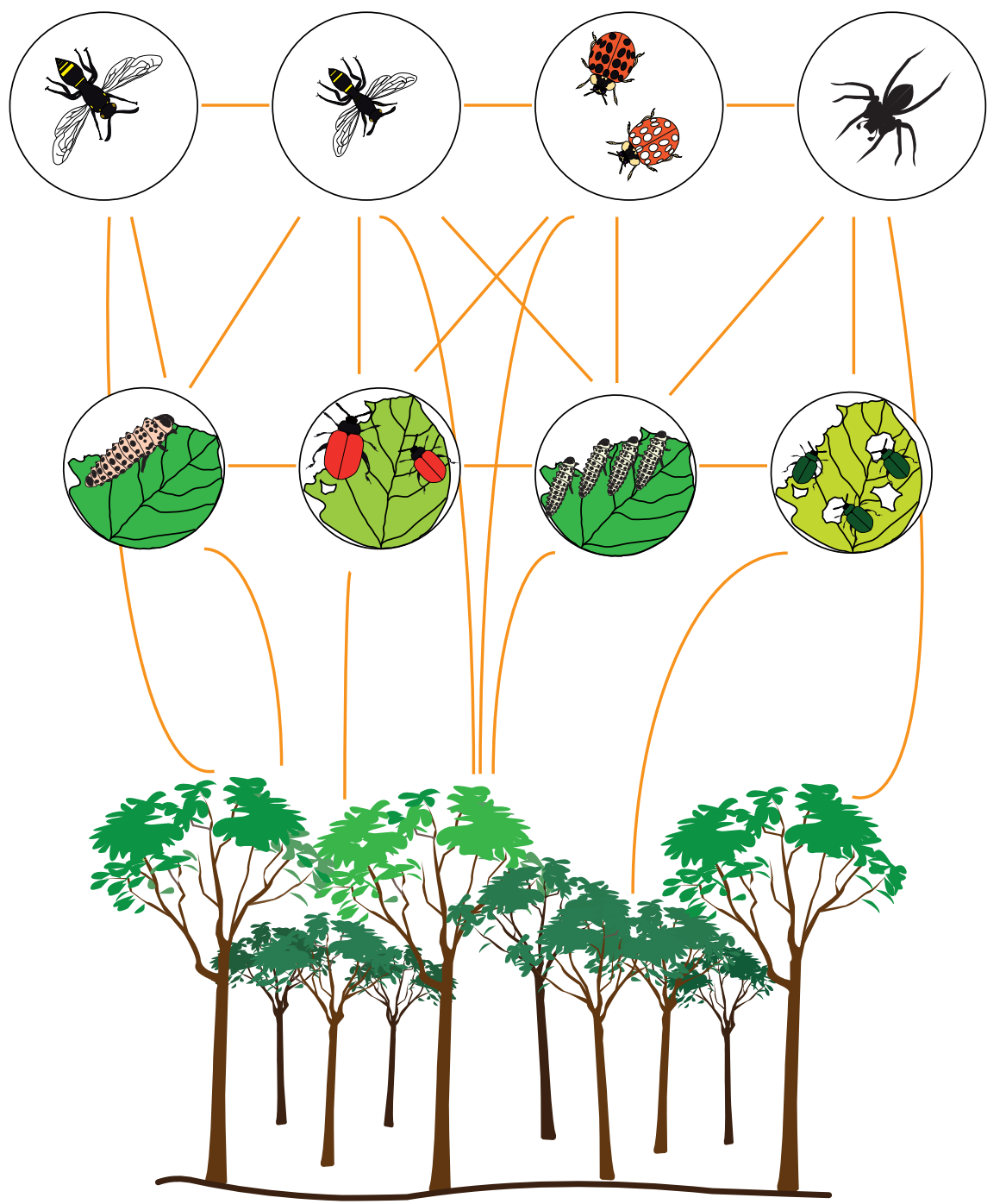

Predators

third trophic level

\section{Herbivores}

second trophic level

\section{Plants}

first trophic level

Figure 1: Scheme of multitrophic interactions modified after Dicke and Baldwin (2010). Orange lines represent infochemically mediated interactions.

Previous research in community ecology is dominated by investigating such two trophic level interactions (plant-herbivore and predator-prey) (Tscharntke and Hawkins, 2002). Studies dealing with the tritrophic system consisting of Populus and/or Salix, herbivorous insects, and their natural enemies were also often concentrated on only two levels.

In the last three decades many studies have been conducted regarding the interactions of the first and second trophic level, between willows or poplars and different herbivorous insects, especially specialized leaf beetles of the genera Chrysomela (Augustin et al., 1993, La Spina et al., 2010) and Phratora (Finet and Gregoire, 1982, Peacock and Herrick, 2000, Peacock et 
al., 2004). Genetic differences of the tree species were found to drive tolerance and resistance against herbivore damage (Denno et al., 1990, Shen and Bach, 1997). A lot of studies refer to the leaf chemistry and the relationship with phytophagous insects (Osier and Lindroth, 2006, Donaldson and Lindroth, 2007, Stevens et al., 2007). Additionally, several studies were conducted on the interactions between specialized salicin using leaf beetle larvae and natural enemies (specialists and generalists) (Pasteels and Gregoire, 1984, Smiley, 1991, Gathmann and Tscharntke, 1999, Gross et al., 2004), but less is known about multitrophic interactions in this system. Only few studies investigated tritrophic interactions on willows: Sipura (1999) showed that bird predation can alter the patterns of insect densities on willows with positive effects for the trees. Kagata et al. (2005) described indirect bottom-up effects in laboratory experiments of leaf beetle larvae to a lady bird beetle in a system with cut and uncut willows. Cha et al. (2009) proved that the preference of Chrysomela knabi for phenolic glycoside rich willow plants increases larval growth and survival, and that predation pressure by common and exotic generalist predators would reinforce this preference.

\section{STUDY ORGANISMS AND DESIGN}

\section{The Göttingen Poplar Diversity Project}

The Göttingen Poplar Diversity Project is a sub-project of the Göttingen cluster of excellence "Functional Biodiversity Research", which was established in 2008 at the University of Göttingen. The overall topic of the cluster is biodiversity and ecosystem functioning, including experiments in grasslands and historical studies in terms of long-term biodiversity change. The poplar diversity project involves several working groups investigating the functional role of intraspecific diversity in woody plants using aspen (Populus tremula) as a model species. The molecular analyses of the P. tremula trees were performed by the Department of Forest Genetics and Forest Tree Breeding. The Department of Plant Ecology and Ecosystem Research and the Department of Forest Botany and Tree Physiology adressed the questions how phenological, morphological and physiological traits as well as plant-fungi interactions affect growth performance of the trees. The Department of Forest Zoology and Forest 
Conservation investigated the Volatile Organic Compound (VOC) emission by the trees and the influence of VOCs on herbivorous insects. My own thesis aimed at analyzing the influence of different morphological and chemical tree traits (leaf chemistry and herbivoreinduced plant volatiles) on herbivorous insects and their natural arthropod enemies.

Study organisms - The Populus tremula trees

The European aspen (Populus tremula) was used as model tree for the experiments, because this economically impacted species is able to reach considerable growth rates even on poor soils and under unfavourable habitat conditions (Hofman, 1998) and is less sensitive to drought like e.g. P. trichocarpa. The European aspen is a pioneer species with an extensive distribution range and is one of the most widespread tree species in boreal and temperate forests (Bradshaw et al., 2000, Dickmann and Kuzovkina, 2008). Aspen reproduce via root suckers as well as via sexual reproduction and evolved several aspen genotypes caused by lots of possible crossing constellations of parent trees in given surroundings. This high level of genetic diversity creates genetically rich tree patches (Madritch et al., 2007, 2009). Within these patches Madritch et al. (2009) found that ecosystem soil processes are linked with canopy herbivore interactions. Naturally grown aspen forests provide habitat and food for numerous insect and pathogen species, even endangered ones (David et al., 2001, Kouki et al., 2004), and they are significantly embedded in the carbon cycle by their high rates of carbon sequestration (Kurz and Apps, 1999). Hence, aspen became more important in short rotation forestry because of its ecological functions (Kouki et al., 2004) as well as a possible resource for biomass production on marginal soils (Hofman, 1998). Because of this benefit aspen may be preferred to drought sensitive species such as $P$. trichocarpa under predicted future climate scenarios with increasing drought periods in summer.

The $P$. tremula trees used in our experiments originated from eight full-sib families with German origin. The progenies of each full-sib family were bred by controlled crossings in 2000, from parent tree material originating from 30-year-old trees selected in the district of Geismar in Göttingen. The crossings and molecular analyses of the trees were conducted by the Department of Forest Genetics and Forest Tree Breeding. 
Study organisms - Leaf beetles and natural enemies (arthropods)

The leaf beetles of the genera Chrysomela, especially C. populi and C. tremulae, and Phratora

(Phratora vitellinae and P. vulgatissima) are reported to be the most important defoliating

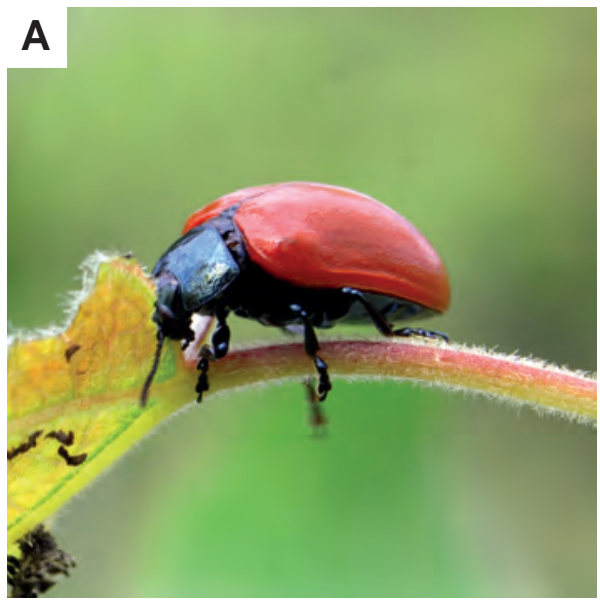

B

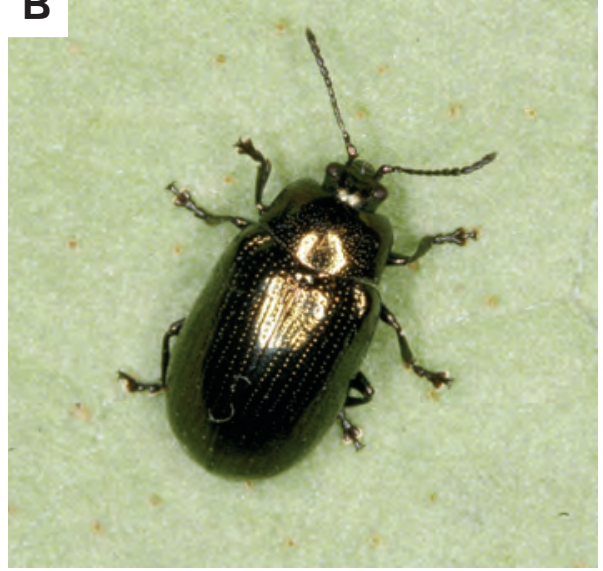

\section{C}

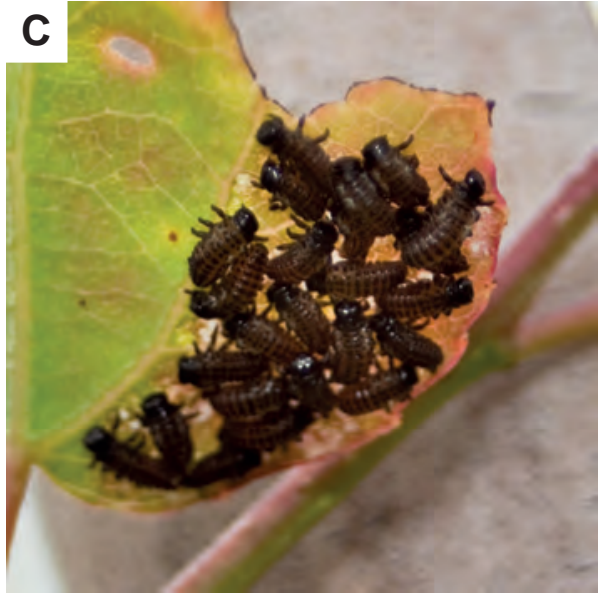

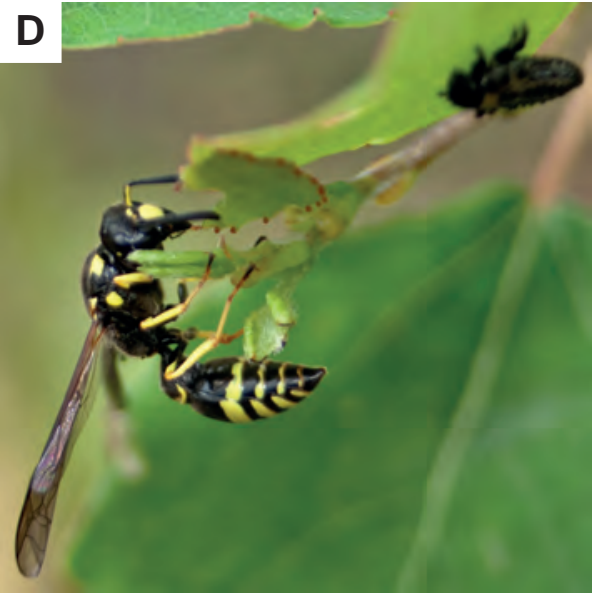

$\mathbf{E}$

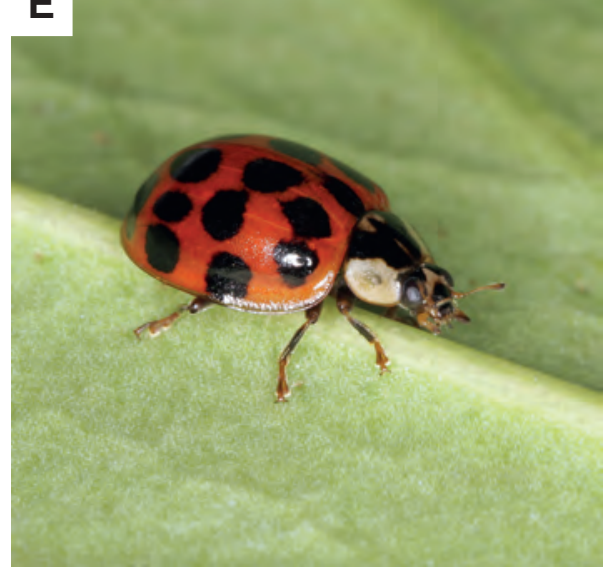

$\mathbf{F}$

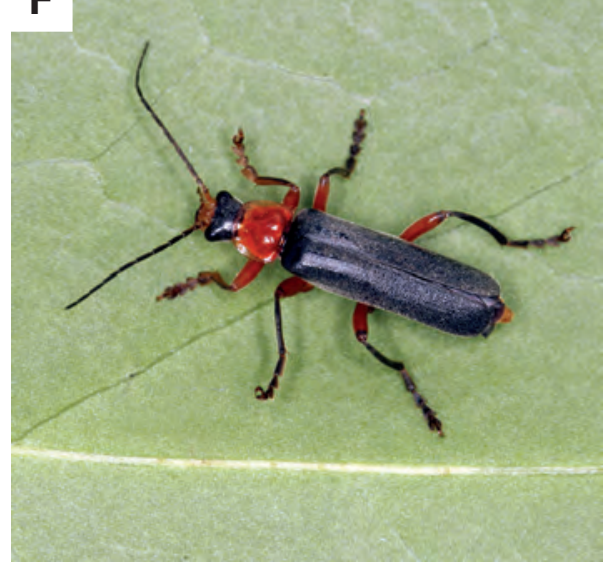

Figure 2: Pictures of leaf beetles, their larvae (A-C) as well as specialist and generalist predators (D-E). A: Chrysomela populi. B: Phratora vitellinae. C: Phratora sp. larvae. D: Symmorphus gracilis. E: Harmonia axyridis. F: Cantharis pellucida. B, E and F copyright by Christoph Benisch (www.kerbtier.de). 
pests in young short rotation plantations in Central Europe (Sinreich, 1955, Augustin et al., 1993, Gruppe et al., 1999). Among these leaf beetle species such as Phratora vulgatissima and Galerucella lineola prefer leaves with low concentrations of phenolic glycosides (Kendall et al., 1996, Orians et al., 1997, Glynn et al., 2004), whereas Chrysomela populi, Phratora vitellinae and Gonioctena decemnotata, prefer salicaceous tree species with relatively high concentrations of phenolic glycosides in the leaves (Rowell-Rahier, 1984, Orians et al., 1997, Ikonen, 2002). Leaf beetle larvae feeding on willow and poplar sequester phenolic glycosides, especially salicin and its derivatives, to salicylaldehyde (Pasteels et al., 1983, Smiley et al., 1985, Köpf et al., 1998). This salicylaldehyde provides protection against several generalist arthropod predators such as ants (Wallace and Blum, 1969), ladybird beetles (Smiley, 1991) and spiders (Palokangas and Neuvonen, 1992) (Fig. 2). Only specialized natural enemies such as eumenid wasps (Blüthgen, 1961, Gathmann and Tscharntke, 1999), phorid flies (Zvereva and Rank, 2004), syrphid flies (Rank and Smiley, 1994, Gross et al., 2004) and the sawfly Tenthredo olivacea (Pasteels and Gregoire, 1984) are reported to attack the leaf beetle larvae because they are attracted by the larvae’s defense secretion.

\section{Experimental sites - Common garden experiments}

Two common-garden experiments with $P$. tremula were established in 2008. One was established in beds next to the greenhouses of the Department of Forest Botany and Tree Physiology at the University of Göttingen (a); the other experiment was established on a study site next to the greenhouse of the Institute of Agroecology (b). Both sites are located in Göttingen. In both experiments $P$. tremula trees of eight full-sib families were selected and planted. For the first experiment (a) trees were planted in a randomized design in two blocks. Each block contained four plots and each plot included three aspen saplings of each full-sib family (Fig. 3). The trees were planted with a distance of $40 \mathrm{~cm}$ to each other. An additional treatment with a systematic fungicide was applied monthly on four plots, whereas the other four plots were treated with water and acted as controls.

For the second experiment (b) trees were planted in a randomized block design containing nine plots (Fig. 4 A). Each full-sib family was represented by 18 trees. The trees were planted into pots with a distance of $2 \mathrm{~m}$ between two pots following the randomized design with 144 trees. The trees were watered as necessary in both experiments. 


\section{A}

\begin{tabular}{|l|llllll|llllll|llllll|lllllll|}
$\mathrm{m}$ & $\mathrm{m}$ & $\mathrm{m}$ & $\mathrm{m}$ & $\mathrm{m}$ & $\mathrm{m}$ & $\mathrm{m}$ & $\mathrm{m}$ & $\mathrm{m}$ & $\mathrm{m}$ & $\mathrm{m}$ & $\mathrm{m}$ & $\mathrm{m}$ & $\mathrm{m}$ & $\mathrm{m}$ & $\mathrm{m}$ & $\mathrm{m}$ & $\mathrm{m}$ & $\mathrm{m}$ & $\mathrm{m}$ & $\mathrm{m}$ & $\mathrm{m}$ & $\mathrm{m}$ & $\mathrm{m}$ & $\mathrm{m}$ & $\mathrm{m}$ \\
$\mathrm{m}$ & 7 & 8 & 3 & 2 & 4 & 5 & 6 & 3 & 2 & 8 & 2 & 7 & 8 & 1 & 6 & 5 & 3 & 4 & 1 & 3 & 1 & 2 & 1 & 2 & $\mathrm{~m}$ \\
$\mathrm{~m}$ & 5 & 3 & 6 & 4 & 5 & 8 & 7 & 5 & 3 & 2 & 6 & 4 & 2 & 3 & 7 & 2 & 5 & 3 & 3 & 6 & 4 & 8 & 4 & 5 & $\mathrm{~m}$ \\
$\mathrm{~m}$ & 7 & 4 & 2 & 7 & 6 & 3 & 3 & 1 & 8 & 4 & 8 & 1 & 4 & 5 & 6 & 7 & 2 & 8 & 6 & 3 & 7 & 5 & 7 & 2 & $\mathrm{~m}$ \\
$\mathrm{~m}$ & 1 & 8 & 6 & 1 & 2 & 1 & 7 & 5 & 4 & 1 & 5 & 6 & 7 & 8 & 1 & 4 & 6 & 1 & 7 & 4 & 8 & 6 & 8 & 5 & $\mathrm{~m}$ \\
$\mathrm{~m}$ & $\mathrm{~m}$ & $\mathrm{~m}$ & $\mathrm{~m}$ & $\mathrm{~m}$ & $\mathrm{~m}$ & $\mathrm{~m}$ & $\mathrm{~m}$ & $\mathrm{~m}$ & $\mathrm{~m}$ & $\mathrm{~m}$ & $\mathrm{~m}$ & $\mathrm{~m}$ & $\mathrm{~m}$ & $\mathrm{~m}$ & $\mathrm{~m}$ & $\mathrm{~m}$ & $\mathrm{~m}$ & $\mathrm{~m}$ & $\mathrm{~m}$ & $\mathrm{~m}$ & $\mathrm{~m}$ & $\mathrm{~m}$ & $\mathrm{~m}$ & $\mathrm{~m}$ & $\mathrm{~m}$ \\
\hline
\end{tabular}

\begin{tabular}{|c|cccccc|cccccc|cccccc|ccccccc|}
\hline $\mathrm{m}$ & $\mathrm{m}$ & $\mathrm{m}$ & $\mathrm{m}$ & $\mathrm{m}$ & $\mathrm{m}$ & $\mathrm{m}$ & $\mathrm{m}$ & $\mathrm{m}$ & $\mathrm{m}$ & $\mathrm{m}$ & $\mathrm{m}$ & $\mathrm{m}$ & $\mathrm{m}$ & $\mathrm{m}$ & $\mathrm{m}$ & $\mathrm{m}$ & $\mathrm{m}$ & $\mathrm{m}$ & $\mathrm{m}$ & $\mathrm{m}$ & $\mathrm{m}$ & $\mathrm{m}$ & $\mathrm{m}$ & $\mathrm{m}$ & $\mathrm{m}$ \\
$\mathrm{m}$ & 4 & 7 & 8 & 5 & 3 & 2 & 6 & 2 & 7 & 8 & 7 & 3 & 1 & 6 & 7 & 6 & 8 & 2 & 5 & 3 & 6 & 7 & 4 & 8 & $\mathrm{~m}$ \\
$\mathrm{~m}$ & 3 & 5 & 1 & 6 & 2 & 1 & 1 & 6 & 5 & 3 & 6 & 1 & 3 & 2 & 5 & 2 & 6 & 5 & 3 & 7 & 3 & 1 & 2 & 6 & $\mathrm{~m}$ \\
$\mathrm{~m}$ & 4 & 6 & 2 & 1 & 8 & 5 & 2 & 8 & 1 & 2 & 4 & 8 & 1 & 4 & 3 & 7 & 4 & 7 & 8 & 4 & 2 & 8 & 1 & 4 & $\mathrm{~m}$ \\
$\mathrm{~m}$ & 8 & 3 & 7 & 6 & 7 & 4 & 4 & 5 & 4 & 5 & 3 & 7 & 8 & 5 & 4 & 8 & 1 & 3 & 1 & 7 & 5 & 6 & 5 & 2 & $\mathrm{~m}$ \\
$\mathrm{~m}$ & $\mathrm{~m}$ & $\mathrm{~m}$ & $\mathrm{~m}$ & $\mathrm{~m}$ & $\mathrm{~m}$ & $\mathrm{~m}$ & $\mathrm{~m}$ & $\mathrm{~m}$ & $\mathrm{~m}$ & $\mathrm{~m}$ & $\mathrm{~m}$ & $\mathrm{~m}$ & $\mathrm{~m}$ & $\mathrm{~m}$ & $\mathrm{~m}$ & $\mathrm{~m}$ & $\mathrm{~m}$ & $\mathrm{~m}$ & $\mathrm{~m}$ & $\mathrm{~m}$ & $\mathrm{~m}$ & $\mathrm{~m}$ & $\mathrm{~m}$ & $\mathrm{~m}$ & $\mathrm{~m}$ \\
\hline
\end{tabular}

\section{B}

\begin{tabular}{|llllll|llllll|llllll|llllllll}
$\mathrm{m}$ & $\mathrm{m}$ & $\mathrm{m}$ & $\mathrm{m}$ & $\mathrm{m}$ & $\mathrm{m}$ & $\mathrm{m}$ & $\mathrm{m}$ & $\mathrm{m}$ & $\mathrm{m}$ & $\mathrm{m}$ & $\mathrm{m}$ & $\mathrm{m}$ & $\mathrm{m}$ & $\mathrm{m}$ & $\mathrm{m}$ & $\mathrm{m}$ & $\mathrm{m}$ & $\mathrm{m}$ & $\mathrm{m}$ & $\mathrm{m}$ & $\mathrm{m}$ & $\mathrm{m}$ & $\mathrm{m}$ & $\mathrm{m}$ & $\mathrm{m}$ \\
$\mathrm{m}$ & 3 & 2 & 4 & 5 & 6 & 3 & 2 & 5 & 2 & 3 & 7 & 1 & 6 & 5 & 3 & 4 & 1 & 3 & 1 & 2 & 1 & 2 & $\mathrm{~m}$ \\
$\mathrm{~m}$ & 3 & 6 & 4 & 5
\end{tabular}

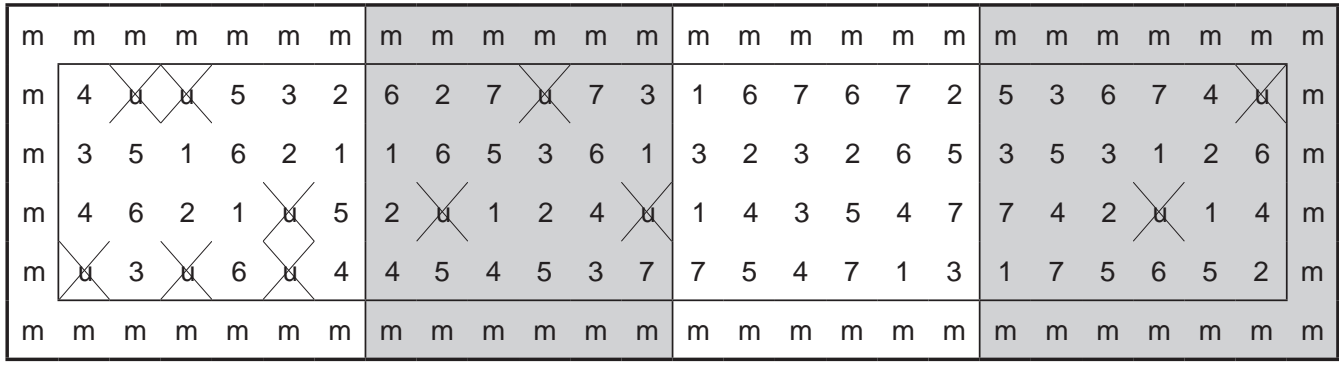

\section{$10 \mathrm{~m}$}

Figure 3: Design of the poplar common-garden experiment at the Department of Forest Botany and Tree Physiology at the University of Göttingen (A) before and (B) after the additional molecular analyses of the trees. 24 progenies of eight (1-8) full-sib families were planted in eight plots, of which four (grey) were treated monthly with a systematic fungicide and four were used as control. $\mathrm{m}=$ margin trees (P. tremula). $\mathrm{u}=$ tree of unknown full-sib family. 
An additional molecular analysis of the trees of all full-sib families revealed that the trees of full-sib family C8 (in both experiments) had to be excluded from statistical analyses because they cannot assign to an own full-sib family. Due to this fact the block design of experiment (b) had to be revised into a fully randomized design (Fig. 4 B).

\begin{tabular}{|l|lll|llll|llll|}
\hline \multicolumn{10}{|l|}{} & \multicolumn{10}{|l}{} \\
\hline 4 & 1 & 5 & 2 & 3 & 6 & 8 & 5 & 4 & 1 & 2 & 5 \\
7 & 3 & 4 & 6 & 5 & 1 & 2 & 1 & 6 & 5 & 3 & 1 \\
8 & 5 & 1 & 8 & 2 & 6 & 7 & 8 & 2 & 8 & 6 & 8 \\
3 & 2 & 7 & 6 & 7 & 4 & 3 & 4 & 7 & 4 & 7 & 3 \\
\hline 5 & 8 & 1 & 8 & 5 & 6 & 8 & 1 & 2 & 3 & 1 & 4 \\
2 & 6 & 4 & 3 & 2 & 7 & 2 & 3 & 5 & 7 & 6 & 7 \\
4 & 7 & 1 & 7 & 1 & 5 & 8 & 7 & 4 & 8 & 2 & 5 \\
2 & 6 & 5 & 3 & 4 & 3 & 4 & 6 & 3 & 1 & 6 & 8 \\
\hline 4 & 3 & 4 & 6 & 7 & 1 & 7 & 5 & 2 & 5 & 4 & 7 \\
8 & 1 & 7 & 5 & 2 & 3 & 4 & 6 & 4 & 1 & 3 & 8 \\
3 & 2 & 6 & 1 & 8 & 5 & 8 & 1 & 8 & 5 & 2 & 7 \\
8 & 5 & 7 & 2 & 4 & 2 & 6 & 3 & 6 & 3 & 6 & 1 \\
\hline
\end{tabular}

\begin{tabular}{|cccccccc:cccc|}
\hline B & 1 & 7 & 2 & 3 & 6 & 4 & 5 & 4 & 1 & 2 & 5 \\
4 & 3 & 4 & 6 & 5 & 3 & 2 & 3 & 6 & 4 & 4 & 3 \\
4 & 5 & 3 & 7 & 2 & 6 & 7 & 4 & 2 & 4 & 6 & 7 \\
3 & 2 & 7 & 6 & 7 & 1 & 3 & 4 & 7 & 4 & 4 & 4 \\
\hline 5 & 4 & 1 & 7 & 5 & 6 & 4 & 1 & 2 & 3 & 3 & 4 \\
2 & 6 & 4 & 6 & 2 & 4 & 2 & 3 & 5 & 5 & 6 & 4 \\
4 & 5 & 1 & 4 & 3 & 5 & 4 & 7 & 4 & 4 & 2 & 5 \\
2 & 6 & 5 & 4 & 4 & 3 & 4 & 6 & 6 & 1 & 6 & 4 \\
4 & 6 & 4 & 6 & 7 & 1 & 4 & 5 & 2 & 4 & 4 & 4 \\
4 & 1 & 7 & 5 & 2 & 4 & 4 & 6 & 4 & 1 & 3 & 4 \\
6 & 2 & 6 & 4 & 4 & 5 & 4 & 1 & 4 & 5 & 2 & 5 \\
4 & 4 & 5 & 2 & 4 & 2 & 6 & 3 & 6 & 3 & 6 & 1 \\
\hline
\end{tabular}

\section{$35 \mathrm{~m}$}

Figure 4: Design of the poplar common-garden experiment at the greenhouse area of the Agroecology Institute at the University of Göttingen (A) before and (B) after the additional molecular analyses of the trees. 18 progenies of eight (1-8) full-sib families were planted into pots with two meter distance between two pots. Dashed line = altered block design. $\mathrm{u}=$ tree of unknown full-sib family.

\section{Experimental sites - Chemical field bioassays}

The field bioassays were performed testing the leaf beetle larvae's allomone, salicylaldehyde, in 2009 and 2010 on an area with an young seral stage in the vicinity of Göttingen near Lutterberg $\left(51^{\circ} 37^{\prime} \mathrm{N} 9^{\circ} 64^{\prime} \mathrm{O}\right)$. The field is located under a high-tension line, the reason for which the trees are cut at regular intervals. 


\section{RESEARCH OBJECTIVES AND CHAPTER OUTLINE}

In the present study we investigated the effects of morphological and chemical (leaf chemistry) traits of genetically closely related aspen (P. tremula) on herbivorous insects. The general focus of this study was to characterize trait variability in aspen differing in genetic relatedness, with an emphasis on productivity (chapter 2). We analyzed the influence of morphological traits as well as the effects of herbivore-induced plant volatiles (HIPV) on specialized leaf beetle adults and larvae and predatory arthropods over two generations of the leaf beetles (chapter 3). Further focal points were the odor perception of HIPVs and salicylaldehyde (the beetle larvae's allomone) of specialized predators of salicin using leaf beetles. We investigated three potter wasp species differing in their prey specialization (chapter 4). Finally we tested the attractiveness of salicylaldehyde to generalist predatory beetles such as Harmonia axyridis (Coccinellidae) and Cantharis pellucida (Cantharidae) (chapter 5).

Our main hypotheses were (Fig. 4):

I. Variability of morphological, phenological and chemical traits differs between aspen along a genetic gradient (chapter $2 \& 3$ ).

II. Chemical and genetic traits influence biomass productivity and herbivore abundances (chapter 2).

III. Plant size and resource abundance, e.g. leaf number, as well as herbivoreinduced plant volatiles influence specialized leaf beetles and their natural enemies (chapter 3).

IV. Generalist predators are able to detect defense compound of salicin using leaf beetle larvae (salicylaldehyde) (chapter 4).

V. Specialist predatory wasps are able to perceive volatiles emitted by prey and the prey’s host plants (chapter 5). 
Are there differences in plant traits between the $P$. tremula full-sib families? 1st \& 2nd trophic level

\section{chapter 2}

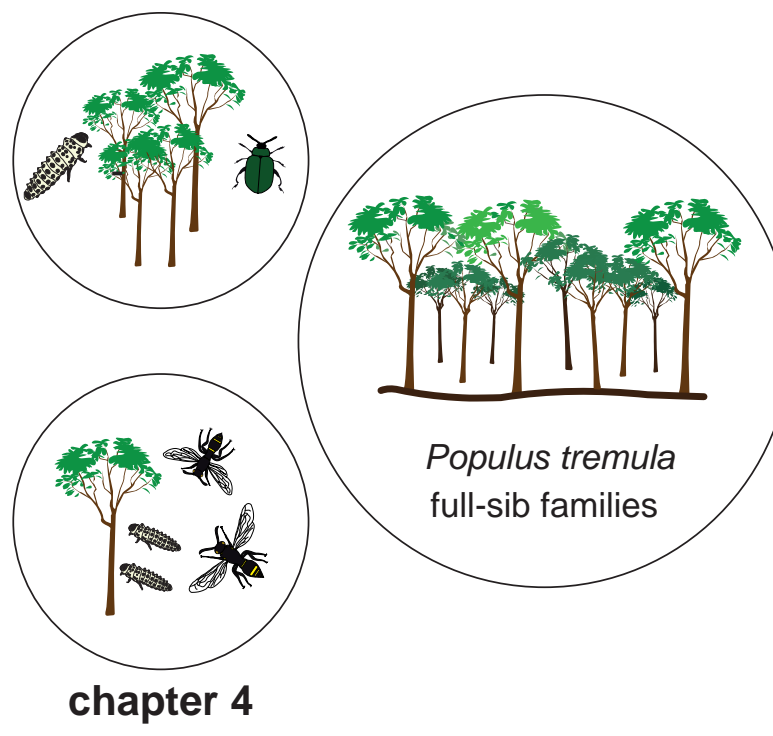

Which tree traits shape multitrophic interactions? 1st, 2nd \& 3rd trophic level

Are specialist predatory wasps able to percieve HIPVs and SA?

1st, 2nd \& 3rd trophic level

\section{chapter 3}

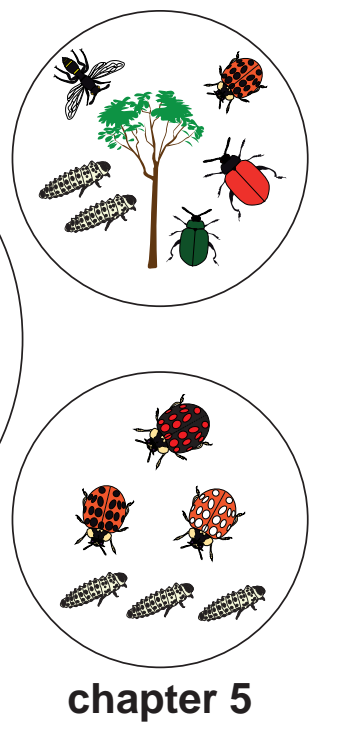

How do generalist predatory beetles respond to SA? 2nd \& 3rd trophic level

Figure 5: Scheme of the study objectives with the main questions of each chapter of the thesis. HIPVs = herbivore-induced plant volatiles. SA = salicylaldehyde. 


\section{REFERENCES}

Augustin, S., Courtin, C., and Delplanque, A. 1993. Poplar clones effect on development, mortality, and fecundity of Chrysomela (= Melasoma) populi L. and Chrysomela tremulae F. (Col., Chrysomelidae). Journal of Applied Entomology. 116. 39-49.

Barigah, T. S., Saugier, B., Mousseau, M., Guittet, J., and Ceulemans. R. 1994. Photosynthesis, leaf-area and productivity of 5 poplar clones during their establishment year. Annals of Forest Sciences. 51: 613-625.

Bassman, J., Myers, W., Dickmann, D., and Wilson, L. 1982. Effects of simulated insect damage on early growth of nursery-grown hybrid poplars in northern Wisconsin. Canadian Journal of Forest Research. 12: 1-9.

Bernays, E. A., and Chapman, R. F. 2000. Plant secondary compounds and greasshoppers: beyond plant defenses. Journal of Chemical Ecology. 26: 1773-1794.

Blüthgen, P. 1961. Die Faltenwespen Mitteleuropas (Hymenoptera, Diploptera). Abhandlungen der deutschen Akademie der Wissenschaften zu Berlin, AkademieVerlag, Berlin, Germany.

Bottrell, D. G., Barbosa, P., and Gould, F. 1998. Manipulating natural enemies by plant variety selection and modification: a realistic strategy? Annual Review of Entomology. 43: 347-367.

Bradshaw, H. D. JR., Ceulemans, R., Davis, J., and Stettler, R. 2000. Emerging model systems in plant biology: Poplar (Populus) as model forest tree. Journal of Plant Growth Regulation. 19: 306-313.

Cha, D. H., Hochwender, C. G., Bosecker, E. M., Tucker, R. E., Kaufman, A. D., Fritz, R. S., and Sмyтн, R. R. 2009. Do exotic generalist predators alter host plant preference of a native willow beetle? Agricultural and Forest Entomology. 11: 175-184. 
David, A. J., Zasada, J. C., Gilmore, D. W., and Landhäusser, S. M. 2001. Current trends in the management of aspen and mixed aspen forests for sustainable production. Forestry Chronicle. 77: 525-532.

Denno, R. F., Larsson, S., and Olmstead, K. L. 1990. Role of enemy-free space and plant quality in host-plant selection by willow beetles. Ecology. 71: 124-137.

Dicke, M., and Baldwin, I. T. 2010. The evolutionary context for herbivore-induced plant volatiles: beyond the “cry for help”. Trends in Plant Science. 15: 167-175.

Dickmann, D. I. 2006. Silviculture and biology of short-rotation woody crops in temperate regions: Then and now. Biomass and Bioenergy. 30: 696-705.

Dickmann, D. I., and Kuzovkina, J. 2008. Poplars and willows of the world, with emphasis on silviculturally important species. FAO Forest Management Division Working Paper IPC/9-2. Rome. Italy. 129 pp.

Donaldson, J. R., and Lindroth, R. L. 2007. Genetics, environment, and their interaction determine efficacy of chemical defense in trembling aspen. Ecology. 88: 729-739.

Dougherty, M. J., Guerin, P. M., Ward, R. D., and Hamilton, J. G. C. 1999. Behavioral and electrophysiological responses of the phlebotomine sandfly Lutzomyia longipalpis (Diptera: Psychodidae) when exposed to canid host odor kairomones. Physiological Entomology. 24: 251-262.

Eckenwalder, J. E. 1996. Systematics and evolution of Populus. in: R. F. Stettler, H. D. Bradshaw, P. E. Heilman, and T. M. Hinckley, eds. Biology of Populus and its implications for management and conservation. NRC Research Press, Ottawa, Ontario, Canada, pp. 7-30.

EhrLich, P. R., and RAVEN, P. H. 1964. Butterflies and plants: a study in coevolution. Evolution. 18: 586-608. 
FenNing, T. M., and Gershenzon, J. 2002. Where will the wood come from? Plantation forests and the role of biotechnology. Trends in Biotechnology. 20: 291-296.

Finet, Y., and Gregoire, J. C. 1982. A study of poplar resistance to Phratora (=Phyllodecta) viteelinae L. (Col., Chrysomelidae). Journal of Applied Entomology. 94: 363-376.

FAO. 2008. Forest and energy - Key issues. Food and Agriculture Organization of the United Nations (FAO). Forestry Paper No. 154. Rome. Italy.

Fox, T. R. 2000. Sustained productivity in intensively managed forest plantations. Forest Ecology and Management. 138: 187-202.

Gathmann, A., and TscharntKe, T. 1999. Landschafts-Bewertung mit Bienen und Wespen in Nisthilfen: Artenspektrum, Interaktionen und Bestimmungsschlüssel Naturschutz und Landschaftspflege Baden-Württemberg 73: 277-305.

Glynn, C., RönnBerg-Wästluung, A.-C., Julkunen-Tittto, R., and Weih, M. 2004. Willow genotype, but not drought treatment, affects foliar phenolic conentrations and leaf beetle resistance. Entomologia Experimentalis et Applicata. 113: 1-14.

Gross, J., Fatouros, N. E., Neuvonen, S., and Hilker, M. 2004. The importance of specialist natural enemies for Chrysomela lapponica in pioneering a new host plant. Ecological Entomology. 29: 584-593.

GrupPe, A., Fusseder, M., and Schopf, R. 1999. Short rotation plantations of aspen and balsam poplar on former arable land in Germany: defoliating insects and leaf constituents. Forest Ecology and Management. 121: 113-122.

Halitschke, R., Stenberg, J. A., Kessler, D., Kessler, A., and Baldwin I. T. 2008. Shared signals - 'alarm calls' from plants increase apparency to herbivores and their enemies in nature. Ecology Letters. 11: 24-34. 
Hendrichs, J., Katsoyannos, B. I., Wornoayporn, V., and Hendrichs, M. A. 1994. Odormediated foraging by yellowjacket wasps (Hymenoptera: Vespidae): predation on leks of pheromone-calling Mediterranean fruit fly males (Diptera: Tephritidae). Oecologia. 99: 88-94.

Herms, D. A., HaAck, R. A., and Ayres, B. D. 1991. Variation in semiochemical mediated prey-predator interaction: Ips pini (Scolytidae) and Thanasimus dubius (Cleridae). Journal of Chemical Ecology. 17: 515-524.

Hinchee, M., Rottmann, W., Mullinax, L., Zhang, C. S., Chang, S. J., Cunningham, M., Pearson, L., and Nehra, N. 2009. Short-rotation woody crops for bioenergy and biofuels applications. In Vitro Cellular \& Developmental Biology-Plant. 45: 619-629.

Hofman, M. 1998. Bewirtschaftung schnellwachsende Baumarten auf landwirtschaftlichen Flächen im Kurzumtrieb. Forschungsinstitut für schnellwachsende Baumarten. Merkblatt 11. Hann. Münden, Germany.

HunTER, M. D. 1992. Interactions within herbivore communities mediated by the host plant: the keystone herbivore concept. in: Hunter, M. D., Ohgushi, T., and Price, P. W. eds. Effects of resource distribution on animal-plant interactions. Academic. New York. pp. 287-325.

IKonen, A. 2002. Preferences of six leaf beetle species among qualitatively different leaf age classes of three Salicaceous host species. Chemoecology. 12: 23-28.

Kagata, H., Nakamura, M., and Ogushi, T. 2005. Bottom-up cascade in a tritrophic system: different impacts of host-plant regeneration on performance of a willow leaf beetle and its natural enemy. Ecological Entomology. 30: 58-62.

Kalberer, N. M., Turlings, T. C. J., and Rahier, M. 2001. Attraction of a leaf beetle (Oreina cacaliae) to damaged host plants. Journal of Chemical Ecology. 27: 647-661. 
Kendall, D. A., Hunter, T., Arnold, G. M., Liggit, J., Morris, T., and Wiltshire, C. W. 1996. Susceptibility of willow clones (Salix spp.) to herbivory by Phyllodecta vulgatissima (L.) and Galerucella lineola (Fab.) (Coleoptera, Chrysomelidae). Annals of Applied Biology. 129: 379-390.

Kouki, J., Arnold, K., and Martikainen, P. 2004. Long-term persistence of aspen - a key host for many threatened species - is endangered in old-growth conservation areas in Finland. Journal of Nature Conservation. 12: 41-52.

Köpf, A., Rank, N. E., Roininen, H., Julkunen-Tittto, R., Pasteels, J. M., and Tahvanainen; J. 1998. Phylogeny and the evolution of host plant use and sequestration in the willow leaf beetle genus Phratora (Coleoptera: Chrysomelidae). Evolution 52: 517-528.

KuRz, W. A., and Apps, M. J. 1999. A 70-year retrospective analysis of carbon fluxes in the Canadian forest sector. Journal of Applied Ecology. 9: 526-547.

Lasch, P., Kollas, C., Rock, J., and Suckow, F. 2010. Potentials and impacts of short-rotation coppice plantation with aspen in Eastern Germany under conditions of climate change. Regional Environmental Change. 10: 83-94.

La Spina, S., Gregoire, J. C., Mertens, P., and De-Canniere, C. 2010. Impact of poplar water status on leaf beetle (Chrysomela populi) survival and feeding. Annals of Forest Science. 67: 209.

Lawton, J. H. 1983. Plant architecture and the diversity of phytophagous insects. Annual Review of Entomology. 28: 23-39.

Legrand, A., and Barbosa, P. 2003. Plant morphological complexity impacts foraging efficiency of adult Coccinella septempunctata L. (Coleoptera: Coccinellidae). Environmental Entomology. 32: 1219-1226.

Madritch, M. D., Donaldson, J. R., and Lindroth, R. L. 2007. Canopy herbivory can mediate the influence of plant genotype on soil processes through frass deposition. Soil Biology \& Biochemistry. 39: 1192-1201. 
Madritch, M. D., Greene, S. L., and Lindroth, R. L. 2009. Genetic mosaics of ecosystem functioning across aspen-dominated landscapes. Oecologia. 160: 119-127.

Makeschin, F. 1999. Short rotation forestry in Central and Northern Europe - introduction and conclusions. Forest Ecology and Management. 121: 1-7.

Marques, E. S. D. A., Price, P. W., and Cobb, N. S. 2000. Resource abundance and insect herbivore diversity on woody fabaceous desert plants. Environmental Entomology. 29: 696-703.

Neuvonen, S., and Niemelä, P. 1981. Species richness of macrolepidoptera on Finnish deciduous trees and shrubs. Oecologia. 51: 364-370.

Orians, C. M., Huang, C. H., Wild, A., Dorfman, K. A., Zee, P., Dao, M. T. T., and Fritz, R. S. 1997. Willow hybridization differentially affects preference and performance of herbivorous beetles. Entomologia Experimentalis et Applicata. 83: 285-294.

Osier, T. L., and Lindroth R. L. 2006. Genotype and environment determine allocation to and costs of resistance in quaking aspen. Oecologia. 148: 293-303.

Quicke, D. L. J. 1997. Parasitic wasps. Chapman Hall, London.

Palokangas; P., and Neuvonen, S. 1992. Differences between species and instars of leaf beetles in the probability to be preyed on. Annales Zoologici Fennici. 29: 273-278.

Pasteels, J. M., Rowhell-Rahier, M., Braekmann, J. C., and Dupont, A. 1983. Salicin from host plant as precursor of salicylaldehyde in defensive secretion of Chrysomelinae larvae. Physiological Entomology. 8: 307-314.

Pasteels, J. M., and Gregoire J.-C. 1984. Selective predation on chemically defended chrysomelid larvae. A conditioning process. Journal of Chemical Ecology. 12: 16931700. 
Peacock, L., and Herrick, S. 2000. Responses of the willow beetle Phratora vulgatissima to genetically and spatially diverse Salix spp. plantations. Journal of Applied Ecology. 37: 821-831.

Peacock, L., Herrick, S., and Brain, P. 1999. Spatio-temporal dynamics of willow beetle (Phratora vulgatissima) in short-rotation coppice willows grown as monocultures or a genetically diverse mixture. Agricultural and Forest Entomology, 1: 287-296.

Peacock, L., Harris, J., and Powers, S. 2004. Effects of host variety on blue willow beetle Phratora vulgatissima performance. Annals of Applied Biology. 144: 45-52.

Pregitzer, K. S., Dickmann, D. I., Hendrick R., and Nguyen, P. V. 1990. Whole-Tree carbon and nitrogen partitioning in young hybrid poplars. Tree Physiology 7: 79-93.

Price, P. W., Bouton, C. E., Gross, P., McPheron, B. A., Thompson, J. N., and Weis, A. E. 1980. Interactions among three trophic levels: influence of plants on interactions between insect herbivores and natural enemies. Annual Review of Ecology and Systematics. 11: 41-65.

Punzo, F., and Ludwig, L. 2005. Behavioral responses of Pepsis thisbe (Hymenoptera: Pompilidae) to chemosensory cues associated with host spiders. Journal of Insect Behavior. 18: 757-766.

Rank N. E., and Smiley, T. S. 1994. Host-plant effects on Parasyrphus melanderi (Diptera: Syrphidae) feeding on a willow leaf beetle Chrysomela aenicollis (Coleoptera: Chrysomelidae). Ecological Entomology. 19: 31-38.

Risch, S. J. 1981. Insect herbivore abundance in tropical monocultures and polycultures: an experimental test of two hypotheses. Ecology. 62: 1325-1340.

RoJAS, J. C. 1999. Influence of host plant damage on the host-finding behavior of Mamestra brassicae (Lepidoptera: Noctuidae). Environmental Entomology. 28: 588-593. 
Rоот, R. B. 1973.Organization of a plant-arthropod association in simple and diverse habitats: the fauna of collards (Brassica oleracea). Ecological Monographs. 43: 95-124.

Rutledge, C. E. 1996. A survey if identified kairomones and synomones used by insects to locate and accept their hosts. Chemoecology 7: 121-131.

Russell, E. P. 1989. Enemies hypothesis: a review of the effect of vegetational diversity on predatory insects and parasitoids. Environmental Entomology. 18: 590-599.

SAGE, R. B. 1998. Short rotation coppice for energy: towards ecological guidelines. Biomass and Bioenergy. 15: 39-47.

Schoonhoven, L. M., van Loon, J. J. A., and Dicke M. 2005. Insect-Plant Biology, Oxford University Press. Oxford. UK.

Shen, C. S., and BACH, C. E. 1997. Genetic variation in resistance and tolerance to insect herbivory in Salix cordata. Ecological Entomology. 22: 335-342.

SinReICH, A., 1955. Pappelschädlinge und -krankheiten in Österreich in den Jahren 1951 1954. Anzeiger für Schädlingskunde. 28: 1-5.

SiPuRA, M. 1999. Tritrophic interactions: willows, herbivorous insects and insectivorous birds. Oecologia. 121: 537-545.

SMILEY, K. S. 1991. Aggregation benefits in a willow leaf beetle along an elevational gradient, pp. 148-160. In: Hall, C. A. Doyle-Jones, V., and Widawski, B. (eds). Natural history of eastern California and high-altitude research, University of California. White Mountain Research Station Symposium. The regents of the University of California, Los Angeles, USA.

Smiley, T. S., Horn, J. M., and RAnK, N. E. 1985. Ecological effects of salicin at three trophic levels: New problems from old adaptions. Science. 229: 649-651. 
StAMPs, W. T., and LinIt, M. J. 1998. Plant diversity and arthropod communities: implications for temperate agroforestry. Agroforestry Systems. 39: 73-89.

Steidle, J. L. M., and van Loon, J. J. A. 2003. Dietary specialization and infochemical use in carnivorous arthropods: testing a concept. Entomologia Experimentalis et Applicata. 108: 133-148.

Stevens, M. T., Waller, D. M., and Lindroth, R. L. 2007, Resistance and tolerance in Populus tremuloides: genetic variation, costs and environmental dependency. Evolutionary Ecology. 21: 829-847.

TABakayashi, J., and Dicke, M. 1996. Plant-carnivore mutualism through herbivore-induced carnivore attractants. Trends in Plant Science. 1: 109-113.

TscharntKe, T., and Hawkins, B. A. 2002. Multitrophic level interactions: an introduction. in: Tscharntke, T., and Hawkins, B. A. eds. Multitrophic Level Interactions. Cambridge University Press. Cambridge. U.K. pp. 1-7.

Tuskan, G. A., Difazio, S., Jansson, S., Bohlmann, J., Grigoriev, I., Hellsten, U., Putnam, N., Ralph, S., Rombauts, S., Salamov, A., et al. 2006. The genome of black cottonwood, Populus trichocarpa (Torr. \& Gray). Science. 313: 1596-1604.

VAndermeer, J. 1989. The ecology of intercropping. Cambridge University Press. Cambridge. United Kingdom.

Wallace, J. B., and Blum, M. S. 1969. Refined defensive mechanisms in Chrysomela scripta. Annals of the Entomological Society of America. 62: 503-506.

Weissbecker, B., van Loon, J. J. A., Posthumus, M. A., Boummeester, H. J., and Dicke, M. 2000. Identification of volatile potato sesquiterpenoids and their olfactory detection by the two-spotted sinkbug Pericellus bioculatus. Journal of Chemical Ecolology. 26: 1433-1445. 
Whitham, T. G., Bailey, J. K., Schweitzer, J. A., Shuster, S. M., Bangert, R. K., Leroy, C. J., Lonsdorf, E. V., Allan, G. J., DiFazio, S. P., Potts, B. M., Fischer, D. G., Gehring, C. A., Lindroth, R. L., Marks, J. C., Hart, S. C., Wimp, G. M., and Wooley, S. C. 2006. A framework for community and ecosystem genetics: from genes to ecosystems. Nature Reviews Genetics. 7: 510-523.

Yoneya, K., Kugimiya, S., and Takabayashi, J. 2009. Can herbivore-induced plant volatiles inform predatory insect about the most suitable stage of its prey? Physiological Entomology 34: 379-386.

YU, Q. 2001. Selection and propagation of hybrid aspen clones for growth and fibre quality. Dissertation University of Helsinki Finland.

Zsuffa, L., Giordano, E., Pryor, L. D., and Stettler, R. F. 1996. Trends in poplar culture: some global and regional perspectives. in: Stettler, R. F., Bradshaw, H. D., Heilman, P. E., and Hinckley, T. M., eds. Biology of Populus and its implications for management and conservation. NRC Research Press, Ottawa, Ontario, Canada, pp. 515-539.

Zvereva, E. L., and Rank, N. E. 2004. Fly parasitoid Megaselia opacicornis uses defensive secretions of the leaf beetle Chrysomela lapponica to locate its host. Oecologia 140: 516-522. 


\section{Chapter}

\section{2}

Relating Genetic Variation of Ecologically

Important Tree Traits to Associated Organisms in Full-Sib Aspen Families

Frauke Kleemann, Maximilian von Fragstein, Barbara Vornam, Annika Müller,

Christoph Leuschner, Andrea Holzschuh, Teja Tscharntke, Reiner Finkeldey, ANd ANdRea Polle

in: European Journal of Forest Research 2011, 130: 707-716

DOI: 10.1007/s10342-010-0460-6 


\section{ABSTRACT}

Knowledge on phenological, morphometric, and phytochemical variation of local progenies of European aspen (Populus tremula) is limited. The goal of this study was to characterize variation in growth and ecologically important leaf properties in aspen full-sib families in relation to interacting organisms (mycorrhiza, endophytes and insects) and to determine if these interactions were affected by soil-application of a systemic fungicide. In local progenies, within family variation of neutral molecular genetic markers (nuclear microsatellites) was higher than between families. Significant variation in growth, production of phenolic defensive compounds and other phytochemical leaf traits was found between families. Phenolic compounds showed clear negative correlation with generalist herbivores, but did not result in negative trade-off with biomass production. Differences in mycorrhizal colonization were not found among full-sib families and application of a systemic fungicide suppressed neither mycorrhizal colonization nor infestation with insects. However, a strong suppression of endophytes occurred, whose long-term consequences may require attention when fungicides are used in agro-forestry plantations.

Key Words: Agro-forestry, molecular marker, nitrogen, nutrition, phenolic compounds, Populus 


\section{INTRODUCTION}

European and American aspen (Populus tremula, P. tremuloides) are among the most wide-spread tree species in circumpolar boreal and temperate forest regions (Hultén and Fries, 1986, Dickmann and Kuzovkina, 2008). They are pioneering species with low nutrient demand that colonize disturbed and shallow soils (Dimpflmeier, 1963, Tamm, 2006). In contrast to other poplar species that are typically found in alluvial, riparian and wetland ecosystems, aspens are relatively drought tolerant and form distinct forest communities. In past European silvicultural practices aspens have usually been removed to avoid competition in even aged, traditionally managed coniferous forests (DeChantal et al., 2009). However, it has recently been recognized that aspen create habitats for specific fauna including many endangered species and therefore provide important ecosystem services (Kouki et al., 2004). To date, aspens are increasingly valued because of their ecological functions as well as a possible resource for biomass production on marginal soils.

Traits of ecological and economic value have mainly been studied in American aspen (P. tremuloides) or in hybrids of P. tremuloides with P. tremula ( $\mathrm{Li}$ and $\mathrm{Wu}, 1997$, Liesebach et al., 1999), whereas less information is available on its close relative, European aspen. American aspen show significant genetic variation in the phytochemistry of defence compounds such as phenolic glucosides and condensed tannins, whereas other foliar traits such as nitrogen content respond mainly to environment (Osier and Lindroth, 2006, Donaldson and Lindroth, 2007). Phenolic compounds protect against Venturia shoot blight infection (Holeski et al., 2009) and influence feeding behaviour of herbivorous insects on Salicaceae (Rowell-Rahier, 1984, Donaldson \& Lindroth, 2007). Among herbivores, generalists such as the chrysomelid beetles Phratora vitellinae, Phratora vulgatissima and Galerucella lineola prefer leaves with low concentrations of phenol glucosides (Kendall et al., 1996, Orians et al., 1997, Glynn et al., 2004). In contrast, specialized chrysomelid beetles, for example, Chrysomela populi and Gonioctena decemnotata, prefer salicaceous species with relatively high concentrations of phenol glycosides in the leaves (Orians et al., 1997, Ikonen, 2002) because their larvae sequester plant-derived allelochemicals such as salicylaldehyde for defence (Pasteels et al., 1983).

Trade-off between allocation to defence compounds and growth has been reported, at least 
under limiting nutrient resources (Donaldson et al., 2006). Therefore, differences in growth and biomass production among $P$. tremula progenies may have consequences for phytochemical traits, in particular for allocation of defence compounds, and for interactions with associated organisms such as mycorrhizae, endophytes or leaf feeding insects. Since economically and ecologically sustainable biomass production requires cultivation of trees adapted to regional climate with optimum growth and stress tolerance, we investigated variation in phenological, morphological and ecophysiological traits in a common garden experiment with seven full-sib families generated by crossing of local $P$. tremula parent trees (Göttingen, Central Germany). It is often required to apply phyto-protective agents to prevent spreading of diseases in plantations. Therefore, we also studied the influence of a systemic fungicide on plant performance and biotic interactions. The following hypotheses were tested: (i) fullsib aspen families show significant variation in growth and ecophysiological leaf traits that are related to parenthood and modulate interactions with associated organisms; (ii) defensive compounds and growth are negatively related providing evidence for an energetic trade-off; (iii) application of a systemic fungicide has negative effects on associated organisms such as endophytes, mycorrhiza, and leaf-feeding insects.

\section{MATERIAL AND METHODS}

\section{Plant materials and experimental set-up}

The parent $P$. tremula trees were located close to Göttingen (Geismar, $51^{\circ} 31^{\prime} \mathrm{N}, 9^{\circ} 57^{\prime} \mathrm{E}$ ). In the year 2000, shoots with male and female flowers were transported to a greenhouse and used for controlled crossing of male trees number 1, 3 and 5 with female trees number 2, 4, 7, 8, and 9, respectively, resulting in the following crossings: C1 (4x5), C2 (9x5), C3 (8x5), C4 (2x5), C5 (2x3), C6 (9x3), and C7 (7x1). Seeds were germinated on moist Vermiculite (grain size 3 to $8 \mathrm{~mm}$, Deutsche Vermiculite Dämmstoff GmbH, Sprockhövel, Germany). Seedlings were planted in pots (Fruhsdorfer soil, type N, Fruhsdorf, Germany), cultivated outdoors and watered as necessary. In spring 2008, 8-yrs-old trees were out-planted according to a randomized block design with 8 blocks (4 blocks treated monthly with 75 l Amistar 
Opti [25 $\mu$ l L-1, Syngenta, Maintal, Germany], 4 control blocks treated with water). Each block contained 24 plants; i.e. 3 trees of each of the 7 full-sib families in addition to 3 plants of a further crossing which was however contaminated and therefore not included in further analyses. A bed contained four blocks of alternating control and fungizide treated blocks, which were separated by plastic barriers and surrounded by a row of additional trees to avoid edge effects. The experiment consisted of two beds. The trees were cultivated for one growth phase and watered as necessary. The mean ambient air temperature was $15^{\circ} \mathrm{C}$.

\section{Phenological and morphometric measurements}

Before bud break, diameter at the bottom (root collar) and height of the main shoot of each tree were measured. Bud break at the apex of the leader shoot was scored regularly. The Julian days were recorded until the first leaf was fully expanded (according to the scores described by UPOV, 1981). The trees were harvested in the first week of September 2008. At harvest, root collar diameter, height of main shoot, number of side branches, lengths of side branches, number of leaves, fresh mass of leaves, stems, fine and coarse roots were determined. Leaf mass was determined for 5 fully expanded leaves collected at the top of the leader shoot of each tree and their areas were measured using ImageJ (http://rsbweb.nih. gov/ij/). These data were used to convert leaf mass per tree to leaf area per tree. Aliquots of plant tissues were shock-frozen in liquid nitrogen and stored at $-80^{\circ} \mathrm{C}$ for biochemical analysis. Aliquots of roots were used for mycorrhizal assessment. Other plant tissues were dried at $60^{\circ} \mathrm{C}$ to determine dry mass and the relative water content [fresh mass - dry mass)*100/fresh mass].

\section{Endophyte colonization}

Two fully expanded, healthy top leaves of 20 plants per treatment of C3 and of 18 plants per treatment of C4 were harvested (21 ${ }^{\text {th }}$ Aug. 2008), cut into quarters and surface-sterilized for $1 \mathrm{~min}$ in $96 \% \mathrm{EtOH}, 3 \mathrm{~min}$ in $4 \% \mathrm{NaOCl}$ and $30 \mathrm{~s}$ in $96 \% \mathrm{EtOH}$. The four leaf pieces were placed upside down in a Petri dish on antibiotics containing water-agar (15 g L-1 agar with $15 \mathrm{mg}$ tetracycline, 100 ampicilline, $50 \mathrm{mg}$ kanamycine, and $0.1 \mathrm{mg}$ streptomycine) and were incubated for 7 days at $20^{\circ} \mathrm{C}$ in darkness (Petrini, 1986). Subsequently hyphal outgrowth of leaf pieces was scored as absent or present on each leaf piece yielding a scale 
from $0 \%, 25 \%, 50 \%, 75 \%$ and $100 \%$ endophyte presence, respectively, per leaf in a Petri dish.

\section{Insect sampling}

Insects were captured by using a sweep net and an exhauster or were identified directly on the trees. Aphids, leaf beetle larvae and galls were quantified visually on each tree. Counting was done four times (monthly) from May to the middle of August. We recorded three leaf beetle (Phratora vitellinae, Crepidodera aurata and Crepidodera aurea) and one aphid species (Chaitophorus populi). The identification of adult insects was done in the laboratory. Due to negligible abundances, miners, galls, Homoptera and different predators were not included in statistical analysis. Leaf beetles and their larvae and other chewing insects like Symphyta larvae and caterpillars were pooled and denominated as "sum of chewing insects" and aphids and cicada were pooled as "sum of sucking insects".

\section{Mycorrhizal colonization}

To determine colonization with ectomycorrhizal fungi fine roots were cut into small pieces and mixed. Aliquots of the mixtures were spread under a dissecting microscope (Zeiss, Stemi 2000-C) and the presence or absence of typical ectomycorrhizal mantle structures was recorded on 100 root tips per sample. To measure colonization with arbuscular mycorrhizal fungi, root samples were placed immediately after harvest in $80 \% \mathrm{EtOH}$. The samples were subsequently stained with trypane-blue in lactophenol, destained and mycorrhizae detected by the presence of hyphae, arbuscules or vesicles in root tissue whose abundance was recorded by the gridline intersection method as reported previously (Ducic et al., 2009).

\section{Genetic analysis}

To control the crossing experiment the DNA of the parental trees and their offspring was analysed using 5 nuclear encoded microsatellite markers. Total DNA was extracted from young leaves using the DNeasyPlant Minikit (Qiagen, Hilden, Germany). The amount and the quality of the DNA were analyzed by $0.8 \%$ agarose gel electrophoresis with $1 \mathrm{x}$ TAE as running buffer (Sambrook et al., 1989). DNA was stained with ethidium bromide and 
visualized by UV illumination.

For microsatellite analysis the primers PMS14, PMS16 (Van der Schoot et al., 2000), PTR2, PTR4 (Dayanandan et al., 1998), and PTR5 (Rahman et al., 2000) were used. The PCR reactions were carried out as described above with the exception that primers were labelled with the fluorescent dyes 6-carboxyfluorescein (6-FAM) or hexachloro-fluorescein phosphoramidite (HEX). Fragments were separated on the ABI Genetic Analyser in a multiplex analysis. The microsatellite alleles were recognized using the software packages Genescan 3.7 and Genotyper 3.7 from Applied Biosystems.

Microsatellite loci were scored for the analysis of genetic parameters by using the computer program GENALEX (Peakall and Smouse, 2001). The analysis confirmed seven of initially eight full-sib families. Genetic variances within and between full-sib families were calculated with Molecular Analysis of Variance (MAMOVA, www.biosis.ac.uk/smart/ unix/mamova) using 99 permutations.

\section{Biochemical analysis}

The biochemical analyses were conducted as described previously (Luo et al., 2006, Luo et al., 2008) and are therefore recorded here only briefly. Frozen leaves were ground to a fine powder in a ball mill cooled with liquid nitrogen (Retsch, Haan, Germany). Material of three plants of a full-sib family in each block was pooled. Glucose, fructose, sucrose and starch were extracted in $\mathrm{DMSO} / \mathrm{HCl}$ and their concentrations were determined after enzymatic conversion at a wavelength of 340nm (Schopfer, 1989). Soluble proteins were extracted in phosphate buffer and measured spectrophotometrically at a wavelength of 562nm using the bicinchoninic acid kit (BCA assay, Uptima, Montlucon, France). Bovine serum albumin served as the standard. Soluble phenolics were extracted twice in 50\% methanol and measured spectrophotometrically after incubation with Folin-Ciocalteus phenol reagent at $765 \mathrm{~nm}$. Catechin was used for calibration. Leaf pigments were extracted in $80 \%$ acetone and measured at wavelengths of 646nm (chlorophyll b), 663nm (chlorophyll a) and $470 \mathrm{~nm}$ (carotenoids). Their concentrations were calculated using the extinction coefficients determined by Lichtenthaler and Wellburn (1983). 


\section{Element analysis}

Dry leaves were milled to a fine powder in a ball mill (Retsch, Haan, Germany). The powder was wet-ashed in $65 \% \mathrm{HNO}_{3}$ at $170^{\circ} \mathrm{C}$ for $12 \mathrm{~h}$. The filtrate was used for ICP-OES analysis of P, S, K, Ca, Mg, Mn, and Fe (Spectro Analytic Instruments, Kleve, Germany) after Heinrichs et al. (1986). For analysis of nitrogen and carbon contents leaf powder was weighed into 5 x $9 \mathrm{~mm}$ tin cartouches (Hekatech, Wegberg, Germany) and analysed in a CHNS-O element analyzer EA1108 (Carlo Erba Instruments, Milan, Italy). Acetanilide was used as the standard.

\section{Data analysis}

Data were tested for normality with the Shapiro-Wilk's test. If required, data were logtransformed to meet the assumption of normality of residuals. For data analysis herbivore data of all sampling dates were pooled. Differences between parameter means were considered significant when the $P$ value of the ANOVA $F$ test was less than 0.05 . Univariate or multivariate analysis of variance, principle component analysis, linear mixed effects models, simple regression and graphics were carried out using the software R 2.10.0 (R Development Core Team, 2009). The experimental design with two beds divided into four blocks each required statistical analysis with linear mixed effects models. We fitted linear mixedeffects models ("Ime”-function in package "nlme”, Pinheiro and Bates, 2000) using maximum likelihood with genotype, soluble phenolics and relative leaf water content plus their twoway interactions as fixed factors. To account for non-independence of different plot sizes, we used the following sequence of random effects: bed, block and genotype. To account for heteroscedasticity we inspected the residuals for constant variance and normality and used variance functions (Pinheiro and Bates, 2000). For model simplification we performed stepwise backwards model selection by using the Akaike Information Criterion (AIC) (Crawley, 2007, “stepAIC“-function within the "MASS“-package, Venables and Ripley, 2002). The minimal adequate model was the one with the lowest AIC (Burnham and Anderson, 2002). Multiple comparisons among factors having a significant effect in the minimal model were calculated using Tukey contrasts with $P$-values adjusted by single-step method ("multcomp“package, Hsu, 1996). The figures were generated with the software Origin 7.0 (Origin Lab Corp., Northampton, USA). 


\section{RESULTS}

Phenotypic and genetic differences between full-sib families of P. tremula

Bud break, a trait under strong genetic control, revealed distinct differences among P. tremulacrossings (Fig. 1A). Bud break was completed 8 days earlier in C7 than in C6. The other full-sib families showed intermediate behaviour. The full-sib families furthermore differed significantly in growth (Fig 1B) as well as in many other morphometric parameters (for details, see supplement 1$)$ such as the number of side shoots $(P<0.001)$, cumulative lengths of side per tree $(P=0.048)$, relative leaf water content $(P=0.003)$, relative height growth $(P=$ 0.002), stem diameter $(P=0.007)$, stem height $(P<0.001)$, stem biomass $(P<0.001)$, leaf biomass $(P<0.001)$, below-ground biomass $(P=0.033)$, and whole plant fresh $(P<0.001)$ and dry mass $(P<0.001)$. Significant differences among full-sib families were also found for the concentrations of some leaf nutrients and for phytochemical traits [Ca $(P<0.001)$, $\mathrm{N}(P=0.004), \mathrm{Mg}(P=0.004), \mathrm{Mn}(P<0.001)$, $(P=0.002), \mathrm{K}(P=0.009)$, soluble phenolic compounds $(P=0.005)$, glucose $(P<0.001)$, fructose $(P=0.009)]$, whereas $\mathrm{C}, \mathrm{S}$, Fe, starch, chlorophyll, carotenoids, and soluble protein $(P>0.05)$ were unaffected by genetic differences between the full-sib families. Fungicide treatment had no significant influence on morphometric or phytochemical parameters in aspen (Supplement 1).

To classify full-sib aspen families according to their morpho- and chemometric characteristics, principle component analysis of growth and phytochemical parameters was conducted. Three components were extracted that contributed $39.7 \%$ (component 1), 22 \% (component 2) and $21 \%$ (component 3) of the variability. The performance of $\mathrm{C} 1$, C2, and C4 was strongly influenced by shoot biomass and side shoots numbers and that of C3, C5 and C7 by relative growth and Mn concentrations (1st component, Fig. 2). Only C6 was strongly affected by component 2 that was mainly defined by bud break and soluble phenolics (Fig. 2).

To investigate relationships between genetic variance of the neutral markers and two parameter sets for tree performance, i.e. green leaf chemistry (mineral nutrients, phenolic compounds, carbohydrates, pigments and protein) and tree morphology (biomass of leaves, stem, and roots, leaf area, stem height increment, stem diameter, leaf numbers, 

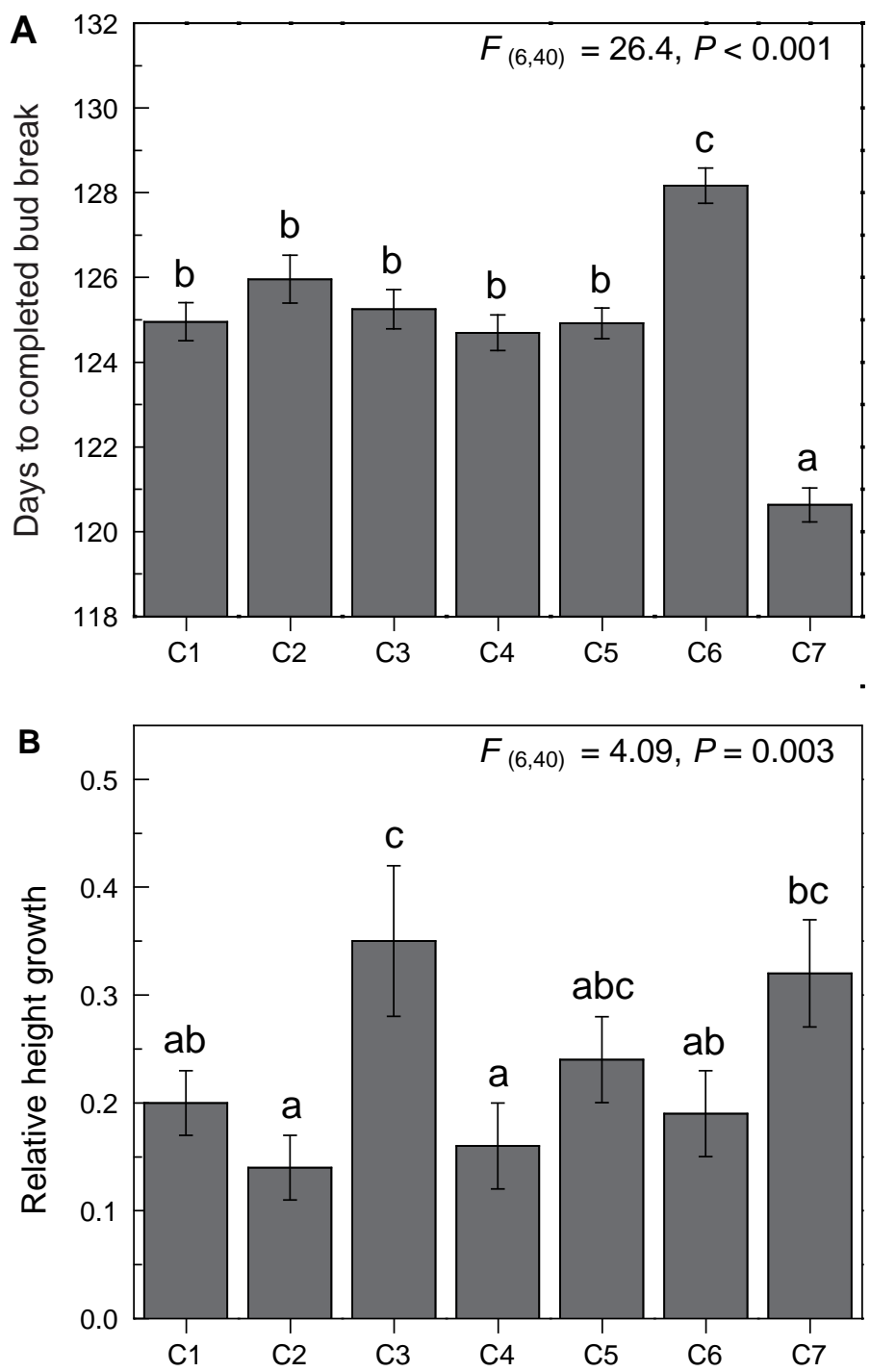

Figure 1: Bud break (A) and relative growth rate $(\mathbf{B})$ of seven full sib families of aspen (P. tremula). (A) Bud break was measured as Julian days to the first fully expanded leaf on the leader shoot. (B) Relative growth rate was determined as annual increment in shoot height/shoot height before bud break. Data indicate means $(\mathrm{N}=24$ to $28, \pm \mathrm{SE})$. Different lower-case letters indicate significant pairwise differences between respective means at $P \leq 0.05$.

whole-plant leaf area, relative leaf water content, number of side shoots, cumulative length of side shoots), Mantel tests were conducted (Tab. 1). However, neither leaf chemistry nor tree morphology showed significant relations with the genetic variance of the five neutral markers applied here. Furthermore, the neutral markers showed significantly higher molecular variance within a full-sib family than between families (Among families: $D F=6$, 


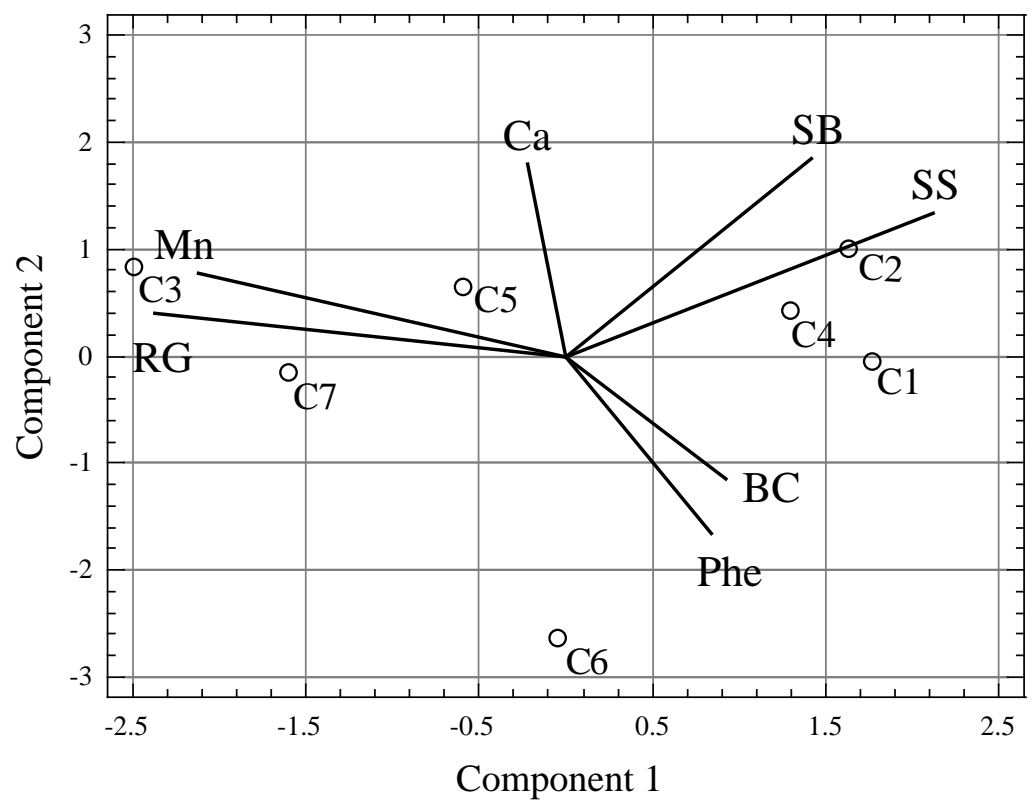

Fig. 2: Principal component analysis. The analysis was based on the following parameters: $\mathrm{SB}=$ stem biomass, $\mathrm{BC}=$ time until bud break was completed, $\mathrm{SS}=$ number of side shoots, $\mathrm{RG}=$ relative growth rate, and foliar concentrations of Phe = soluble phenolics, $\mathrm{Mn}=$ manganese, and $\mathrm{Ca}=$ calcium.

Table 1: Results of a Mantel test conducted for the relationship between genetic variance and tree performance.

\begin{tabular}{ll}
\hline Parameter group & $P_{\text {(genetic variance) }}{ }^{*}$ \\
\hline Green leaf chemistry & 0.3816 \\
Plant morphology & 0.9013 \\
All parameters & 0.8957 \\
\hline
\end{tabular}

* Genetic variances were calculated on the basis of the five neutral markers used to test the populations. Performance parameters were leaf chemistry (mineral nutrients, phenolic compounds, carbohydrates, pigments, and protein), tree morphology (biomass of leaves, stem, and roots, leaf area, stem height increment, stem diameter, leaf numbers, whole-plant leaf area, relative leaf water content, number of side shoots, cumulative length of side shoots), or all plant parameters analysed. 
variation $39 \%$, within families: $D F=108$, variation $69 \%$, PhiPT 0.3941, $P=0.010$ ).

To investigate whether plant traits differed more strongly between families without common parents than between those with a common parent, the trees were combined in a matrix showing 7 combinations for common fatherhood, 2 combinations for common motherhood and 12 combinations without common parents (Supplement 2). The differences between tree traits were calculated for each combination and compared by ANOVA. Among 30 traits tested 26 \% (annual stem diameter increment, number of side shoots, fructose, protein, carbon, calcium, potassium, and manganese) showed significant differences according to parenthood (Tab. 2). However, only half of them (annual stem increment, number of side shoots, fructose and protein) showed the expected stronger difference in progenies without than in those with common parents and suggests a strong paternal influence on these parameters.

Table 2: Differences in plant traits between different parenthoods.

\begin{tabular}{|c|c|c|c|c|c|c|c|c|}
\hline \multirow[t]{2}{*}{ Parameter } & \multicolumn{7}{|c|}{ Differences* for } & \multirow[t]{2}{*}{$P$} \\
\hline & \multicolumn{2}{|c|}{ Common father } & \multicolumn{3}{|c|}{ Common mother } & \multicolumn{2}{|c|}{ No common parent } & \\
\hline \multicolumn{9}{|l|}{ Annual stem } \\
\hline Increment (mm) & $-0.06 \pm$ & $0.27 \mathrm{a}$ & 0.30 & \pm & $0.37 \mathrm{ab}$ & $1.02 \pm$ & $0.26 b$ & 0.042 \\
\hline Number of side shoots & $1.32 \pm$ & $2.80 a$ & 11.17 & \pm & $1.37 \mathrm{~b}$ & $1.71 \pm$ & $1.71 b$ & 0.004 \\
\hline Fructose (mg g-1 DM) & $-0.09 \pm$ & $0.03 a$ & 0.25 & \pm & $0.09 \mathrm{~b}$ & $0.20 \pm$ & $0.04 \mathrm{ab}$ & 0.001 \\
\hline Protein (mg g-1 DM) & $0.64 \pm$ & $0.072 \mathrm{a}$ & -2.87 & \pm & $1.02 \mathrm{~b}$ & $-1.27 \pm$ & $0.57 b$ & 0.052 \\
\hline Carbon (\%) & $-0.29 \pm$ & $0.13 a$ & 0.33 & \pm & $0.45 b$ & $0.09 \pm$ & $0.08 b$ & 0.037 \\
\hline Calcium (mg g-1 DM) & $-2.15 \pm$ & $0.50 \mathrm{a}$ & -0.81 & \pm & $0.17 \mathrm{a}$ & $1.62 \pm$ & $0.24 b$ & 0.001 \\
\hline Potassium (mg g-1 DM) & $-1.65 \pm$ & $0.22 \mathrm{a}$ & -1.12 & \pm & $0.15 a b$ & $1.34 \pm$ & $0.48 b$ & 0.001 \\
\hline Manganese (mg g-1 DM) & $-0.02 \pm$ & $0.00 \mathrm{a}$ & -0.01 & \pm & $0.00 \mathrm{a}$ & $0.01 \pm$ & $0.00 \mathrm{~b}$ & 0.000 \\
\hline
\end{tabular}

* Differences were calculated for means for the combinations shown in supplement 2. Data were tested with the factors: no common parents (0), common father (1), common mother (2). Data show means $( \pm$ SE). Different lower-case letters indicate significant respective pairwise differences at $P \leq 0.05$. Parameters that showed no significant differences are not shown.

\section{Performance of full-sib families in relation to growth and defence compounds}

Since growth-related parameters and soluble phenolic concentrations showed significant differences between the full-sib families, the relationship between these features was further explored. We expected that high production of phenolic compounds would consume carbon and energy, which would, thus, be unavailable for biomass production of stem and root 
tissues. Instead of negative trade-off, we found that the total amount of phenolics in leaves was strictly positively correlated with total plant stem + root biomass (= non-green tissue, Fig. 3, open symbols). The same was true if the relationship between the amount of phenolics and stem biomass was considered $(R=0.911, P=0.004)$. We further argued that if there was a trade-off between the production of non-green tissue and phenolics in leaves, a negative relationship between the concentration of phenolics per unit of leaf tissue and the amount of non-green tissue per green tissue must be expected. However, this was not observed (Fig. 3, closed symbols). Similarly, the concentration of phenolic compounds and the relative annual growth rate were unrelated $(R=0.449, P=0.311)$.

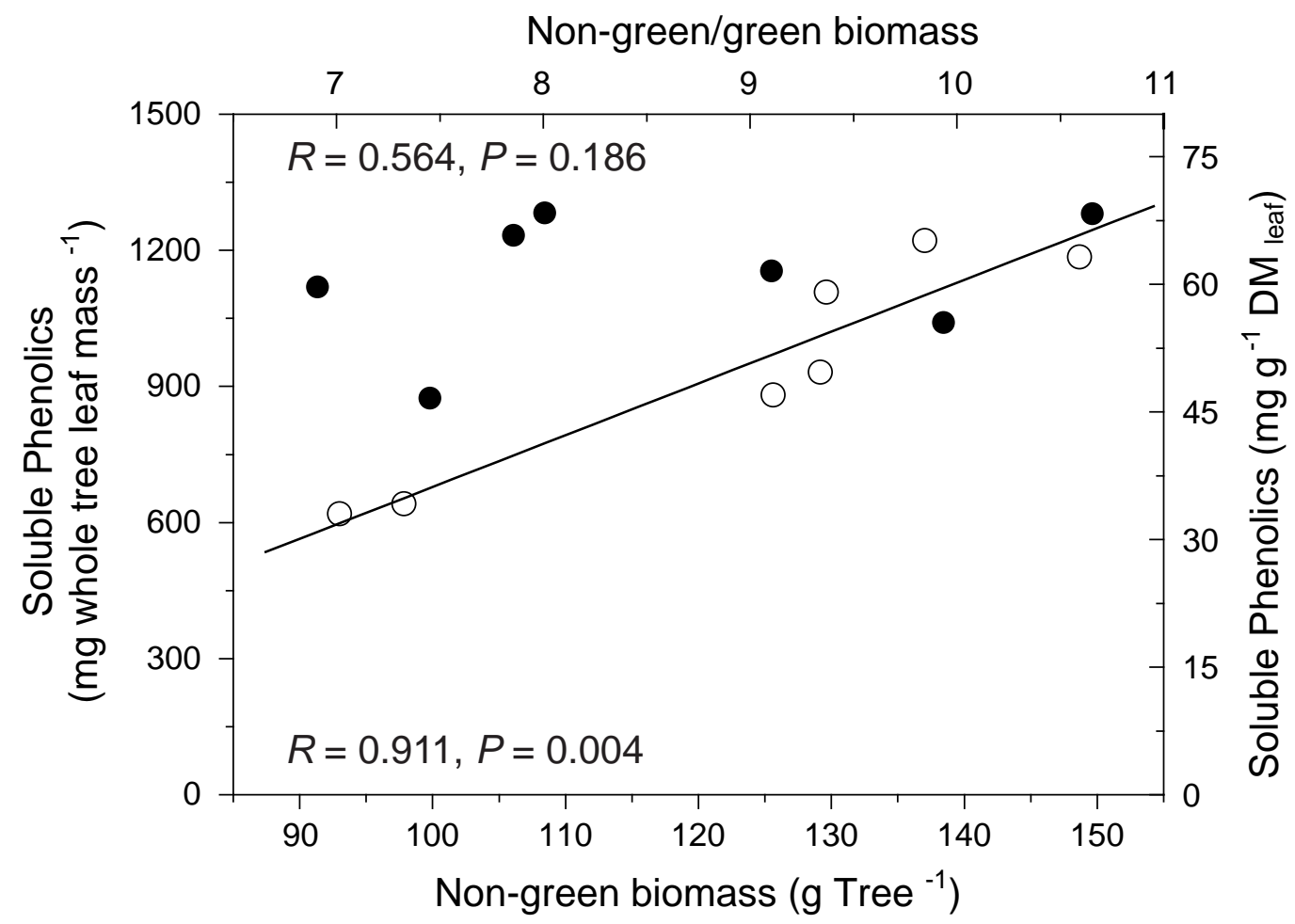

Fig. 3: Relationship between total amount of soluble phenolics in leaves and non-green (= stem + root) biomass (left and lower axis, black symbols) and between the concentration of soluble phenolics and the ratio of non-green tissue-to-green tissue (right and upper axis, white symbols). 
Relationships of full-sib aspen families with interacting biota and influence of fungicide treatment

The roots of all full-sib families were colonized by arbuscular (27\%) and ectomycorrhizal fungi $(16 \%)$. Spearman correlation revealed a marginally significant negative correlation between the abundance of arbuscular and ectomycorrhizal fungi $(R=-0.741, P=0.056)$. Significant effects of full-sib families or of fungicide treatment on mycorrhizal abundance were not found (Supplement 1).

Endophyte colonization was only scored in two full-sib families, C3 and C4, respectively, which were characterized by a stark contrast in the concentrations of phenolic compounds (20.9 versus $30.8 \mathrm{mg}$ g-1 leaf fresh mass). Between these two families no significant differences for endophyte colonization were detected (score of leaf colonization: $43 \pm 8 \%$, $P=0.948)$. However, treatment with the fungicide Amistar, which was applied by soil drench, resulted in a significant decrease in endophyte colonization of leaves of both families (Tab. 3). The effect was specific for this fungal life style because mycorrhizal colonization was unaffected by the fungicide (Tab. 3, Supplement 1 ).

The full-sib families also differed in herbivorous insect infestation since leaf beetle larvae were significantly less abundant on leaves of the families C2 and C6 than on those of C3 (Fig. 4). There were no effects of different full sib families on aphids and the sum of sucking insect abundance (Supplement 1). A linear mixed-effect model of foliar phenolics was significant for the abundance leaf beetle larvae $\left(F_{(1,19)}=7.22, P=0.014\right)$ as well as for the sum of chewing insects (Fig. 5), whereas no significant effects were found for the abundance of aphids $\left(F_{(1,19)}=0.37, P=0.545\right)$ or the sum of sucking insects $\left(F_{(1,19)}=0.28\right.$, $P=0.602)$. 
Table 3: Influence of fungicide treatment on endophytes and mycorrhizas.

\begin{tabular}{lccc}
\hline & Control & Fungicide * & $P$ \\
\hline Endophyte (\% of leaf pieces) & $65 \pm 6$ & $24 \pm 5$ & $<0.001$ \\
Arbuscular mycorrhiza (\% of root cells) & $25 \pm 3$ & $27 \pm 3$ & 0.634 \\
Ectomycorrhiza (\% of root tips) & $14 \pm 1$ & $18 \pm 1$ & 0.010 \\
\hline
\end{tabular}

* The fungicide Amistar(c) was applied once a month from April to August. Colonization by endophytic fungi was scored on leaf pieces, colonization by ecto- and arbuscular mycorrhizal fungi was scored on roots. Data show means $( \pm \mathrm{SE})$ for families $\mathrm{C} 3$ and $\mathrm{C} 4$.
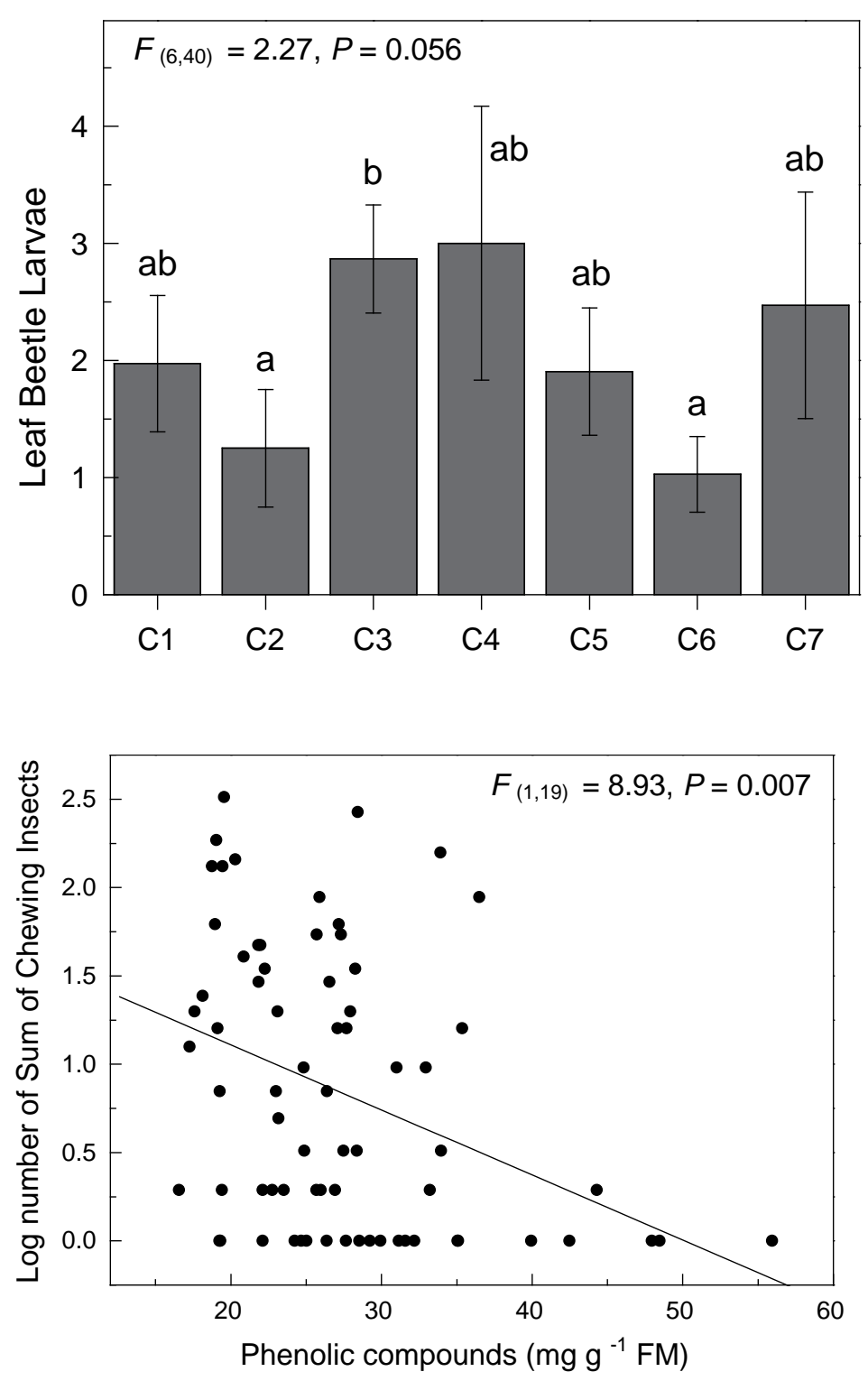

Figure 4: Abundance of chrysomelid larvae on leaves of seven full sib families of aspen (P. tremula). Data indicate means $(\mathrm{N}=24$ to $28, \pm \mathrm{SE})$. Different lower-case letters indicate significant pairwise differences between respective means at $P \leq 0.05$.

Figure 5: Relationship between the concentration of soluble phenolics in leaves and the abundance of chewing insects (note log-scale). 


\section{DISCUSSION}

In this study we included a large range of morphometric and chemometric measures for phenotyping of aspen. We found significant variation in these quantitative traits in the progenies of local parental trees but correspondence between variance for neutral molecular genetic markers and phenotypic characteristics was not found. This was not unexpected since attempts to correlate genetic information based on neutral markers with traits of ecophysiological significance, e.g. timing of bud break, growth, or other quantitative traits have frequently been unsuccessful (McKay and Latta, 2002, Bekessy et al., 2003). Similarly, meta-analysis revealed only a very weak correlation between quantitative traits and molecular measures for genetic variation (mainly isozyme-based analyses, Reed and Frankham, 2001). A comparison of neutral markers, SNPs in candidate genes and quantitative phenological parameters such as bud break, bud set, seasonal increase in tree height and stem diameters in $P$. tremula genotypes from a clinal gradient also failed to detect significant correlations between molecular and phenological measures (Hall et al., 2007). In contrast to those studies, Madritch et al. (2009) found a significant correlation between genetic distance and green leaf chemistry for $P$. tremuloides clones. However, our data do not support such a relationship in $P$. tremula, probably, because the genetic variance within a family of siblings was higher than between different families. Nevertheless, some morphological and phytochemical traits showed significant parental influence. The reason for this apparent contradiction is probably that genetic variance was measured with neutral markers, whereas phenotypic characteristics are the integrative result of many functional genes.

In $P$. tremula the concentration of phenolics was under genetic control such as in P. tremuloides (Osier and Lindroth, 2006, Donaldson and Lindroth, 2007). Interestingly, allocation of a range of nutritional elements such as $\mathrm{N}, \mathrm{P}, \mathrm{Ca}, \mathrm{Mg}$ and $\mathrm{Mn}$ was also under genetic control in P. tremula. $\mathrm{N}$ and $\mathrm{P}$ are major compounds in biogeochemical cycles. The elements $\mathrm{Ca}$ and $\mathrm{Mg}$ are important in ecological nutrient cycles stabilizing or counteracting decreases in soil pH (Guckland et al., 2009). Litter input of fast-degrading leaves therefore has profound effects on ecosystem processes. Whether the observed differences in leaf quality and quantities would be sufficient to influence ecosystem functions, for example, in plantations remains to be seen. With respect to Mn, genetic differences in uptake and root-to- 
shoot allocation have been reported for the interior and coastal race of Douglas fir (Ducic et al., 2006). The interior Douglas fir showed better performance on poor soils than the coastal provenience (Ducic et al., 2009), but in some locations its inability to limit Mn translocation to above-ground plant tissues caused severe bark diseases resulting in significant economic loss (Schöne, 1992). Our findings underline that it will be worthwhile to investigate the genetic basis of mineral nutrient allocation, especially if aspens were used for agro-forestry systems.

Leaf concentrations of phenolic compounds are important factors shaping interactions with other biota (Orians et al., 1997, Glynn et al., 2004, Whitham et al., 2006). Their concentrations vary strongly between different Populus species and their hybrids and these variations are inverselycorrelated with infestation with leaf galls and arthropods (Glynn et al., 2004, Whitham et al., 2006, Holeski et al., 2009). In greenhouse experiments with $P$. tremuloides phenolic glycoside concentrations were the best predictor for gypsy moth larval performance (Donaldson et al., 2006, Donaldson and Lindroth, 2007). Our data indicate that variation in leaf phenolics of $P$. tremula mediated interactions with leaf beetle larvae, belonging to the genus Phratora and Crepidodera. These chrysomelid species are generalists on salicaceous plants and not specifically adapted to utilization of phenolic glucosides like some other Chrysomela species (Denno et al., 1990, Glynn et al., 2004, Ikonen, 2002). High concentrations of leaf phenolic compounds provide a protection from generalist herbivores as indicated by the negative relationship between phenolics and leaf beetle larvae abundance. Our data further suggest that the costs incurred by this constitutive protection are too small to result in significant trade-off for growth or biomass production.

In this study the influence of Amistar Opti, a strobilurin-based antifungal compound, was also studied. The active agent has initially been isolated from Strobilurus tenacelus, a saprophytic fungus growing on pine cones (Anke et al., 1975). Although this fungicide acts against a broad number of fungal species from different classes (ascomycota, basidiomycota, oomycetes), we showed that it does not suppress mycorrhiza formation. This has also been reported for other modern fungicides (Feldman, 2003, Watson, 2006). Mycorrhizal colonization of aspens in our study was similar to that found in other field studies (Baum and Makeschin, 2000). In fact, ectomycorrhizas even tended to be more abundant in fungicide 
treated trees, which may be the result of reduced growth of potential competitors. Endophytic fungi, which colonize the apoplastic space of plant tissues and feed on plant carbohydrates, may be such competitors. They were strongly suppressed by Amistar Opti. Although endophytes often increase plant performance (Clay, 1996, Morse et al., 2002, Bailey et al., 2005, but see Feath and Sullivan, 2003), we did not find negative effects of their suppression on plant nutrition, growth or insect feeding in this short term study. Since trees are cultivated for several years before harvest, it will be important for future investigations to assess if reduction of endophytes has long-term negative effects.

\section{CONCLUSIONS}

We showed that full-sib aspen families exhibit significant intra-specific variation in growth and ecophysiological leaf traits and that some of these traits are clearly related to parenthood. In contrast to our expectation, production of phenolic compounds, which act as defence against generalist herbivores, did not show negative trade-off with growth. Probably, the concentrations of these compounds were too low compared with lignin production or other energy consuming processes to influence growth behaviour. Application of a systemic fungicide did neither suppress mycorrhizal colonization nor affected infestation with insects. However, a strong suppression of endophytes was found, whose long-term consequences may require attention when fungicides are used in agro-forestry plantations.

\section{ACKNOWLEDGEMENTS}

We grateful to G. Langer-Kettner, C. Kettner, M. Smiatacz for help with installation of the common garden experiment and plant harvest and to M. Franke-Klein for help with the photometric assays. We thank the Niedersächsisches Ministerium für Wissenschaft und Kultur and the „Niedersächsisches Vorab“ for funding „Functional Ecology Research“. The authors declare that they have no conflict of interest. 


\section{REFERENCES}

Anke, T., Oberwinkler, F., Steglich, W., and Schramm, G. 1977. The strobilurins - new antifungal antibiotics from the basidiomycete Strobilurus tenacellus (PERS. Ex FR.). The Journal of Antibiotics. 30 :806-810.

Bailey, J. K., Deckert, R., Schweitzer, J. A., Rehill, B. J., Lindroth, R. L., Gehring, C., and Whitham, T. 2005. Host plant genetics affect hidden ecological players: links among Populus, condensed tannins, and fungal endophyte infection. Can. J. Bot. 83: 356-361.

Baum, C., and Makeschin, F. 2000. Effects of nitrogen and phosphorus fertilization on mycorrhizal formation of two poplar clones (Populus trichocarpa and P. tremula $\mathrm{x}$ tremuloides). J. Plant. Nutr. Soil. Sci. 163: 491-497.

Bekessy, S. A., Ennos, R. A., Burgman, M. A., Newton, A. C., and Ades, P. K. 2003. Neutral DNA markers fail to detect genetic divergence in an ecologically important trait. Biol. Conserv. 110: 267-275.

Burnham, K P., and Anderson, D. R. 2002. Model Selection and Multimodel Interference. A Practical Information-Theoretic Approach. Springer Science \& Business Media, New York.

Clay, K. 1996. Interactions among fungal endophytes, grasses and herbivores. Res. Popul. Ecol. 38: 191-201.

Crawley, M. J. 2007. The R Book. Wiley, New York.

DAYANANDAN, S., RAJORA, O. P., and BAWA, K. S. 1998. Isolation and characterization of microsatellites in trembling aspen (Populus tremuloides). Theor. Appl. Genet. 96: 950-956.

DeChantal, M., Lindberg, H., and Kallonen, S. 2009. The condition of Populus tremula and other deciduous saplings in a moose winter foraging area in southern Finland. Ann. Bot. Fennici. 46: 280-290. 
Denno, R. F., Larsson, S., and Olmstead, K. L. 1990. Role of enemy-free space and plant quality in host-plant selection by willow beetles. Ecol. 71: 124-137.

Dickmann, D. I., and Kuzovkina, J. 2008. Poplars and Willows of the World, with Emphasis on Silviculturally Important Species. Rome, Italy: FAO Forest Management Division Working Paper IPC/9-2. 129 p.

Dimpfelmeier, R. 1963. Ergebnisse fünfjähriger Kombinationszüchtungsversuche mit Populus tremula L. Forstwiss. Centralbl. 82: 295-304.

Donaldson, J. R., Kruger, E. L., and Lindroth, R. L. 2006. Competition- and resourcemediated tradeoffs between growth and defensive chemistry in trembling aspen (Populus tremuloides) New. Phytol. 169: 561-570.

Donaldson, J. R., and Lindroth, R. L. 2007. Genetics, environment, and their interaction determine efficacy of chemical defense in trembling aspen. Ecol. 88: 729-739.

Dučić, T., Berthold, D., Langenfeld-Heyser, R., Beese, F., and Polle, A. 2009. Mycorrhizal communities in relation to biomass production and nutrient use efficiency in two varieties of Douglas fir (Pseudotsuga menziesii var. menziesii and var. glauca) in different forest soils. Soil. Biol. Biochem. 41: 742-753.

Dučić, T., Leinemann, L., Finkeldey, R., and Polle. A. 2006. Uptake and translocation of manganese in seedlings of two races of Douglas fir (Pseudotsuga menziesii var. viridis and glauca). New. Phytol. $170: 11-20$.

Faeth, S., and Sullivan, T. 2003. Mutualistic asexual endophytes in a native grass are usually parasitic. American Nat. 161: 310-325.

Feldmann, F. 2003. Nebenwirkungen von Pflanzenschutzmitteln auf arbuskuläre Mykorrhizapilze als Nichtzielorganismen, Fachtagung, 4.11.2003, BBA Braunschweig. 
Glynn, C., Rönnberg-Wästluung, A.-C., Julkunen-Tittto, R., and Wein, M. 2004. Willow genotype, but not drought treatment, affects foliar phenolic conentrations and leaf beetle resistance. Entomol. Exp. Appl. 113: 1-14.

Guckland, A., Jacob, M., Flessa, H., Thomas, F. M., and Leuschner, C. 2009. Acidity, nutrient stocks, and organic-matter content in soils of a temperate deciduous forest with different abundance of European beech (Fagus sylvatica L.) J. Plant. Nutr. Soil. Sci. 172: 500-511.

Hall, D., Luquez, V., Garcia, V. M., St Onge, K. R., Jansson, S., and Ingvarsson, P. K. 2007. Adaptive population differentiation in phenology across latitudinal gradient in European aspen (Populus tremula, L.): a comparison of neutral markers, candidate genes and phenotypic traits. Evol. 61: 2849-2860.

Heinrichs, H., Brumsack, H. J., LoftField, N., and Konig, N. 1986. Improved pressure digestion system for biological and anorganic materials. Z. Pflanzenernähr. Bodenkd. 149: 350-353.

Holeski, L. M., Vogelzang, A., Stanosz, G., and Lindroth, R. L. 2009. Incidence of Venturia shoot blight in aspen (Populus tremuloides Michx.) varies with tree chemistry and genotype. Biochem. Syst. Ecol. 37: 139-145.

Hsu, J. C. 1996. Multiple Comparisons: Theory and Methods. Chapman and Hall, London.

Hultén, E., and Fries, M. 1986. Atlas of North European Vascular Plants, North of the Tropic of Cancer. Konigstein. V. 1-3: 1172.

IKONEN, A. 2002. Preferences of six leaf beetle species among qualitatively different leaf age classes of three Salicaceous host species. Chemoecol. 12: 23-28.

Kendall, D. A., Hunter, T., Arnold, G. M., Liggit, J., Morris, T., and Wiltshire, C. W. 1996. Susceptibility of willow clones (Salix spp.) to herbivory by Phyllodecta vulgatissima (L.) and Galerucella lineola (Fab.) (Coleoptera, Chrysomelidae). Ann. Appl. Biol. 129: 379-390. 
Kouki, J., Arnold, K., and Martikainen, P. 2004. Long-term persistence of aspen - a key host for many threatened species - is endangered in old-growth conservation areas in Finland. J. Nature Conserv. 12: 41-52.

LI, B., and Wu, R. 1997. Heterosis and genotype x environment interactions of juvenile aspens in two contrasting sites. Can. J. For. Res. 27: 1525-1537.

Lichtenthaler, H. K., and Wellenburn, A. R. 1983. Determinations of total carotenoids and chlorophylls a and b of leaf extracts in different solvents. Biochem. Soc. Trans. 11: 591-592.

Liesebach, M., von Wuehlisch, G., and Muhs, H.-J. 1999. Aspen for short-rotation coppice plantations on agricultural sites in Germany: Effects of spacing and rotation time on growth and biomass production of aspen progenies. For. Ecol. Manag. 121: 25-39.

Luo, Z. B., Calfapietra, C., Libberloo, M., Scarascia-Mugnozza, G., and Polle, A. 2006. Carbon partitioning to mobile and structural fractions in poplar wood under elevated CO2 (EUROFACE) and N fertilization. Global Change Biol. 12: 272-283.

Luo, Z. B., Calfapietra, C., Scarascia-Mugnozza, G., Liberloo, M., and Polle, A. 2008. Carbon-based secondary metabolites and internal nitrogen pools in Populus nigra under free Air CO2 Enrichment (FACE) and nitrogen fertilisation. Plant. Soil. 304: 45-57.

Madritch, M. D., Greene, S. L., and Lindroth, R. L. 2009. Genetic mosaics of ecosystem functioning across aspen-dominated landscapes. Oecol. 160: 119-127.

McKay, J. K., and LATtA, R. G. 2002. Adaptive population divergence: markers, QTL and traits. Trends Ecol. Evol. 17: 285-291.

Morse, L. J., DAY, T. A., and FAeth, S. H. 2002. Effect of Neotyphodium endophyte infection on growth and leaf gas exchange of Arizona fescue under contrasting water availability regimes. Environ. Exp. Bot. 48: 257-268. 
Orians, C. M., Huang, C. H., Wild, A., Dorfman, K. A., Zee, P., Dao, M. T. T., and Fritz, R. S. 1997. Willow hybridization differentially affects preference and performance of herbivorous beetles. Entomol. Exp. Appl. 83: 285-294.

Osier, T. L., and Lindroth, R. L. 2006. Genotype and environment determine allocation to and costs of resistance in quaking aspen. Oecol. 148: 293-303.

Pasteels, J. M., Rowell-Rahier, M., Braekman, J. C., and Dupont, A. 1983. Salicin from host plant as precursor of salicylaldehyde in defensive secretion of chrysomeline larvae. Physiol. Entomol. 8: 307-314.

Peakall, R., and Smouse, P. E. 2001. GenAleX V5.04: Genetic Analysis in EXCEL. Population Genetic Software for Teaching and Research. Australian National University, Canberra, Australia, available at http://www.anm.edu.au/ BoZo/GcnAlEX/.

Petrini, O. 1986. Taxonomy of endophytic fungi of aerial plant tissues, In: Fokkema, N. J., van den Heuvel, J. (eds.) Microbiology of the Phyllosphere, Cambridge University Press, Cambridge, pp. 175-187.

Pinheiro, J. C., and Bates, D. M. 2000. Mixed-effects models in S and S-PLUS. Springer, New York.

R Development Core Team 2007. R: A language and environment for statistical computing. R foundation for statistical computing. Vienna, Austria, http://www.R-project.org

Rahman, M. H., Dayanandan, S., and Rajora, O. P. 2000. Microsatellite DNA markers in Populus tremuloides. Genome. 43: 293-297.

ReEd, D. H., and Frankham, R. 2001. How closely correlated are molecular and quantitative measures of genetic variation? A meta-analysis. Evolution. 55: 1095-1103.

Rowell-RAHIER, M. 1984. The presence or absence of phenolglycosides in Salix (Salicaceae) leaves and the level of dietary specialisation of some of their herbivorous insects. Oecol. 62: 26-30. 
Sambrook, J., Fritsch, E. F., and Maniatis, T. 1989. Molecular Cloning: A Laboratory Manual, 2nd edn. Cold Spring Harbor Laboratory Press, Plainview, New York.

SCHÖNE, D. 1992. Site-rain and acid-rain induced nutritional disorders of Douglas fir in Southwestern Germany. Allg. Forst. Jagdztg. 163: 53-59.

Schopfer, P. 1989. Experimentelle Pflanzenphysiologie, Band 2, Einführung in die Anwendung, Springer-Verlag, Berlin, Heidelberg, New York, pp. 39-50.

TAмm, Ü. 2006. Populus tremula, in Enzyklopädie der Laubbäume, Nikolai, Hamburg, pp. $405-414$.

UPOV. 1981. Guidelines for the conduct of tests for distinctness, homogeneity and stability: poplar (Populus L.), UPOV, TG 21/7, pp. 20.

Van Der Schoot, M., Pospiškova, M., Vosman, B., and Smulders, M. J. M. 2000. Development and characterization of microsatellite markers in black poplar (Populus nigra L.). Theor .Appl. Genet. 101: 317-322.

Venables, W. N., and Ripley, B. D. 2002. Modern applied statistics with S, fourth ed. Springer, New York.

Watson, G. W. 2006. The effect of paclobutrazol treatment on starch content, mycorrhizal colonization, and fine root density of white oaks (Quercus alba L.). Arboricult. Urb. For. 32: 114-117.

Whitham, T. G., Bailey, J. K., Schweitzer, J. A., Shuster, S. M., Bangert, R. K., LeRoy, C. J., Lonsdorf, E., Allan, G. J., DiFazio, S. P., Potts, B. M., Fischer, D. G., Gehring, C. A., Lindroth, R. L., Marks, J., Hart, S. C., Wimp, G. M., and Wooley, S. C. 2006. A framework for community and ecosystem genetics: from genes to ecosystems. Nature Rev. Gen. 7: 510-523. 


\section{APPENDIX}

Supplement 1: Results of linear mixed-effects models for different response variables in seven full-sib aspen families (C1, C2, C3, C4, C5, C6, and C7), describing the effects of full-sib families (genotype) and of fungicide treatment. NumDF $=$ numerator degrees of freedom, DenDF $=$ denominator degrees of freedom. Bold font indicates significant $P$-values.

\begin{tabular}{|c|c|c|c|c|c|c|}
\hline \multirow[t]{2}{*}{ group of traits } & \multirow[t]{2}{*}{ parameter } & \multirow[t]{2}{*}{ units } & \multicolumn{4}{|c|}{ genotype } \\
\hline & & & num DF & den DF & $F$-value & $P$-value \\
\hline \multirow[t]{4}{*}{ herbivory } & chrysomelidae larvae & number & 6 & 40 & 2.27 & 0.0561 \\
\hline & sum of cewing insects & number & 6 & 40 & 2.06 & 0.0800 \\
\hline & aphidae & number & 6 & 40 & 1.40 & 0.2370 \\
\hline & sum of sucking insects & number & 6 & 40 & 1.59 & 0.1756 \\
\hline \multirow[t]{2}{*}{ mycorrhiza } & EM & $\%$ colonization & 6 & 40 & 0.56 & 0.7604 \\
\hline & $\mathrm{AM}$ & \% colonization & 6 & 25 & 1.41 & 0.2510 \\
\hline phytochemical & soluble phenolic compounds & mg g-1 fresh mass & 6 & 37 & 17.26 & $<0.0001$ \\
\hline \multirow[t]{6}{*}{ leaf traits } & glucose & mg g-1 fresh mass & 6 & 37 & 6.90 & 0.0001 \\
\hline & fructose & mg g-1 fresh mass & 6 & 37 & 3.39 & 0.0091 \\
\hline & starch & mg g-1 fresh mass & 6 & 37 & 1.03 & 0.4328 \\
\hline & chlorophyll a+b & mg g-1 dry mass & 6 & 35 & 0.86 & 0.5323 \\
\hline & carotinoid & mg g-1 dry mass & 6 & 37 & 2.30 & 0.0546 \\
\hline & soluble protein & mg g-1 dry mass & 6 & 35 & 0.96 & 0.4644 \\
\hline leaf & $\mathrm{Ca}$ & mg g-1 dry mass & 6 & 37 & 92.65 & $<0.0001$ \\
\hline \multirow[t]{7}{*}{ nutrients } & $\mathrm{Mn}$ & mg g-1 dry mass & 6 & 37 & 7.04 & $<0.0001$ \\
\hline & $\mathrm{N}$ & $\%$ & 6 & 37 & 3.83 & 0.0045 \\
\hline & $\mathrm{C}$ & $\%$ & 6 & 37 & 1.00 & 0.2179 \\
\hline & $\mathrm{P}$ & mg g-1 dry mass & 6 & 37 & 4.24 & 0.0024 \\
\hline & $\mathrm{K}$ & mg g-1 dry mass & 6 & 37 & 3.39 & 0.0092 \\
\hline & S & mg g- 1 dry mass & 6 & 37 & 0.41 & 0.8665 \\
\hline & $\mathrm{Fe}$ & mg g-1 dry mass & 6 & 37 & 2.05 & 0.0835 \\
\hline morphometric & number of side shoots & number & 6 & 40 & 4.87 & 0.0008 \\
\hline \multirow[t]{13}{*}{ parameter } & cumulative lenghts of side shoots & $\mathrm{cm}$ & 6 & 40 & 2.44 & 0.0483 \\
\hline & leaf number per tree & number & 6 & 40 & 5.43 & 0.0003 \\
\hline & total leaf biomass & g & 6 & 40 & 4.81 & 0.0009 \\
\hline & leaf area per tree & $\mathrm{cm}^{2}$ & 6 & 40 & 2.87 & 0.0203 \\
\hline & relative leaf water content & $\%$ of fresh mass & 6 & 40 & 3.95 & 0.0034 \\
\hline & relative height growth & & 6 & 40 & 4.09 & 0.0027 \\
\hline & stem diameter & $\mathrm{mm}$ & 6 & 40 & 3.53 & 0.0068 \\
\hline & stem height & $\mathrm{cm}$ & 6 & 40 & 9.33 & $<0.0001$ \\
\hline & stem biomass & g & 6 & 40 & 6.32 & 0.0001 \\
\hline & below ground biomass & g & 6 & 40 & 2.58 & 0.0333 \\
\hline & plant fresh biomass (above ground) & g & 6 & 40 & 5.72 & 0.0002 \\
\hline & whole plant dry biomass & g & 6 & 40 & 5.06 & 0.0006 \\
\hline & days to completed bud break & days & 6 & 40 & 26.40 & $<0.0001$ \\
\hline
\end{tabular}


Supplement 1: Results of linear mixed-effects models for different response variables in seven full-sib aspen families (C1, C2, C3, C4, C5, C6, and C7), describing the effects of full-sib families (genotype) and of fungicide treatment. $\mathrm{NumDF}=$ numerator degrees of freedom, $\mathrm{DenDF}=$ denominator degrees of freedom. Bold font indicates significant $P$-values.

\begin{tabular}{|c|c|c|c|c|c|c|}
\hline \multirow[t]{2}{*}{ group of traits } & \multirow[t]{2}{*}{ parameter } & \multirow[t]{2}{*}{ units } & \multicolumn{4}{|c|}{ fungicide treatment } \\
\hline & & & num DF & DenDF & $F$-value & $P$-value \\
\hline \multirow[t]{4}{*}{ herbivory } & chrysomelidae larvae & number & 1 & 5 & 0.1765 & 0.6919 \\
\hline & sum of cewing insects & number & 1 & 5 & 0.0937 & 0.7718 \\
\hline & aphidae & number & 1 & 5 & 3.3125 & 0.1284 \\
\hline & sum of sucking insects & number & 1 & 5 & 3.5309 & 0.1190 \\
\hline \multirow[t]{2}{*}{ mycorrhiza } & EM & $\%$ colonization & 1 & 5 & 2.7835 & 0.1561 \\
\hline & $\mathrm{AM}$ & $\%$ colonization & 1 & 5 & 0.9100 & 0.3839 \\
\hline phytochemical & soluble phenolic compounds & mg g-1 fresh mass & 1 & 5 & 0.0920 & 0.7736 \\
\hline \multirow[t]{6}{*}{ leaf traits } & glucose & mg g-1 fresh mass & 1 & 5 & 0.9350 & 0.2229 \\
\hline & fructose & mg g-1 fresh mass & 1 & 5 & 0.0110 & 0.9207 \\
\hline & starch & mg g-1 fresh mass & 1 & 5 & 4.0342 & 0.1008 \\
\hline & chlorophyll a+b & mg g-1 dry mass & 1 & 5 & 0.0373 & 0.8545 \\
\hline & carotinoid & mg g-1 dry mass & 1 & 5 & 7.2800 & 0.0429 \\
\hline & soluble protein & mg g-1 dry mass & 1 & 5 & 0.4422 & 0.5355 \\
\hline leaf & $\mathrm{Ca}$ & mg g- 1 dry mass & 1 & 5 & 0.3508 & 0.5794 \\
\hline \multirow[t]{7}{*}{ nutrients } & Mn & mg g- 1 dry mass & 1 & 5 & 0.3760 & 0.5666 \\
\hline & $\mathrm{N}$ & $\%$ & 1 & 5 & 1.8490 & 0.2320 \\
\hline & C & $\%$ & 1 & 5 & 0.0000 & 0.8229 \\
\hline & $\mathrm{P}$ & mg g-1 dry mass & 1 & 5 & 1.9620 & 0.2203 \\
\hline & K & mg g-1 dry mass & 1 & 5 & 1.9140 & 0.2251 \\
\hline & S & mg g-1 dry mass & 1 & 5 & 0.3880 & 0.5608 \\
\hline & $\mathrm{Fe}$ & mg g-1 dry mass & 1 & 5 & 5.7100 & 0.0625 \\
\hline morphometric & number of side shoots & number & 1 & 5 & 0.3800 & 0.5648 \\
\hline \multirow[t]{13}{*}{ parameter } & cumulative lenghts of side shoots & $\mathrm{cm}$ & 1 & 5 & 1.1344 & 0.3655 \\
\hline & leaf number per tree & number & 1 & 5 & 0.3740 & 0.5675 \\
\hline & total leaf biomass & g & 1 & 5 & 2.4540 & 0.1780 \\
\hline & leaf area per tree & $\mathrm{cm}^{2}$ & 1 & 5 & 0.0090 & 0.9288 \\
\hline & relative leaf water content & $\%$ of fresh mass & 1 & 5 & 0.9800 & 0.3669 \\
\hline & relative height growth & & 1 & 5 & 0.7783 & 0.4180 \\
\hline & stem diameter & $\mathrm{mm}$ & 1 & 5 & 0.3300 & 0.5897 \\
\hline & stem height & $\mathrm{cm}$ & 1 & 5 & 0.0600 & 0.8183 \\
\hline & stem biomass & g & 1 & 5 & 1.6620 & 0.2537 \\
\hline & below ground biomass & g & 1 & 5 & 0.7990 & 0.4123 \\
\hline & plant fresh biomass (above ground) & g & 1 & 5 & 0.3060 & 0.6040 \\
\hline & whole plant dry biomass & g & 1 & 5 & 0.5370 & 0.4964 \\
\hline & days to completed bud break & days & \multicolumn{4}{|c|}{ not tested } \\
\hline
\end{tabular}

(continued) 
Supplement 1: Mean and standard error of different herbivorous insects as well as distinct tree traits of seven full-sib aspen families (C1, C2, C3, C4, C5, C6, and C7).

\begin{tabular}{|c|c|c|c|c|c|c|}
\hline \multirow[t]{2}{*}{ group of traits } & \multirow[t]{2}{*}{ parameter } & \multirow[t]{2}{*}{ units } & \multicolumn{2}{|c|}{ C1 } & \multicolumn{2}{|c|}{$\mathrm{C} 2$} \\
\hline & & & mean & SE & mean & SE \\
\hline \multirow[t]{4}{*}{ herbivory } & chrysomelidae larvae & number & 1.97 & 0.60 & 1.25 & 0.51 \\
\hline & sum of cewing insects & number & 2.22 & 0.59 & 1.36 & 0.51 \\
\hline & aphidae & number & 4.13 & 1.00 & 4.94 & 1.70 \\
\hline & sum of sucking insects & number & 4.25 & 1.02 & 5.11 & 1.71 \\
\hline \multirow[t]{2}{*}{ mycorrhiza } & EM & \% colonization & 15.96 & 1.86 & 14.42 & 1.68 \\
\hline & $\mathrm{AM}$ & \% colonization & 26.27 & 2.65 & 37.64 & 3.24 \\
\hline phytochemical & soluble phenolic compounds & mg g-1 fresh mass & 26.35 & 1.13 & 25.69 & 1.23 \\
\hline \multirow[t]{6}{*}{ leaf traits } & glucose & mg g-1 fresh mass & 17.79 & 0.39 & 17.67 & 1.28 \\
\hline & fructose & mg g-1 fresh mass & 0.60 & 0.02 & 0.54 & 0.03 \\
\hline & starch & mg g-1 fresh mass & 1.65 & 0.39 & 1.72 & 0.31 \\
\hline & chlorophyll a+b & mg g-1 dry mass & 3.54 & 0.28 & 3.78 & 0.28 \\
\hline & carotinoid & mg g-1 dry mass & 443.05 & 29.81 & 488.56 & 23.00 \\
\hline & soluble protein & mg g-1 dry mass & 34.35 & 1.46 & 34.89 & 2.46 \\
\hline leaf & $\mathrm{Ca}$ & mg g-1 dry mass & 12.06 & 0.50 & 16.36 & 0.34 \\
\hline \multirow[t]{7}{*}{ nutrients } & $\mathrm{Mn}$ & mg g- 1 dry mass & 49.52 & 1.72 & 48.62 & 2.37 \\
\hline & $\mathrm{N}$ & $\%$ & 2.25 & 0.05 & 2.03 & 0.04 \\
\hline & $\mathrm{C}$ & $\%$ & 47.22 & 0.19 & 47.00 & 0.15 \\
\hline & $\mathrm{P}$ & mg g-1 dry mass & 1.85 & 0.05 & 1.79 & 0.07 \\
\hline & $\mathrm{K}$ & mg g-1 dry mass & 12.42 & 0.51 & 8.23 & 0.42 \\
\hline & $\mathrm{S}$ & mg g-1 dry mass & 1.90 & 0.04 & 1.84 & 0.06 \\
\hline & $\mathrm{Fe}$ & mg g-1 dry mass & 85.95 & 2.20 & 84.15 & 4.51 \\
\hline morphometric & number of side shoots & number & 53.48 & 7.22 & 53.50 & 4.56 \\
\hline \multirow[t]{13}{*}{ parameter } & cumulative lenghts of side shoots & $\mathrm{cm}$ & 55.57 & 10.68 & 33.55 & 10.36 \\
\hline & leaf number per tree & number & 310.90 & 31.48 & 237.96 & 28.91 \\
\hline & total leaf biomass & g & 43.99 & 4.91 & 32.96 & 5.37 \\
\hline & leaf area per tree & $\mathrm{cm}^{2}$ & 3504.61 & 410.33 & 2795.96 & 641.54 \\
\hline & relative leaf water content & $\%$ of fresh mass & 47.23 & 0.69 & 51.55 & 1.37 \\
\hline & relative height growth & & 0.21 & 0.02 & 0.15 & 0.03 \\
\hline & stem diameter & $\mathrm{mm}$ & 15.29 & 0.44 & 14.66 & 0.48 \\
\hline & stem height & $\mathrm{cm}$ & 223.29 & 6.72 & 204.04 & 7.01 \\
\hline & stem biomass & $\mathrm{g}$ & 172.96 & 16.91 & 140.88 & 12.42 \\
\hline & below ground biomass & $\mathrm{g}$ & 57.88 & 6.39 & 46.89 & 4.26 \\
\hline & plant fresh biomass (above ground) & g & 233.40 & 22.31 & 191.73 & 18.28 \\
\hline & whole plant dry biomass & g & 171.18 & 68.76 & 141.23 & 60.54 \\
\hline & days to completed bud break & days & 124.95 & 0.45 & 125.96 & 0.57 \\
\hline
\end{tabular}

(continued) 
Supplement 1: Mean and standard error of different herbivorous insects as well as distinct tree traits of seven full-sib aspen families (C1, C2, C3, C4, C5, C6, and C7).

\begin{tabular}{|c|c|c|c|c|c|c|}
\hline \multirow[t]{2}{*}{ Group of traits } & \multirow[t]{2}{*}{ parameter } & \multirow[t]{2}{*}{ units } & \multicolumn{2}{|c|}{$\mathrm{C} 3$} & \multicolumn{2}{|c|}{$\mathrm{C} 4$} \\
\hline & & & mean & SE & mean & $\mathrm{SE}$ \\
\hline \multirow[t]{4}{*}{ herbivory } & chrysomelidae larvae & number & 2.87 & 0.47 & 3.00 & 1.19 \\
\hline & sum of cewing insects & number & 3.13 & 0.52 & 3.15 & 1.20 \\
\hline & aphidae & number & 18.45 & 8.86 & 2.43 & 1.68 \\
\hline & sum of sucking insects & number & 18.67 & 8.84 & 2.56 & 1.69 \\
\hline \multirow[t]{2}{*}{ mycorrhiza } & EM & \% colonization & 13.71 & 2.03 & 16.75 & 2.23 \\
\hline & $\mathrm{AM}$ & $\%$ colonization & 27.75 & 4.24 & 25.72 & 2.91 \\
\hline phytochemical & soluble phenolic compounds & mg g-1 fresh mass & 20.98 & 0.65 & 30.84 & 1.90 \\
\hline \multirow[t]{6}{*}{ leaf traits } & glucose & mg g-1 fresh mass & 21.57 & 1.91 & 17.96 & 1.40 \\
\hline & fructose & mg g-1 fresh mass & 0.68 & 0.03 & 0.66 & 0.02 \\
\hline & starch & mg g-1 fresh mass & 2.17 & 0.61 & 1.82 & 0.47 \\
\hline & chlorophyll a+b & mg g-1 dry mass & 3.28 & 0.42 & 3.28 & 0.26 \\
\hline & carotinoid & mg g- 1 dry mass & 665.64 & 78.55 & 425.39 & 29.91 \\
\hline & soluble protein & mg g-1 dry mass & 32.68 & 1.89 & 32.75 & 2.38 \\
\hline leaf & $\mathrm{Ca}$ & mg g- 1 dry mass & 14.70 & 0.55 & 14.19 & 0.52 \\
\hline \multirow[t]{7}{*}{ nutrients } & Mn & mg g- 1 dry mass & 79.43 & 3.15 & 63.36 & 2.30 \\
\hline & $\mathrm{N}$ & $\%$ & 2.17 & 0.04 & 2.11 & 0.04 \\
\hline & $\mathrm{C}$ & $\%$ & 47.21 & 0.29 & 47.76 & 0.29 \\
\hline & $\mathrm{P}$ & mg g- 1 dry mass & 1.87 & 0.07 & 1.78 & 0.05 \\
\hline & K & mg g- 1 dry mass & 9.73 & 0.50 & 10.09 & 0.33 \\
\hline & S & mg g- 1 dry mass & 1.92 & 0.06 & 1.95 & 0.06 \\
\hline & $\mathrm{Fe}$ & mg g- 1 dry mass & 95.72 & 3.30 & 80.45 & 2.09 \\
\hline morphometric & number of side shoots & number & 43.75 & 3.07 & 55.08 & 3.13 \\
\hline \multirow[t]{13}{*}{ parameter } & cumulative lenghts of side shoots & $\mathrm{cm}$ & 50.78 & 10.90 & 77.59 & 16.25 \\
\hline & leaf number per tree & number & 230.33 & 19.30 & 303.42 & 25.68 \\
\hline & total leaf biomass & g & 32.25 & 3.73 & 45.61 & 5.22 \\
\hline & leaf area per tree & $\mathrm{cm}^{2}$ & 2615.82 & 317.86 & 3255.67 & 408.08 \\
\hline & relative leaf water content & $\%$ of fresh mass & 47.68 & 0.86 & 47.47 & 0.87 \\
\hline & relative height growth & & 0.41 & 0.07 & 0.19 & 0.03 \\
\hline & stem diameter & $\mathrm{mm}$ & 13.67 & 0.48 & 14.28 & 0.28 \\
\hline & stem height & $\mathrm{cm}$ & 160.88 & 8.84 & 201.75 & 7.63 \\
\hline & stem biomass & g & 113.41 & 10.93 & 159.25 & 13.30 \\
\hline & below ground biomass & g & 38.79 & 2.96 & 54.19 & 3.45 \\
\hline & plant fresh biomass (above ground) & g & 163.34 & 15.25 & 220.98 & 18.86 \\
\hline & whole plant dry biomass & g & 112.11 & 46.30 & 156.69 & 50.71 \\
\hline & days to completed bud break & days & 125.04 & 0.41 & 124.38 & 0.42 \\
\hline
\end{tabular}

(continued) 
Supplement 1: Mean and standard error of different herbivorous insects as well as distinct tree traits of seven full-sib aspen families (C1, C2, C3, C4, C5, C6, and C7).

\begin{tabular}{|c|c|c|c|c|c|c|}
\hline \multirow[t]{2}{*}{ group of traits } & \multirow[t]{2}{*}{ parameter } & \multirow[t]{2}{*}{ units } & \multicolumn{2}{|c|}{ C5 } & \multicolumn{2}{|c|}{ C6 } \\
\hline & & & mean & SE & mean & SE \\
\hline \multirow[t]{4}{*}{ herbivory } & chrysomelidae larvae & number & 1.98 & 0.59 & 1.03 & 0.34 \\
\hline & sum of cewing insects & number & 2.17 & 0.63 & 1.18 & 0.34 \\
\hline & aphidae & number & 4.25 & 2.10 & 6.53 & 3.02 \\
\hline & sum of sucking insects & number & 4.40 & 2.11 & 6.71 & 3.03 \\
\hline \multirow[t]{2}{*}{ mycorrhiza } & EM & $\%$ colonization & 15.97 & 1.88 & 18.09 & 2.18 \\
\hline & $\mathrm{AM}$ & $\%$ colonization & 31.65 & 4.13 & 15.78 & 1.58 \\
\hline phytochemical & soluble phenolic compounds & mg g-1 fresh mass & 27.61 & 1.65 & 30.76 & 1.59 \\
\hline \multirow[t]{6}{*}{ leaf traits } & glucose & mg g-1 fresh mass & 20.25 & 2.02 & 18.75 & 3.10 \\
\hline & fructose & mg g-1 fresh mass & 0.48 & 0.04 & 0.81 & 0.18 \\
\hline & starch & mg g-1 fresh mass & 1.54 & 0.45 & 1.91 & 0.41 \\
\hline & chlorophyll a+b & mg g-1 dry mass & 4.06 & 0.23 & 3.21 & 0.18 \\
\hline & carotinoid & mg g-1 dry mass & 503.26 & 25.07 & 418.77 & 23.52 \\
\hline & soluble protein & mg g-1 dry mass & 40.02 & 2.43 & 33.49 & 1.85 \\
\hline leaf & $\mathrm{Ca}$ & mg g-1 dry mass & 14.44 & 0.46 & 13.04 & 0.47 \\
\hline \multirow[t]{7}{*}{ nutrients } & $\mathrm{Mn}$ & mg g-1 dry mass & 65.00 & 3.61 & 55.22 & 1.77 \\
\hline & $\mathrm{N}$ & $\%$ & 2.12 & 0.03 & 2.08 & 0.04 \\
\hline & $\mathrm{C}$ & $\%$ & 46.96 & 0.09 & 47.12 & 0.08 \\
\hline & $\mathrm{P}$ & mg g-1 dry mass & 1.60 & 0.04 & 1.83 & 0.11 \\
\hline & $\mathrm{K}$ & mg g-1 dry mass & 9.28 & 0.43 & 10.41 & 0.88 \\
\hline & $\mathrm{S}$ & mg g-1 dry mass & 1.98 & 0.11 & 1.85 & 0.06 \\
\hline & $\mathrm{Fe}$ & mg g-1 dry mass & 90.05 & 2.65 & 92.67 & 5.71 \\
\hline morphometric & number of side shoots & number & 46.04 & 3.35 & 40.96 & 3.60 \\
\hline \multirow[t]{13}{*}{ parameter } & cumulative lenghts of side shoots & $\mathrm{cm}$ & 63.34 & 15.02 & 21.39 & 4.85 \\
\hline & leaf number per tree & number & 216.33 & 16.87 & 162.00 & 16.89 \\
\hline & total leaf biomass & g & 39.58 & 3.86 & 22.60 & 2.73 \\
\hline & leaf area per tree & $\mathrm{cm}^{2}$ & 2435.54 & 275.82 & 1587.80 & 208.51 \\
\hline & relative leaf water content & $\%$ of fresh mass & 48.72 & 0.89 & 50.56 & 1.01 \\
\hline & relative height growth & & 0.24 & 0.04 & 0.20 & 0.05 \\
\hline & stem diameter & $\mathrm{mm}$ & 15.50 & 0.40 & 13.42 & 0.36 \\
\hline & stem height & $\mathrm{cm}$ & 210.63 & 7.82 & 156.04 & 7.71 \\
\hline & stem biomass & g & 144.15 & 9.24 & 91.16 & 8.79 \\
\hline & below ground biomass & g & 56.52 & 4.13 & 44.51 & 3.17 \\
\hline & plant fresh biomass (above ground) & $\mathrm{g}$ & 200.12 & 12.53 & 124.87 & 11.76 \\
\hline & whole plant dry biomass & g & 146.35 & 45.55 & 103.10 & 37.66 \\
\hline & days to completed bud break & days & 124.79 & 0.45 & 128.17 & 0.37 \\
\hline
\end{tabular}

(continued) 
Supplement 1: Mean and standard error of different herbivorous insects as well as distinct tree traits of seven full-sib aspen families (C1, C2, C3, C4, C5, C6, and C7).

\begin{tabular}{|c|c|c|c|c|}
\hline \multirow[t]{2}{*}{ group of traits } & \multirow[t]{2}{*}{ parameter } & \multirow[t]{2}{*}{ units } & \multicolumn{2}{|c|}{ C7 } \\
\hline & & & mean & SE \\
\hline \multirow[t]{4}{*}{ herbivory } & chrysomelidae larvae & number & 2.47 & 0.97 \\
\hline & sum of cewing insects & number & 2.67 & 1.00 \\
\hline & aphidae & number & 3.71 & 1.02 \\
\hline & sum of sucking insects & number & 3.85 & 1.01 \\
\hline \multirow[t]{2}{*}{ mycorrhiza } & EM & $\%$ colonization & 17.24 & 2.19 \\
\hline & $\mathrm{AM}$ & $\%$ colonization & 22.49 & 1.96 \\
\hline phytochemical & soluble phenolic compounds & mg g-1 fresh mass & 33.80 & 1.43 \\
\hline \multirow[t]{6}{*}{ leaf traits } & glucose & mg g-1 fresh mass & 28.31 & 2.46 \\
\hline & fructose & mg g-1 fresh mass & 0.44 & 0.03 \\
\hline & starch & mg g-1 fresh mass & 5.25 & 0.87 \\
\hline & chlorophyll a+b & mg g- 1 dry mass & 2.72 & 0.13 \\
\hline & carotinoid & mg g- 1 dry mass & 369.10 & 11.92 \\
\hline & soluble protein & mg g- 1 dry mass & 30.09 & 1.19 \\
\hline leaf & $\mathrm{Ca}$ & mg g-1 dry mass & 15.70 & 0.39 \\
\hline \multirow[t]{7}{*}{ nutrients } & $\mathrm{Mn}$ & mg g- 1 dry mass & 64.83 & 3.10 \\
\hline & $\mathrm{N}$ & $\%$ & 1.84 & 0.02 \\
\hline & C & $\%$ & 47.05 & 0.06 \\
\hline & $\mathrm{P}$ & mg g- 1 dry mass & 1.54 & 0.02 \\
\hline & K & mg g-1 dry mass & 7.65 & 0.20 \\
\hline & S & mg g- 1 dry mass & 1.64 & 0.03 \\
\hline & $\mathrm{Fe}$ & mg g-1 dry mass & 83.55 & 1.49 \\
\hline morphometric & number of side shoots & number & 33.32 & 2.04 \\
\hline \multirow[t]{13}{*}{ parameter } & cumulative lenghts of side shoots & $\mathrm{cm}$ & 79.14 & 15.34 \\
\hline & leaf number per tree & number & 231.50 & 15.69 \\
\hline & total leaf biomass & g & 45.55 & 4.27 \\
\hline & leaf area per tree & $\mathrm{cm}^{2}$ & 2805.98 & 291.38 \\
\hline & relative leaf water content & $\%$ of fresh mass & 49.26 & 0.77 \\
\hline & relative height growth & & 0.32 & 0.05 \\
\hline & stem diameter & $\mathrm{mm}$ & 15.37 & 0.58 \\
\hline & stem height & $\mathrm{cm}$ & 212.59 & 13.63 \\
\hline & stem biomass & g & 139.03 & 13.78 \\
\hline & below ground biomass & g & 54.23 & 4.08 \\
\hline & plant fresh biomass (above ground) & g & 197.13 & 18.42 \\
\hline & whole plant dry biomass & g & 147.51 & 51.56 \\
\hline & days to completed bud break & days & 120.43 & 0.44 \\
\hline
\end{tabular}


Supplement 2: Matrix showing combination of common fathers (1), common mothers (2) and no common parents (0) for the full-sib aspen families.

\begin{tabular}{cc|ccccccc}
\hline & & C1 & C2 & C3 & C4 & C5 & C6 & C7 \\
& parent & $4 \times 5$ & $9 \times 5$ & $8 \times 5$ & $2 \times 5$ & $2 \times 3$ & $9 \times 3$ & $7 \times 1$ \\
\hline C1 & $4 \times 5$ & & & & & & & \\
C2 & $9 \times 5$ & 1 & & & & & & \\
C3 & $8 \times 5$ & 1 & 1 & & & & & \\
C4 & $2 \times 5$ & 1 & 1 & 1 & & & & \\
C5 & $2 \times 3$ & 0 & 0 & 0 & 2 & & \\
C6 & $9 \times 3$ & 0 & 2 & 0 & 0 & 1 & & \\
C7 & $7 \times 1$ & 0 & 0 & 0 & 0 & 0 & 0 & \\
\hline
\end{tabular}




\section{Chapter}

\section{3}

Variable Responses of Leaf Beetle Adults and

Larvae and their Predators to Morphological and Genetic Differences in Populus tremula Trees

Maximilian von Fragstein, Teja TscharntKe 


\section{ABSTRACT}

1 Research on plant-herbivore interactions on willows and poplars focuses mostly on the role of leaf chemicals in Salix clones or Populus hybrids. But less is known from realworld multitrophic interactions on genetically different Populus tremula trees.

2 Here, we study seven full-sib families of aspen (P. tremula) trees, leaf beetles and natural enemies to assess the effects of plant morphological traits and herbivore-induced plant volatiles on two generations of specialized herbivores and their predators.

3 The abundances of leaf beetle adults and larvae differed between the full-sib families, the two generations in the field and trees of different morphological traits. Herbivoreinduced plant volatiles changed from spring to summer, but not with aspen genetics or herbivore load. Predatory arthropods were indirectly affected by genetic aspen constitution, as their abundance closely followed the abundance of leaf beetle adults and larvae, but they were also positively and directly attracted by the volatile (Z)-3-hexenyl acetate. In spring, leaf beetles colonized only one half of the experimental field, but in the in summer, they concentrated in the second field half. This spatio-temporal shift was presumably due to (i) spring colonization from adjacent hedges and (ii) summer avoidance of tree leaves with herbivore-induced leaf responses.

4 In conclusion, our results indicate direct bottom-up effects of P. tremula trees via plant morphological and genetic traits on leaf beetles as well as indirect herbivore-mediated effects on predatory arthropods, with patterns of herbivore load changing across field site from spring to summer.

Key Words: Populus tremula, leaf beetle, Phratora sp., Chrysomela populi, predatory arthropods, multitrophic interactions 


\section{INTRODUCTION}

Abiotic and biotic factors influence the abundance of herbivores, including weather conditions, availability of food and the impact of natural enemies (Schoonhoven et al., 2005). Plants provide resources for herbivorous insects and their natural enemies, but resource availability can change in time and space due to changing concentrations of primary or secondary metabolites and due to changing architectural properties, driven by genetic or phenotypic differences (Ehrlich and Raven, 1964, Price et al., 1980, Clark and Messina, 1998, Bernays and Chapman, 2000, Legrand and Barbosa, 2003, Schoonhoven et al., 2005, Whitham et al., 2006). The following features of host plants can influence insect distribution: the spatial and temporal distribution of host plants (Root 1973, Risch, 1981), nutritional quality and chemical defence (Coley, 1983, Coley et al., 1985, Hemming and Lindroth, 1995), plant size and architecture (Lawton and Schröder, 1977, Southwood et al., 1979, Lawton, 1983, Legrand and Barbosa, 2003), and the abundance, i.e. quantity, of the resource (Hunter, 1992).

The plant size hypothesis suggests that larger plants can be settled by more insect species and individuals than smaller host plants, because they are more likely to be found by the herbivore (Lawton, 1983). For example, Neuvonen and Niemelä (1981) showed a significant correlation between plant size and number of herbivores.

Resource abundance measured as plant biomass (number of leaves, leaf area, etc.) is suggested to represent an important factor structuring insect herbivore communities (Hunter and Wilmer, 1989, Hunter, 1992). For example, resource abundance is the main factor responsible for population oscillations of some moth and butterfly species in temperate forests (Myers and Campbell, 1976, Dempster, 1983). Plants with a higher biomass, especially of leaves and flowers, have a higher insect species richness and abundance (Teragushi et al., 1981, Marques et al., 2000).

Whitham et al. (2006) showed that the composition of arthropod communities is also correlated with the genetic structure and diversity of the host plants. The arthropod communities became more similar as their host plants were genetically more similar. Genetic differences in resistance and tolerance against herbivore damage have been found 
within several poplar and willow species (Denno et al., 1990, Shen and Bach, 1997). Most studies refer to differences in leaf chemistry affecting phytophagous insects, which are known to be a key factor in resistance against herbivores in salicaceous trees. For example, P. tremuloides shows significant genetic variation in phenolic glucosides, well known as defence compounds against generalist herbivores (Osier and Lindroth, 2006, Donaldson and Lindroth, 2007, Stevens et al., 2007). Therefore only specialist herbivores such as Phratora vitellinae and Chrysomela populi prefer to feed on salicaceous species with relatively high concentrations of phenolic glycosides in the leaves (Finet and Gregoire, 1981, 1982, Köpf et al., 1998, Ikonen, 2002). Their larvae sequester plant-derived allelochemicals, especially salicin and salicortin, to salicylaldehyde (Pasteels et al., 1983, Smiley et al., 1985, Burse et al., 2009) for effective defence against generalist predators (Hilker and Schulz, 1994, Denno et al., 1990, Palokangas and Neuvonen, 1992) but ineffective against specialist predators (Pasteels and Gregoire, 1984, Rank and Smiley, 1994, Zvereva and Rank, 2003).

Only few studies address the emission of herbivore-induced plant volatiles (HIPV) in poplar trees. Arimura et al. (2004) and Frost et al. (2007) found mono-, sesqui and homo-terpenoids, simple phenolics, and also benzene cyanides, emitted as reactions to herbivore damage. HIPVs often serve as semiochemical cues for host location of prey by predatory insects and parasitoids, and they often shape multitrophic interactions (Takabayashi and Dicke, 1996, Dicke and Baldwin, 2010).

Plant-insect interactions have mainly been studied in willows, $P$. tremuloides or in hybrids of P. tremuloides with P. tremula (Peacock et al., 1999, 2004, Arimura et al., 2004, Osier and Lindroth, 2006), whereas less information is available on its close relative P. tremula, especially about the influence of plant size and resource abundance on herbivorous insects.

In this study we evaluated the relationship between morphological tree traits such as tree height, leaf number and leaf toughness, HIPVs, the abundances of leaf beetle adults and larvae and of their natural enemies on genetically different poplar trees (P. tremula). We posed the following questions: 
1) Is there any relationship between genetic differences of the poplar trees and the herbivore load and predator abundance?

2) Which morphological tree traits drive herbivore abundances? Do these traits have a direct or indirect, prey-mediated influence on natural enemies?

3) Are there differences in volatile emission between full-sib families and seasons, which can be related to the herbivore load or to predators?

\section{MATERIAL AND METHODS}

\section{Plant materials and experimental set-up}

For our experiments we used aspen (Populus tremula) belonging to eight full-sibling (fullsib) families C1, C2, C3, C4, C5, C6, C7, and C8 bred by a controlled crossing. The parent

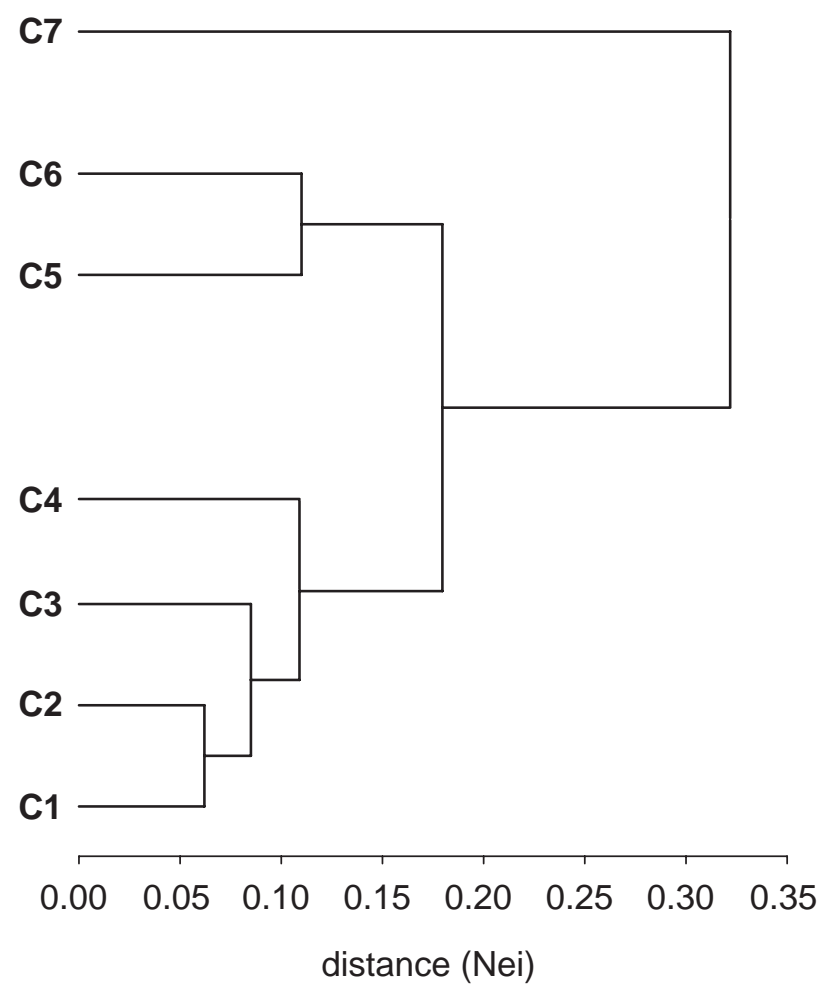

Figure 1: Genetic distance tree (according to Nei, 1978) of the seven full-sib families based on five neutral molecular markers (Kleemann et al., 2010). Hierarchical cluster analysis, average linkage. tree material originates from 30-year-old trees selected in Göttingen-Geismar, Central Germany (513’N, 956ㅌ). Each full-sib family was represented by 18 trees. To characterize the genetic differences between the full-sib families, DNA of the progenies was analyzed using five nuclear encoded microsatellite markers as described in Kleemann et al. (2010). The genetic distance between the different fullsib families was calculated according to Nei (Nei, 1978) (Fig.1, Tab. 1). 
In spring 2008 the trees were planted into 65-litre pots (Fruhstorfer soil, type T 25, Germany) with a distance of $2 \mathrm{~m}$ between two pots following a fully randomized design with 144 trees. The trees were watered when necessary. At the beginning of the season (2008 and 2009) the trees were fertilized (Hakophos ${ }^{\circledR}$ blau, Compo). The trees of full-sib family C8 had to be excluded from the statistical analysis as the genetic analysis revealed they cannot assign to an own full-sib family.

Table 1: Matrix of genetic distances (\% according to Nei, 1978) between the seven aspen fullsib families based on five neutral molecular markers analysis.

\begin{tabular}{cccccccc}
\hline Full-sib families & C1 & C2 & C3 & C4 & C5 & C6 & C7 \\
\hline C1 & 0.0 & & & & & & \\
C2 & 6.2 & 0.0 & & & & & \\
C3 & 6.5 & 10.5 & 0.0 & & & & \\
C4 & 8.6 & 12.2 & 11.9 & 0.0 & & & \\
C5 & 11.8 & 26.5 & 27.0 & 14.0 & 0.0 & & \\
C6 & 8.8 & 11.4 & 22.7 & 21.5 & 11.0 & 0.0 & \\
C7 & 27.3 & 46.3 & 51.0 & 31.4 & 11.8 & 25.3 & 0.0 \\
\hline
\end{tabular}

The experimental area (30 x 30m) was surrounded by a hedge (Acer campestre, A. platanoides, Rosa canina, Crataegus sp., Prunus avium) at one side, a greenhouse at the opposite side; both in a distance of $3 \mathrm{~m}$ to the edge of theexperimental area. The other two sides were bordered by grassland and a strawberry field.

Genetic analyses of the trees were conducted at the Buesgen-Institute of Forest Genetics and Forest Tree Breeding using same methods and markers as described in Kleemann et al. (2010).

\section{Insect sampling}

Leaf beetle adults and larvae were quantified visually on each tree, as were natural enemies such as lady bird beetles (Coccinellidae), soldier beetles (Cantharidae), wasps (solitary and social) and spiders. Counting was done twice a month (with two weeks distance between the sampling dates) from May to the end of August. Further insects were captured using a sweep net and an exhauster or were identified directly on the trees. 
The adult insects were identified in the laboratory. Our sampling approach provided data on the insect species composition and estimates on abundances.

Due to negligible abundances, the adults of Crepidodera, Phratora, and Chrysomela species were pooled as “leaf beetle imagines”. Soldier beetles, lady bird beetles, predatory wasps, syrphid fly larvae and spiders were pooled and denominated as "sum of predators".

\section{Morphometric measurements}

In spring (May and June) and summer (July and August) 2009 morphometric traits were measured on each tree. Tree diameter at the bottom (root collar), and the length of the main shoot (from the base to the terminal bud = tree height) were measured, the number of side branches of a tree was counted. On one side branch per tree the number of leaves was counted. To determine the number of leaves per tree we multiplied the number of side branches with the number of leaves per side branch. Leaf toughness was measured in summer on 10 randomly chosen leaves of each tree, using a Stable Micro Systems Analyser TA.XT 2. Feeding damage was estimated directly on the tree in the field and was measured on 15 leaves of each tree using the software Lamina (http://rsbweb.nih.gov/ij/).

\section{Sampling of volatiles and extracts}

Volatiles were sampled on a charcoal trap (CLSA-Filter, Daumazan sur Arize, France) using a modified push-pull headspace collection system (Tholl et al., 2006) on four randomly chosen trees of the seven full-sib families. About 50 leaves of one branch were enclosed in a plastic roasting bag (Melitta GmbH, Minden, Germany). Air was circulated through the trap by a miniature pump (Fürgut, Aichstetten, Germany) at a flow of $0.81 \mathrm{~min}^{-1}$. The operating time was 2 hrs. Adsorbed volatiles were eluted with $100 \mu \mathrm{l}$ of dichloromethane/methanol (2:1). The solvents used were of analytical quality (both solvents Suprasolv quality, Merck/ VWR, Darmstadt, Germany).

\section{Chemicals}

The following authentic standards were obtained with given purity from commercial sources: 6-methyl-5-hepten-2-one (96 \%, CAS: 110-93-0, Fluka, Germany), (Z)-3-hexenyl acetate (98 \%, CAS:3681-71-8, Aldrich, Germany), methyl salicylate (99 \%, CAS: 119-36-8, Sigma- 
Aldrich, Germany), $\beta$-caryophyllene (CAS: 87-44-5, Fluka, Germany), ocimene (mixture 70 $\%(Z)$-ocimene $+25 \%$ limonene, $98 \%$, CAS: 13877-91-3, Fluka, Germany), $\alpha$-humulene (98 \% CAS: 6753-98-6, Fluka, Germany), and nerolidol (90 \%, Aldrich, Germany).

GC-MS system and data analyses

Analyses of the volatile components (of the extract) were performed with GC-MS consisting of a gas chromatograph Agilent type 6890 (Palo Alto, USA) connected to a type 5973 quadrupole mass spectrometer with electron ionisation (EI, $70 \mathrm{eV}$ ). A HP-5MS column (Agilent, $30 \mathrm{~m}, 0.25 \mathrm{~mm}$ ID, and $0.25 \mu \mathrm{m}$ film thickness, $5 \%$ phenylmethylsiloxane) was used to validate the composition of the extracts. An aliquot of $1 \mu \mathrm{l}$ was injected into a split/ splitless injector held at $250^{\circ} \mathrm{C}$. The oven temperature program was $50^{\circ} \mathrm{C}$ for $1.5 \mathrm{~min}$, followed by an increase of $7.50{ }^{\circ} \mathrm{C} / \mathrm{min}$ to $200^{\circ} \mathrm{C}$, remaining at $200^{\circ} \mathrm{C}$ for $5 \mathrm{~min}$. Helium (purity 99,99 \%) was used as the carrier gas (1 ml/min).

For identification of the constituents, mass spectra and GC linear retention indices (van den Dool and Kratz, 1963) were compared to those of authentic standards and those of given mass spectral databases of the Mass Spectral Search library of the NIST (National Institute of Standards and Technology 08, Gaithersburg, USA) and Whiley ( $9^{\text {th }}$ Edition).

\section{Laboratory feeding experiments}

Feeding experiments were conducted in May 2009 with larvae of Chrysomela populi. Adults of C. populi were caught at three locations in the vicinity of Göttingen, Lower Saxony,

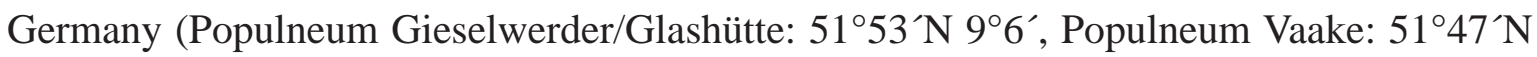
$9^{\circ} 64^{\prime} \mathrm{O}$, Lutterberg: $51^{\circ} 37^{\prime} \mathrm{N} 9^{\circ} 64^{\prime} \mathrm{O}$ ) and were reared in the laboratory for mating and laying eggs. For the feeding experiments first instar larvae were used.

The feeding experiments were conducted in a laboratory at room temperature $\left(20-24{ }^{\circ} \mathrm{C}\right)$ under a natural day-night light rhythm. The C. populi larvae were placed each in a petri dish $(\varnothing 9 \mathrm{~cm})$ provided with a moistened filter paper. Petri dishes were prepared with one leaf disc (Ø 20mm). These discs were punched from leaves deriving from ten randomized chosen trees of each full-sib family, standardizing the leaf area available for feeding. The experiments started in the morning and terminated after 48h. Larvae were weighed before placing into the petri dishes and after $48 \mathrm{~h}$. After finishing the experiments the leaf discs were 
scanned (300 dpi) and the area fed by the larvae was analyzed with Adobe Photoshop CS5.

\section{Data analysis}

Herbivore data of all sampling dates of May and June (spring) and of all sampling dates of July and August (summer) were pooled. All statistical analyses were carried out using the software R 2.11.1 (R Development Core Team, 2010).

To test the genotype effect on the different response variables (morphometric traits, VOCs, and herbivore abundances) we fitted generalized linear models ("glm and glm.nb"-function in package "stats and MASS"; Venables and Ripley, 2002) using quasipoisson (morphometric and VOCs variables) and negative binomial distribution (herbivore abundances) with genotype as fixed factor. We decided to compute the genetic variance with genotype as fixed factor because of the small number of neutral markers applied. Generalized linear models with negative binomial distribution were used to test effects of morphometric variables on herbivore abundances plus their two-way interaction. The same model was used to test the effects of herbivore and morphometric variables on predator abundances plus their two-way interaction. We did not include the number of leaves and tree height in one model, because of the colinearity of the two variables.

For model simplification we performed stepwise backwards model selection by using the Akaike Information Criterion (AIC) (Crawley, 2007; "stepAIC“-function within the "MASS“-package, Venables and Ripley, 2002). The minimal adequate model was the one with the lowest AIC (Burnham and Anderson, 2002). Laboratory feeding experiments and analyses of feeding damage scans were analyzed using ANOVA. Multiple comparisons among factors having a significant effect in the minimal model were calculated using Tukey contrasts with $P$-values adjusted by single-step method (“multcomp“-package, Hsu, 1996).

To investigate relationships between genetic variance of the neutral markers and the different morphometric and insect parameter, Mantel tests were conducted. 


\section{RESULTS}

\section{Morphological tree parameter and volatile organic compounds}

The full-sib families differed significantly in number of leaves (spring: $F_{(6,101)}=3.3684$, $P=0.005$, summer: $\left.F_{(6,101)}=5.9667, P<0.0001\right)$, number of side shoots (spring: $F_{(6,101)}=$ 2.3751, $P=0.03$, summer: $\left.F_{(6,101)}=4.7211, P=0.0003\right)$, tree height (spring: $F_{(6,101)}=11.435$, $P<0.0001$, summer: $\left.F_{(6,101)}=12.892, P<0.0001\right)$, and in root collar diameter (spring: $F_{(6,101)}$ $=3.1102, P=0.008$, summer: $\left.F_{(6,101)}=3.9929, P=0.001\right)$. We found no differences between the full-sib families in the relative growth rate and leaf toughness (only measured in August 2009).

One of the analyzed HIPVs methyl salicylate differ between full-sib families, but only in summer $\left(F_{(6,21)}=2.6613, P=0.04\right)$. All other analyzed HIPVs ocimene, 6-methyl-5-hepten2-one, (Z)-3-hexenyl acetate, $\beta$-caryophyllene, $\alpha$-humulene, and nerolidol did not differ significantly between full-sib families at the two sampling dates. In summer we measured significantly less amounts of these HIPVs than in spring (Appendix Tab. A1).

Results of the Mantel test showed neither significant relations between the five neutral markers and leaf beetles and their larvae, nor relations to predatory arthropods. The same is true for tree morphological and chemical (HIPV) parameters (Tab. 2).

Table 2: Results of the Mantel test conducted for the relationship between genetic variance and herbivore, predator, morphometric, and chemical (HIPV) parameters.

\begin{tabular}{lccc}
\hline Parameter group & \multicolumn{3}{c}{$P$-value (genetic variance)* } \\
\cline { 2 - 4 } & total & spring & summer \\
\hline Leaf beetles and their larvae & 0.579 & 0.111 & 0.862 \\
Predeatory arthropods & 0.166 & 0.055 & 0.316 \\
Plant morphology & 0.804 & 0.833 & 0.779 \\
Herbivore-induced plant volatiles & 0.742 & 0.822 & 0.403 \\
\hline
\end{tabular}

* Genetic variances were calculated on the basis of the five neutral markers used to test the populations. Morphometric parameters of tree morphology were: tree height, stem diameter, number of leaves, and number of side shoots. 


\section{Arthopod community structure}

We recorded leaf beetles of the genera Chrysomela (C. populi, C. vigintipunctata), Crepidodera (C. aurata, C. aurea), and Phratora (P. vitellinae, P. laticollis), two lady bird beetle species (Harmonia axyridis, Coccinella septempunctata), three soldier beetle species (Cantharis fusca, Cantharis pellucida, Rhagonycha fulva), and predatory wasps such as Polistes sp. and Symmorphus sp.

Covering two leaf beetle generations we counted 939 leaf beetle imagines, 3098 eggs, 5206 larvae, and 538 predatory arthropods (adults and larvae) across all seven full-sib families. Phratora sp. reached the highest densities of leaf beetle adults (89\%), followed by Crepidodera sp. (10\%), and Chrysomela populi and C. vigintipunctata (1\%). Spiders (44 \%) and lady bird beetles (40 \%) reached the highest densities of predatory arthropods, followed by soldier beetles (11\%). The remaining predatory arthropods were solitary and social wasps and syrphid fly larvae (together $5 \%$ ).

There were significant differences between the abundances of the spring and summer populations. Leaf beetle larvae ( $\Delta$ Deviance $\left._{(1,214)}=5.5866, P=0.018\right)$ and the imagines of Crepidodera sp. $\left(\Delta\right.$ Deviance $_{(1,214)}=5.2497, P=0.022$ ) were more abundant in spring, whereas the Phratora sp. imagines ( $\Delta$ Deviance $_{(1,214)}=19.036, P<0.0001$ ) were more abundant in summer. Soldier beetles were more abundant in spring than in summer $\left(\Delta\right.$ Deviance $_{(1,214)}=$ 5.2033, $P=0.023$ ), but spider abundance ( $\Delta$ Deviance $_{(1,214)}=57.404, P<0.0001$ ) was higher in summer than in spring. For lady bird beetle we found no temporal pattern (Appendix Tab. A2).

\section{Performance of the first generation (spring 2009)}

Leaf beetle larvae were least abundant on full-sib family C1, different to all other full-sib families. Full-sib family C7 suffered from the highest infestation with chewing insects (Tab. 3). Abundances of leaf beetle imagines and predatory arthropods did not differ, neither between the full-sib families nor the seasons (Tab. 3).

Feeding damage of leaves was related to the abundance of leaf beetle adults $\left(F_{(1,104)}=77.442\right.$, $P<0.0001)$ and larvae $\left(F_{(1,104)}=120.91, P<0.0001\right)$. Leaves of trees of full-sib family C7 were more damaged than leaves of C1 trees $\left(F_{(1,99)}=2.5919, P=0.022\right)$, the others being 
intermediate without significant differences.

Table 3: Densities of leaf beetles, their larvae and predatory arthropods (arithmetic means \pm standard error) on trees of different full-sib families. Results of generalized linear models (GLM) (negative binomial distributed) for leaf beetles, their larvae and predatory arthropods describing different infestations between full-sip families. Small italic letters indicate significant differences between respective means at $P \leq 0.05$. (Multiple comparisons among factors were calculated using Tukey test). Bold font indicates significant $P$-values.

\begin{tabular}{|c|c|c|c|c|c|c|c|c|c|c|c|c|c|}
\hline \multirow[t]{2}{*}{ Full-sib family } & & \multicolumn{3}{|c|}{$\mathrm{C} 1$} & & \multicolumn{3}{|c|}{$\mathrm{C} 2$} & \multicolumn{5}{|c|}{ C3 } \\
\hline & & mean & \pm & $\mathrm{SE}$ & & mean & \pm & $\mathrm{SE}$ & & mean & \pm & $\mathrm{SE}$ & \\
\hline \multirow[t]{2}{*}{ Leaf beetle larvae } & spring & 0.5 & \pm & 0.40 & (c) & 7.3 & \pm & 3.60 & $(a b)$ & 6.4 & \pm & 2.00 & $(a b)$ \\
\hline & summer & 1.3 & \pm & 0.41 & (a) & 1.8 & \pm & 1.00 & (a) & 5.8 & \pm & 3.24 & $(a b)$ \\
\hline \multirow[t]{2}{*}{ Leaf beetle imagines } & spring & 0.6 & \pm & 0.16 & & 1.2 & \pm & 0.30 & & 1.1 & \pm & 0.24 & \\
\hline & summer & 0.8 & \pm & 0.32 & & 2.0 & \pm & 0.79 & & 1.3 & \pm & 0.39 & \\
\hline \multirow[t]{2}{*}{ Phratora sp. } & spring & 0.7 & \pm & 0.15 & & 0.8 & \pm & 0.28 & & 0.6 & \pm & 0.16 & \\
\hline & summer & 0.6 & \pm & 0.28 & (b) & 2.0 & \pm & 0.78 & $(a b)$ & 1.2 & \pm & 0.39 & $(a b)$ \\
\hline \multirow[t]{2}{*}{ Crepidodera sp. } & spring & 0.2 & \pm & 0.08 & & 0.1 & \pm & 0.04 & & 0.2 & \pm & 0.16 & \\
\hline & summer & 0.2 & \pm & 0.12 & & 0.0 & \pm & 0.03 & & 0.1 & \pm & 0.05 & \\
\hline \multirow[t]{2}{*}{ Predatory arthropods } & spring & 0.6 & \pm & 0.12 & & 0.6 & \pm & 0.20 & & 0.4 & \pm & 0.07 & \\
\hline & summer & 1.0 & \pm & 0.22 & & 0.8 & \pm & 0.16 & & 0.9 & \pm & 0.16 & \\
\hline \multirow[t]{2}{*}{ Coccinellidae } & spring & 0.2 & \pm & 0.12 & & 0.3 & \pm & 0.15 & & 0.2 & \pm & 0.06 & \\
\hline & summer & 0.4 & \pm & 0.10 & & 0.2 & \pm & 0.08 & & 0.2 & \pm & 0.08 & \\
\hline \multirow[t]{2}{*}{ Cantharidae } & spring & 0.2 & \pm & 0.06 & & 0.1 & \pm & 0.05 & & 0.2 & \pm & 0.06 & \\
\hline & summer & 0.2 & \pm & 0.10 & & 0.0 & \pm & 0.02 & & 0.1 & \pm & 0.04 & \\
\hline \multirow[t]{2}{*}{ Spiders } & spring & 0.1 & \pm & 0.07 & & 0.1 & \pm & 0.05 & & 0.1 & \pm & 0.03 & \\
\hline & summer & 0.5 & \pm & 0.11 & & 0.6 & \pm & 0.11 & & 0.6 & \pm & 0.12 & \\
\hline
\end{tabular}

(continued) 
Table 3

\begin{tabular}{|c|c|c|c|c|c|c|c|c|c|c|c|c|c|}
\hline \multirow[t]{2}{*}{ Full-sib family } & & \multicolumn{3}{|c|}{ C4 } & & \multicolumn{3}{|c|}{ C5 } & \multicolumn{5}{|c|}{ C6 } \\
\hline & & mean & \pm & $\mathrm{SE}$ & & mean & \pm & $\mathrm{SE}$ & & mean & \pm & SE & \\
\hline \multirow[t]{2}{*}{ Leaf beetle larvae } & spring & 9.9 & \pm & 6.82 & $(a b)$ & 3.8 & \pm & 1.04 & $(a c)$ & 15.0 & \pm & 9.52 & $(a b)$ \\
\hline & summer & 15.3 & \pm & 9.69 & (b) & 3.0 & \pm & 1.00 & (a) & 6.7 & \pm & 2.05 & $(a b)$ \\
\hline \multirow[t]{2}{*}{ Leaf beetle imagines } & spring & 1.5 & \pm & 0.39 & & 1.0 & \pm & 0.23 & & 1.5 & \pm & 0.36 & \\
\hline & summer & 3.8 & \pm & 1.77 & & 2.2 & \pm & 0.68 & & 1.4 & \pm & 0.45 & \\
\hline \multirow[t]{2}{*}{ Phratora sp. } & spring & 0.8 & \pm & 0.38 & & 0.7 & \pm & 0.18 & & 0.8 & \pm & 0.33 & \\
\hline & & 3.7 & \pm & 1.72 & (a) & 2.2 & \pm & 0.67 & $(a b)$ & 1.3 & \pm & 0.42 & $(a b)$ \\
\hline \multirow[t]{2}{*}{ Crepidodera sp. } & spring & 0.1 & \pm & 0.05 & & 0.4 & \pm & 0.12 & & 0.1 & \pm & 0.05 & \\
\hline & summer & 0.1 & \pm & 0.06 & & 0.0 & \pm & 0.02 & & 0.0 & \pm & 0.03 & \\
\hline \multirow[t]{2}{*}{ Predatory arthropods } & spring & 0.7 & \pm & 0.18 & & 0.5 & \pm & 0.12 & & 0.6 & \pm & 0.15 & \\
\hline & summer & 1.5 & \pm & 0.35 & & 1.2 & \pm & 0.24 & & 1.0 & \pm & 0.15 & \\
\hline \multirow[t]{2}{*}{ Coccinellidae } & spring & 0.5 & \pm & 0.16 & & 0.3 & \pm & 0.08 & & 0.3 & \pm & 0.16 & \\
\hline & summer & 0.6 & \pm & 0.22 & & 0.4 & \pm & 0.13 & & 0.2 & \pm & 0.06 & \\
\hline \multirow[t]{2}{*}{ Cantharidae } & spring & 0.1 & \pm & 0.06 & & 0.1 & \pm & 0.03 & & 0.2 & \pm & 0.06 & \\
\hline & summer & 0.0 & \pm & 0.02 & & 0.0 & \pm & 0.02 & & 0.0 & \pm & 0.02 & \\
\hline \multirow[t]{2}{*}{ Spiders } & spring & 0.0 & \pm & 0.02 & & 0.0 & \pm & 0.02 & & 0.1 & \pm & 0.03 & \\
\hline & summer & 0.9 & \pm & 0.26 & & 0.8 & \pm & 0.20 & & 0.8 & \pm & 0.14 & \\
\hline
\end{tabular}

(continued) 
Table 3

\begin{tabular}{|c|c|c|c|c|c|c|c|c|}
\hline \multirow[t]{2}{*}{ Full-sib family } & \multicolumn{5}{|c|}{$\mathrm{C} 7$} & \multicolumn{3}{|c|}{ results of GLM } \\
\hline & & mean & \pm & SE & & Df & $\Delta$ Deviance & $P$-value \\
\hline \multirow[t]{2}{*}{ Leaf beetle larvae } & spring & 36.4 & \pm & 15.13 & (b) & 6 & 23.292 & 0.0007 \\
\hline & summer & 3.0 & \pm & 1.51 & $(a b)$ & 6 & 22.588 & 0.0009 \\
\hline \multirow[t]{2}{*}{ Leaf beetle imagines } & spring & 1.7 & \pm & 0.49 & & 6 & 7.6128 & 0.2679 \\
\hline & summer & 1.6 & \pm & 0.73 & & 6 & 12.288 & 0.0558 \\
\hline \multirow[t]{2}{*}{ Phratora sp. } & spring & 1.5 & \pm & 0.50 & & 6 & 7.4512 & 0.2811 \\
\hline & summer & 1.5 & \pm & 0.70 & $(a b)$ & 6 & 13.917 & 0.0306 \\
\hline \multirow[t]{2}{*}{ Crepidodera sp. } & spring & 0.4 & \pm & 0.12 & & 6 & 5.9627 & 0.4274 \\
\hline & summer & 0.1 & \pm & 0.08 & & 6 & 3.0618 & 0.8010 \\
\hline \multirow[t]{2}{*}{ Predatory arthropods } & spring & 1.1 & \pm & 0.16 & & 6 & 5.5571 & 0.4746 \\
\hline & summer & 0.6 & \pm & 0.16 & & 6 & 6.9808 & 0.3226 \\
\hline \multirow[t]{2}{*}{ Coccinellidae } & spring & 0.8 & \pm & 0.17 & & 6 & 8.0048 & 0.2378 \\
\hline & summer & 0.3 & \pm & 0.07 & & 6 & 5.7277 & 0.4544 \\
\hline \multirow[t]{2}{*}{ Cantharidae } & spring & 0.1 & \pm & 0.04 & & 6 & 2.6364 & 0.8529 \\
\hline & summer & 0.1 & \pm & 0.04 & & 6 & 3.1308 & 0.7923 \\
\hline \multirow[t]{2}{*}{ Spiders } & spring & 0.1 & \pm & 0.06 & & 6 & 2.4364 & 0.8755 \\
\hline & summer & 0.3 & \pm & 0.09 & & 6 & 6.1180 & 0.4101 \\
\hline
\end{tabular}

Performance of the second generation (summer 2009)

On trees of the full-sib family $\mathrm{C} 4$ we counted significantly more leaf beetle larvae (of all genera) than on full-sib family C1, C2 and C5, but for leaf beetle imagines (of all genera) we detected no differences between the full-sib families. The genus Phratora showed a higher infestation of the trees of full-sib family $\mathrm{C} 4$ than $\mathrm{C} 1$ (Tab. 3). There were also no significant differences between the full-sib families regarding all predatory arthropods.

Feeding damage of leaves was less in summer than in spring, but significantly related to the abundance of leaf beetle imagines $\left(F_{(1,105)}=6.8282, P=0.01\right)$ and larvae $\left(F_{(1,105)}=4.1781\right.$, $P=0.04)$. Leaves of trees of full-sib family C1 were less damaged than leaves of C4, C6 and C7 trees $\left(F_{(1,100)}=3.9327, P=0.001\right)$. 

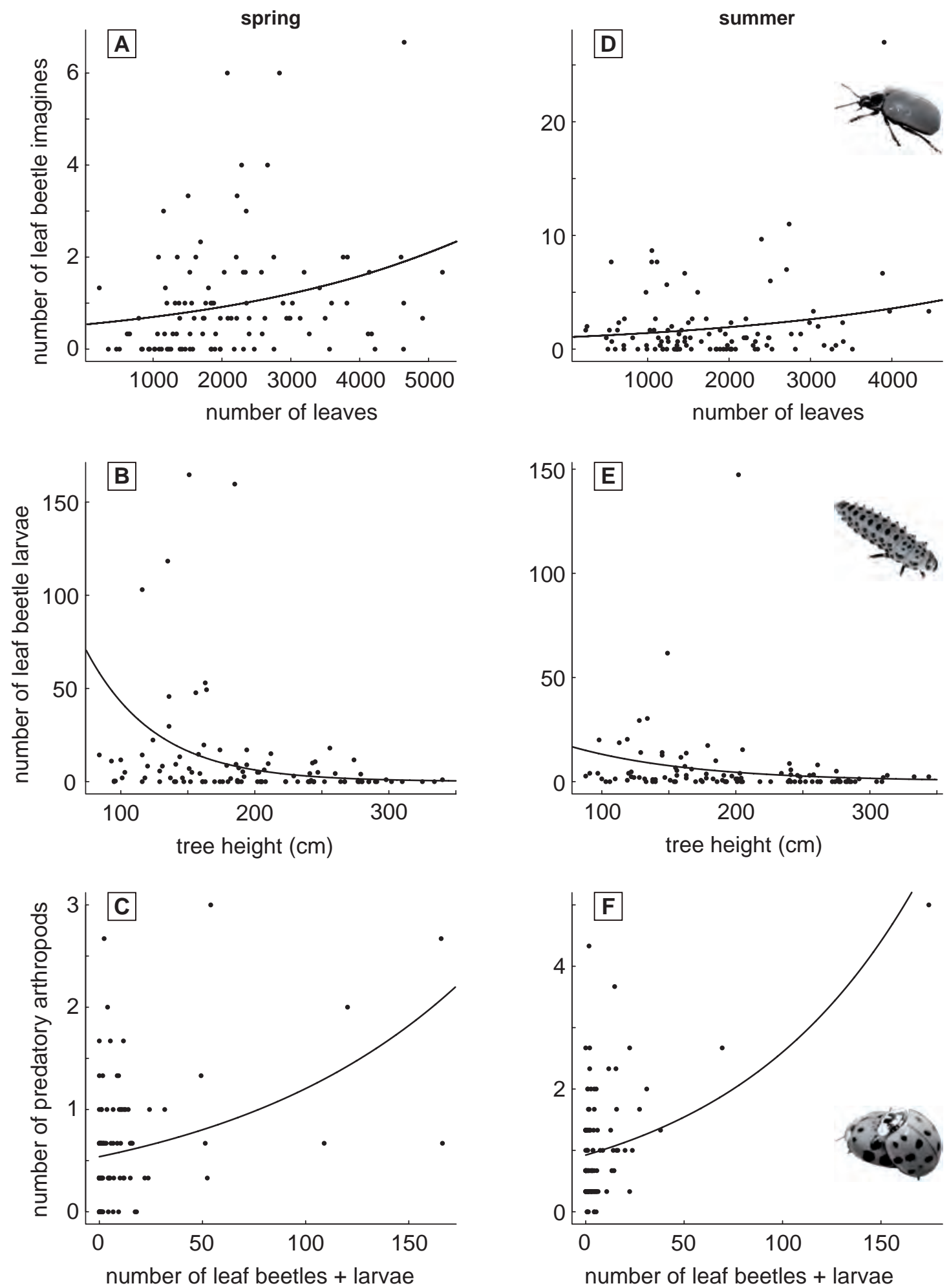

Figure 2: Relationship between morphometric parameters of polar trees and herbivore abundance (A, B, $\mathbf{E}, \mathbf{D})$, herbivore and predator abundance (C, F) in spring (A-C) and summer (D-F). A and D: Relationship between leaf beetle imagines and number of leaves. $\mathbf{B}$ and $\mathbf{E}$ : Leaf beetle larvae in relation to tree height (Generalized Linear Models - negative binomial distributed). C and F: Number of leaf beetle imagines and larvae in relation to the abundance of predatory arthropods (Generalized Linear Models - quasipoisson distributed). 


\section{Tree features and arthropod community}

Both generations of leaf beetle imagines were significantly positively related to the total number of leaves (spring: $\Delta$ Deviance $_{(1,106)}=8.7281, P=0.003$, summer: $\Delta$ Deviance $_{(1,106)}$ $=8.335, P=0.004)($ Fig. $2 \mathrm{~A}, \mathrm{D})$, while tree height had a negative influence on the first, but not the second generation of leaf beetle imagines ( $\Delta$ Deviance $_{(1,106)}=4.58, P=0.03$ ). Leaf beetle larvae were also negatively related to tree height (spring: $\Delta$ Deviance $_{(1,106)}=24.658$, $P<0.0001$, summer: $\Delta$ Deviance $_{(1,106)}=14.352, P=0.0002$ ) (Fig 2B, E), but not to the number of leaves per tree. Adults and larvae were negatively affected by leaf toughness

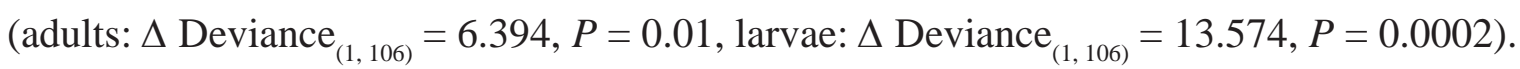
In spring predatory arthropods were positively influenced by the number of leaf beetle imagines $\left(F_{(1,106)}=8.1996, P=0.005\right)$ and leaf beetle larvae $\left(F_{(1,106)}=13.77, P=0.0003\right)$ (Fig. 2C), as well as (Z)-3-hexenyl acetate (HIPV) $\left(\Delta\right.$ Deviance $\left._{(1,26)}=5.8072, P=0.016\right)$ (but neither by number of leaf beetle eggs, nor by one of the morphological parameters of the trees.

In summer we found the positive relationship between predatory arthropods and leaf beetle adults $\left(F_{(1,106)}=18.945, P<0.0001\right)$ and their larvae $\left(F_{(1,106)}=18.833, P<0.0001\right)$ (Fig. 2F) again, and also with leaf beetle eggs $\left(F_{(1,106)}=28.366, P<0.0001\right)$. The factor genotype of full-sib families did not affect relationships between herbivores and morphological parameters or between predators and herbivores.

\section{Spatial distribution across the field site}

In spring leaf beetle larvae were more abundant at the field side adjacent to the hedge ("HA") than at the field side adjacent to the greenhouse ("GA") ("HA" $18.6 \pm 5.1$, "GA" $3.0 \pm 0.8$ ). In the second generation in summer we detected a higher abundance of leaf beetle larvae at the field side adjacent to the greenhouse ("HA" $1.7 \pm 0.4$, "GA" $9.0 \pm 3.0$ ). We found the same spatial distribution pattern for leaf beetle adults (spring: "HA" $1.3 \pm 0.2$, “GA" $0.7 \pm$ 0.1, summer: "HA" $0.8 \pm 0.1$, "GA" $2.9 \pm 0.6$ ) and predatory arthropods (spring: "HA" 0.7 \pm 0.1 , “GA" $0.5 \pm 0.1$, summer: "HA” $0.8 \pm 0.1$, “GA” $1.3 \pm 0.1$ ) (Fig. 3). 


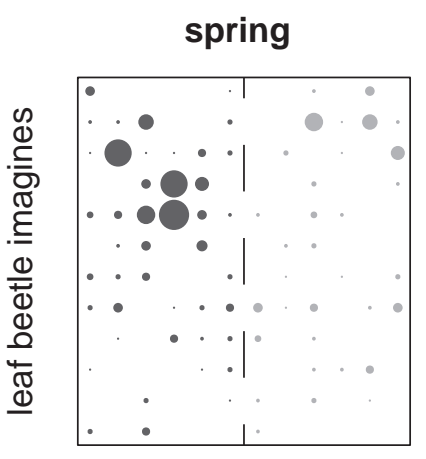

summer
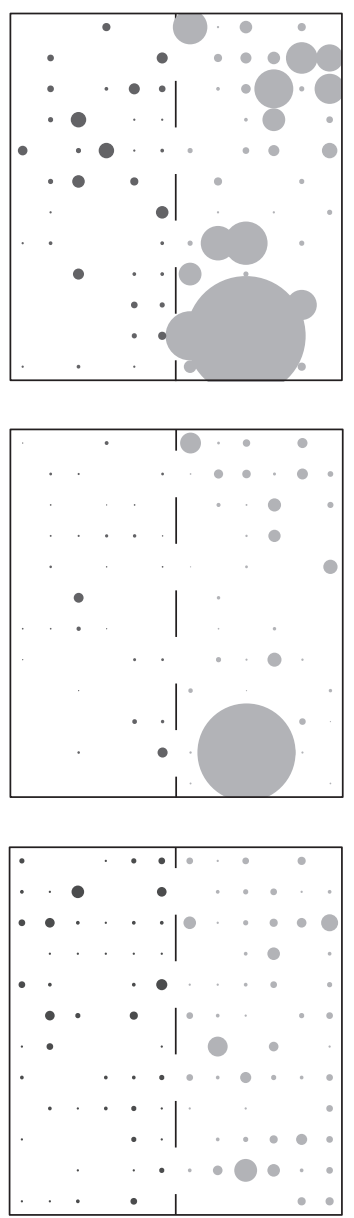

spring

summer
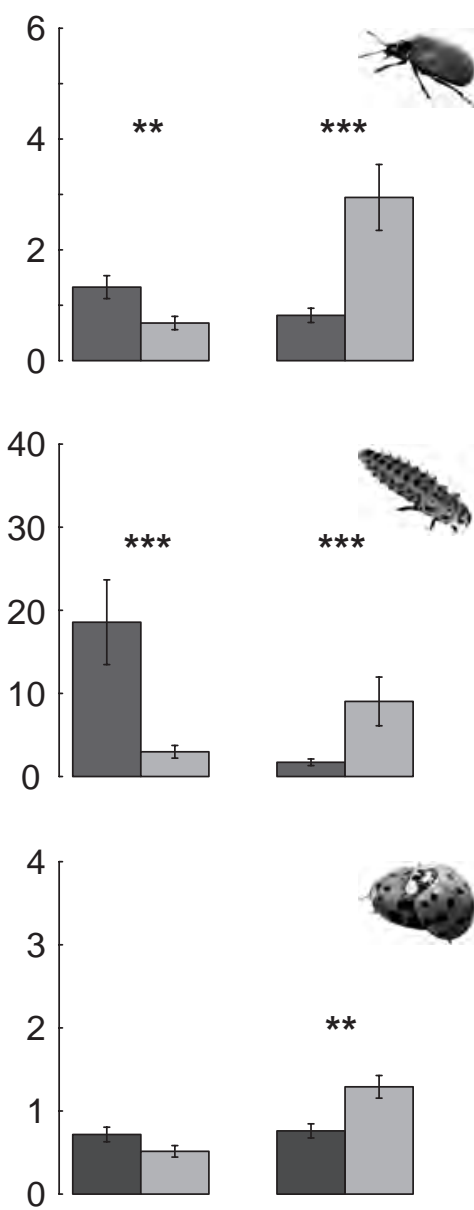
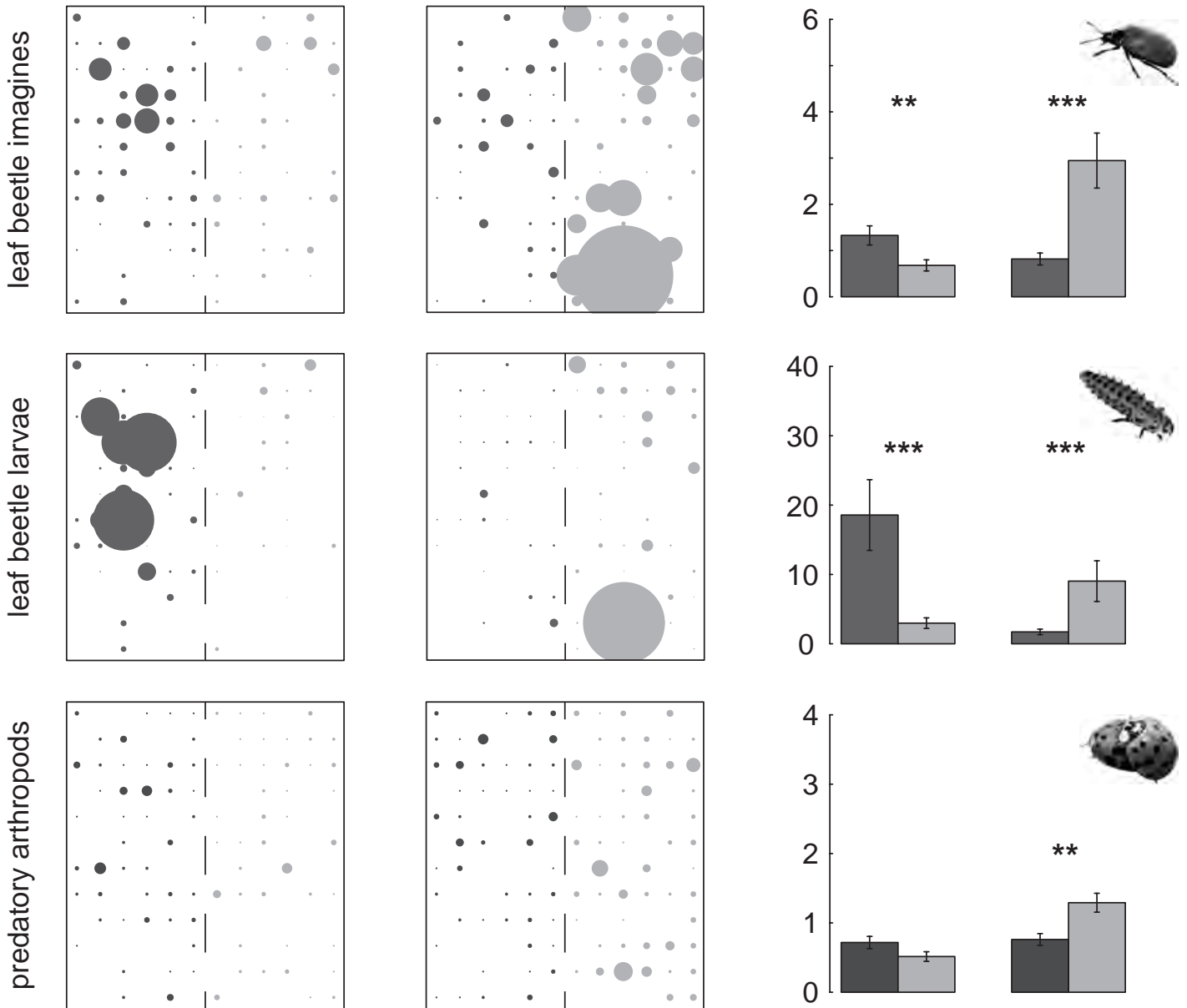

field side adjacent to the hedge

field side adjacent to the greenhouse

Figure 3: Spatial distribution of leaf beetle larvae, leaf beetle imagines, and total number of predatory arthropods on the experimental field in spring (May and June) and summer (July and August) 2009. As bigger a circle as more specimens were found on a tree. Bargraphs show the result of statistical analysis of distribution pattern. ${ }^{* *} P \leq 0.01, * * * P \leq 0.001$. (Generalized Linear Models). 

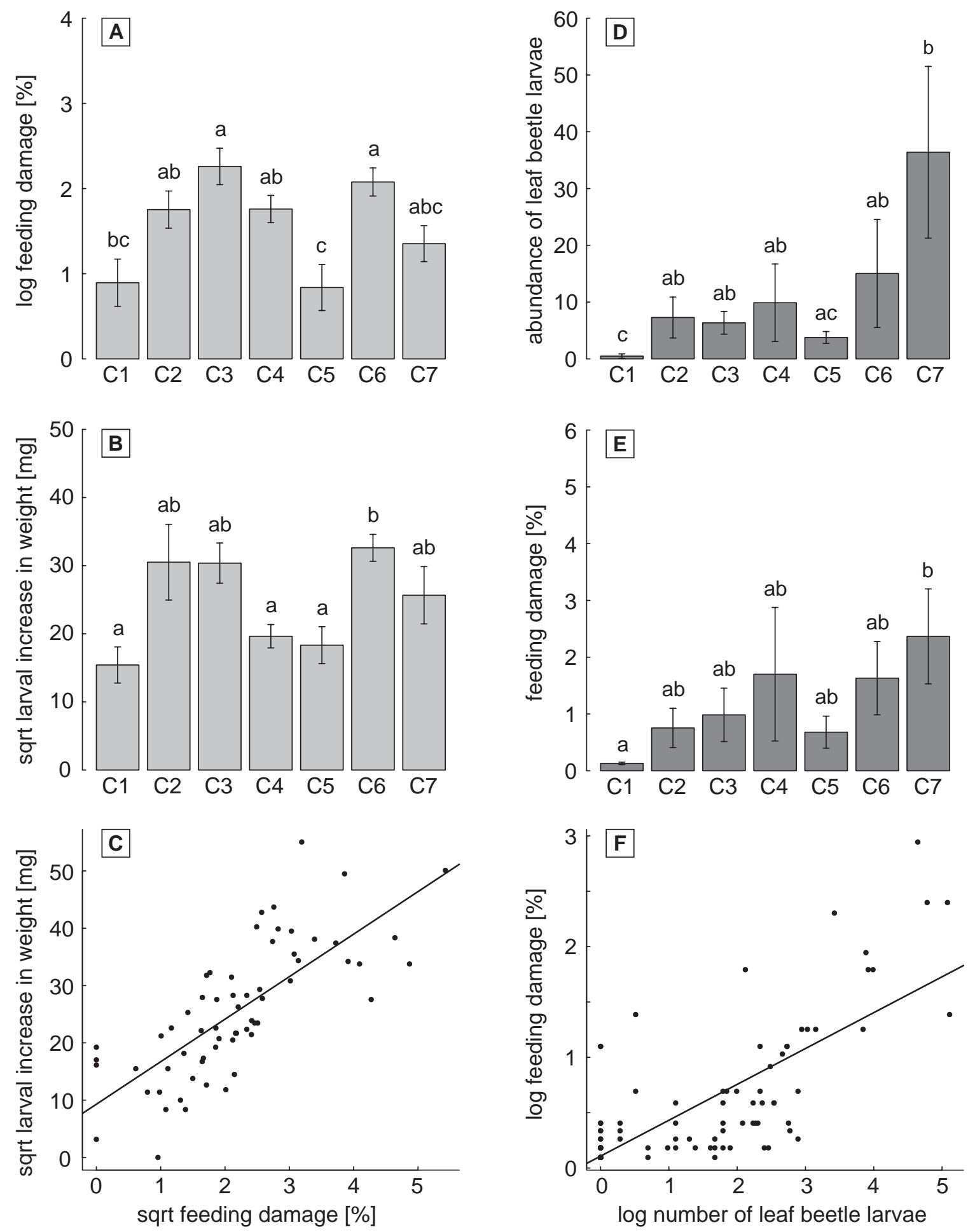

Figure 4: A-C: Laboratory feeding tests with Chrysomela populi larvae. A: Percentage of larval feeding damage. B: Increase in weight of C. populi larvae after 48h. C: Correlation between feeding damage and larval increase in weight. D-F: Survey of larvae abundances and distribution on seven full-sib families in the field in spring 2009. D: Abundance of leaf beetle larvae on trees of seven full-sib families of aspen (P. tremula). E: Feeding damage of leaves on the experimental field. F: Correlation between the number of leaf beetle larvae and feeding damage. Different letters indicate significant differences between respective means at $P \leq 0.05$. C1-C7 = different aspen full-sib families. (Laboratory experiments: ANOVA; Field study: Generalized Linear Models. Multiple comparisons among factors were calculated using Tukey test). 
Insect feeding - laboratory vs. field results

Laboratory feeding experiments were conducted in parallel to field samples in May. Herbivory data from the field came from four records between May and June 2009.

In the laboratory experiment the Chrysomela populi larvae fed more leaf area from C3 and C6 than C1 and C5. Herbivory damage level in C2 and C4 was only different to C5. The larval increase in weight was related to the feeding area of the leaf discs (Fig. 4C).

In the field, trees of full-sib family $\mathrm{C} 7$ were significantly more damaged than of $\mathrm{C} 1$ (Fig. 4E). The feeding damage in the field increased significantly with the number of leaf beetle larvae (Fig. 4F).

\section{DISCUSSION}

In this study we investigated the influence of genetic variation of seven Populus tremula fullsib families on leaf beetle adults and larvae as well as on predatory arthropods. We tested whether morphological and genetic traits can be used to predict abundances of herbivores and predators. Despite genetic distances of 6 to $51 \%$ we found no relationship between molecular markers and morphological tree parameters or the abundances of herbivores and predators. This is probably due to the fact that genetic variance was measured with neutral markers, whereas phenotypic characteristics are the integrative result of many functional genes. This result supports findings that genetic information based on neutral markers is often little related to traits of ecophysiological significance, such as timing of bud break and growth (McKay and Latta, 2002, Bekessy et al., 2003). In contrast, Madritch et al. (2009) found a correlation between genetic distance and green leaf chemistry for $P$. tremuloides clones.

The leaf beetle species in this study are all adapted to the chemical defence of poplar trees (the genera Phratora with P. vitellinae, and P. laticollis, Crepidodera with C. aurea and C. aurata and Chrysomela with C. populi and C. vigintipunctata) and can be mostly found on salicaceous species with high concentrations of leaf phenolic compounds (Gregoire, 1978, Finet and Gregoire, 1981, 1982, Orians et al., 1997, Köpf et al., 1998, Ikonen, 2002). 
Kleemann et al. (2010) showed for P. tremula trees of the seven full-sib families, which were examined also in this study that variation in leaf phenolics mediated interactions with leaf beetle larvae of the genus Phratora and Crepidodera. Generally, high concentrations of leaf phenolic compounds provide protection against generalist herbivores and are important factors shaping trophic interactions and insect community structure on salicaceous trees (Orians et al., 1997, Glynn et al., 2004, Whitham et al., 2006). This might be the reason for the differences of feeding preferences of Chrysomela populi larvae in our laboratory feeding experiments, which showed a different pattern to the leaf beetle larvae abundance on the trees in the field.

The dependency of leaf beetles on resource quantity (number of leaves) and quality (leaf toughness) suggests bottom-up effects. This is in line with the resource quantity hypothesis of Hunter (1992), which suggests that plants with a higher biomass have a higher insect species abundance (Marques et al., 2000). The negative influence of leaf toughness on leaf beetles supports results showing a negative influence of leaf toughness on Plagiodera versicolora, a leaf beetle species on willows (Raupp, 1985).

Leaf beetle larvae of both generations and imagines of the second generation were negatively affected by tree height. This matches with observations by Kelly and Curry (1991) that larvae of $P$. vulgatissima tend to be located on leaves near the bottom and to be more abundant on internal than on distal branches. But the results are in contrast to the plant size hypothesis by Lawton (1983). For example Neuvonen and Niemelä (1981) showed a significant correlation between plant size and number of herbivores. In the case of leaf beetle larvae a possible explanation may be that leaf beetles prefer lower places on a tree, possibly a strategy of enemy avoidance (e.g. birds).

The majority of the detected predatory arthropods are known as generalists, although the salicin-using leaf beetle larvae are defended by salicylaldehyde, which is a strong deterrent against generalist predators (Denno et al., 1990, Smiley, 1991, Palokangas and Neuvonen, 1992). Our results suggest indirect effects of plants on predatory arthropods mediated through the abundance of herbivores. Similarly, Kagata et al. (2005) describe indirect bottom-up effects of leaf beetle larvae on a ladybird beetle when contrasting cut with uncut willow stands. The regeneration of cut willows shortened the developmental time of the leaf beetle 
and thereby also of the ladybird beetle. In addition to such bottom-up effects, top-down effects through predation pressure from predatory arthropods appear to be likely.

Achemical mechanism of plants shaping multitrophic interactions is the emission of herbivoreinduced plant volatiles (HIPVs) after an infestation with herbivores. HIPVs often serve as semiochemical cues for host location of prey as is known from many predatory insects and parasitoids (Takabayashi and Dicke, 1996, Dicke and Baldwin, 2010). Our results showed a significant relationship of (Z)-3-hexenyl acetate to predators. (Z)-3-hexenyl acetate is known to be released after insect damage (Dicke et al., 1990, Rose et al., 1996) and has been found to be an attractant to predators (James, 2005) and parasitoids (Gouinguené et al., 2005). However, we did not find differences between the analyzed HIPVs of the seven full-sib families. Further, we did not find a relationship between the abundance of herbivorous insects and the emission of volatiles, which is in contrast to other studies. Arimura et al. (2004) and Frost et al. (2007) describe the emission of different mono-, sesqui- and homo-terpenoids, simple phenolics, and benzene cyanides in poplar hybrids as a reaction to herbivore damage. We found a spatio-temporal shift of the abundances of leaf beetles on poplar trees on the experimental field. Peacock et al. (1999) described differences in spatio-temporal distribution of Phratora vulgatissima driven by the plantation design. In our study differences between spring and summer may be due to induced changes of leaf quality of the trees that had a high infestation in spring (which was independent of the genetic origin of the trees). Lindroth and Kinney (1998) reported short term induction of phenolic compounds in P. tremuloides in response to feeding damage by Lymantria dispar. A study by Stevens and Lindroth (2005) proved that $P$. tremuloides trees accumulate increased loads of phenolic glycosides in the leaf tissue eight weeks after previous insect damage of trees. These results could explain the strong field side shift of the leaf beetles on our experimental field. In spring, leaf beetle imagines were most abundant at the field half adjacent to a hedge, whereas in summer, most leaf beetles were found on the field half adjacent to the greenhouse. Hedges serve as overwintering site for leaf beetles when the host trees are too small (Kelly and Curry, 1991, Kendall et al., 1996, Kendall \& Wiltshire, 1998). This may explain spring colonization of the field half nearby hedges.

We found differences in the abundances of leaf beetle imagines and larvae between trees of 
seven full-sib families that were not related to the genetic variance of the molecular markers. Instead, we detected a positive relationship between resource quantity and leaf beetle adults as well as inverse relationships between tree height and leaf beetle larvae. In addition, leaf toughness (resource quality) had a strong effect on leaf beetle imagines and larvae. Our results indicate direct bottom-up effects of $P$. tremula trees via plant morphological and genetic traits on leaf beetles as well as indirect herbivore-mediated effects on predatory arthropods, with patterns changing across the field site from spring to summer.

\section{ACKNOWLEDGEMENTS}

We thank J. Groeneveld, E. Eilers, M. Ksinsik, G. Pauls, and B. Scheid for support when measuring tree morphological parameters and herbivore-induced plant volatiles, C. Scherber for statistical advice, B. Weissbecker and S. Schütz for support with GC-MS/EAD-technics. The study was funded by the "Functional Biodiversity research" project of the Ministry of Science and Culture of Lower Saxony (MWK, “Niedersächsisches Vorab”). 


\section{REFERENCES}

Arimura, G., Huber, D. P. W., and Bohlmann, J. 2004. Forest tent caterpillars (Malacosoma disstria) induce local and systemic diurnal emissions of terpenoid volatiles in hybrid poplar (Populus trichocarpa x deltoids): cDNA cloning, functional characterization, and patterns of gene expression of (-)-germacrene D synthase, PtdTPS1. The Plant Journal. 37: 603-616.

Bekessy, S. A., Ennos, R. A., Burgman, M. A., Newton, A. C., and Ades, P. K. 2003. Neutral DNA markers fail to detect genetic divergence in an ecologically important trait. Biological Conservation. 110: 267-275.

Bernays, E. A., and Chapman, R. F. 2000. Plant secondary compounds and greasshoppers: beyond plant defenses. Journal of Chemical Ecology. 26: 1773-1794.

Burnham, K. P., and Anderson, D. R. 2002. Model selection and multimodel interference. A practical information-theoretic approach. Springer Science \& Business Media, New York.

Burse, A., Frick, S., Discher, S., Tolzin-Banasch, K., Kirsch, R., Strauss, A., Kunert, M., and Boland, W. 2009. Always being well prepared for defense: The production of deterrents by juvenile Chrysomelina beetles (Chrysomelidae). Phytochemistry. 70: 1899-1909.

Coley, P. D. 1983. Intraspecific variation in herbivory on two tropical tree species. Ecology. 64: 426-433.

Coley, P. D., Bryant, J. P., and Chapin III, F. S. 1985. Resource availability and plant antiherbivore defense. Science. 230: 895-899.

Crawley, M. J. 2007. The R Book. Wiley, New York.

Dempster, J. P. 1983. The natural control of populations of butterflies and moths. Biological Reviews. 58: 461-481. 
Denno, R. F., Larsson, S., and Olmstead, K. L. 1990. Role of enemy-free space and plant quality in host-plant selection by willow beetles. Ecology. 71: 124-137.

Dicke, M., Sabelis, M. W., Takabayashi, J., Bruin, J., and Posthumus, M. A. 1990. Plant strategies of manipulating predator-prey interactions through allelochemicals: prospects for application in pest control. Journal of Chemical Ecology. 16: 3091- 3118.

Dicke M., and BALDwin, I. T. 2010. The evolutionary context for herbivore-induced plant volatiles: beyond the “cry for help”. Trends in Plant Science. 15: 167-175.

Donaldson J. R., and Lindroth, R. L. 2007. Genetics, environment, and their interaction determine efficacy of chemical defence in trembling aspen. Ecology. 88: 729-739.

EHRLICH, P. R., and RAVEN, P. H. 1964. Butterflies and plants: a study in coevolution. Evolution. 18: 586-608.

Finet, Y., and Gregoire, J. C. 1981. A study of poplar resistance to Phyllodecta vitellinae L. (Col., Chrysomelidae) 1. Greenhouse experiments. Journal of Applied Entomology. 91: 355-367.

Finet, Y., and Gregoire, J. C. 1982. A study of poplar resistance to Phratora (=Phyllodecta) vitellinae L. (Col., Chrysomelidae) 2. Field observations. Journal of Applied Entomology. 94: 363-376.

Frost, J. C., Appel, H. M. Carlson, J. E., De Moares, C. M., Mesher, M., and Schultz, J. C. 2007. Within-plant signaling via volatiles overcomes vascular constraints on systemic signaling and primes responses against herbivores. Ecology Letters. 10: 490-498.

Glynn, C., Rönnberg-Wästljung, A.-C., Julkunen-Titto, R., and Weih, M. 2004. Willow genotype, but not drought treatment, affects foliar phenolic conentrations and leaf beetle resistance. Entomologia Experimentalis et Applicata. 113: 1-14. 
Gouinguené, S., Pickett, J. A., Wadhams, L. J., Birkett, M. A., and Turlings, T. C. J. 2005. Antennal electrophysiological responses of three parasitic wasps to caterpillar-induced volatiles from maize (Zea mays mays), cotton (Gossypium herbaceum), and cowpea (Vigna ungiculata). Journal of Chemical Ecology. 31: 1023-1038.

Hemming, J. D. C., and LindRoth, R. L. 1995. Intrspecific variation in aspen phytochemistry: effects on performance of gypsy moths and forest tent caterpillars. Oecologia. 103: 79-88.

Hilker, M., and Schulz, S. 1994. Composition of larval secretion of Chrysomela lapponica (Coleoptera, Chrysomelidae) and its dependence on host plant. Journal of Chemical Ecology. 5: 1075-1093.

Hsu, J. C. 1996. Multiple Comparisons: Theory and Methods. Chapman and Hall, London. U.K.

Hunter, M. D., and Wilmer, P. G. 1989. The potential for interspecific competition between two abundant defoliators on oak: leaf damage and habitat quality. Ecological Entomology. 14: 267-277.

HunTER, M. D. 1992. Interactions within herbivore communities mediated by the host plant: the keystone herbivore concept. in: Hunter, M. D., Ohgushi, T., and Price, P. W. eds. Effects of resource distribution on animal-plant interactions. Academic. New York. pp. 287-325.

IKONEN, A. 2002. Preferences of six leaf beetle species among qualitatively different leaf age classes of three Salicaceous host species. Chemoecology. 12: 23-28.

JAMES, D. G. 2005. Further field evaluation of synthetic herbivore-induced plant volatiles as attractants for beneficial insects. Journal of Chemical Ecology. 31: 481-495.

Kagata, H., Nakamura, M., and Ogushi, T. 2005. Bottom-up cascade in a tritrophic system: different impacts of host-plant regeneration on performance of a willow leaf beetle and its natural enemy. Ecological Entomology. 30: 58-62. 
Kelly, M. T., and CurRy, J. P. 1991. The biology and population density of the willow beetle (Phratora vulgatissima [L.]) on Salix viminalis in reclaimed cutaway peat. Journal of Applied Entomology. 111: 44-56.

Kendall, D. A., Hunter, T., Arnold, G. M., Liggit, J., Morris, T., and Wiltshire, C. W. 1996. Susceptibility of willow clones (Salix spp.) to herbivory by Phyllodecta vulgatissima (L.) and Galerucella lineola (Fab.) (Coleoptera, Chrysomelidae). Annals of Applied Biology. 129: 379-390.

Kendall, D. A., and Wiltshire, C. W. 1998. Life-cycles and ecology of willow beetles on Salix viminalis in England. European Journal of Forest Pathology. 28: 281-288.

Kleemann, F., Fragstein, M. v., Vornam, B., Müller, A., Leuschner, C., Holzschuh, A., Tscharntke, T., Finkeldey, R., and Polle, A. 2011. Relating genetic variation of ecologically important tree traits to associated organisms in full-sib aspen families. European Journal of Forest Research. 130: 707-716.

Косн, K. 1992. Die Käfer Mitteleuropas, Ökologie 3, Goecke und Evers, Krefeld, Germany.

Köpf, A., Rank, N. E., Roininen, H., Julkunen-Titto, R., Pasteels, J. M., and Tahvanainen; J. 1998. The evolution of host plant use and sequestration in the willow leaf beetle genus Phratora (Coleoptera: Chrysomelidae). Evolution. 52: 517-528.

LAwton, J. H., and Schröder, D. 1977. Effects of plant type, size of geographical range and taxonomic isolation on number of insect species associated with British plants. Nature. 265: 137-140.

Lawton, J. H. 1983. Plant architecture and the diversity of phytophagous insects. Annual Review of Entomology. 28: 23-39.

Lindroth, R. L., and Kinney, K. K. 1998. Consequences of enriched atmospheric $\mathrm{CO}_{2}$ and defoliation for foliar chemistry and gypsy moth performance. Journal of Chemical Ecology. 24: 1677-1695. 
Madritch, M. D., Greene, S. L., and Lindroth, R. L. 2009. Genetic mosaics of ecosystem functioning across aspen-dominated landscapes. Oecologia. 160: 119-127.

Marques, E. S. D. A., Price, P. W., and Cobb, N. S. 2000. Resource abundance and insect herbivore diversity on woody fabaceous desert plants. Environmental Entomology. 29: 696-703.

McKay, J. K., and LatTA, R. G. 2002. Adaptive population divergence: markers, QTL and traits. Trends in Ecology and Evolution. 17: 285-291.

Myers, J. H., and CampBell, B. J. 1976. Distribution and dispersal in populations capable of resource depletion. A field study in cinnabar moth. Oecologia. 24: 7-20.

Nei, M. 1978. Estimation of average heterozygosity and genetic distance from a small number of individuals. Genetics. 89: 583-590.

Neuvonen, S., and Niemelä, P. 1981. Species richness of macrolepidoptera on Finnish deciduous trees and shrubs. Oecologia. 51: 364-370.

Osier, T. L., and Lindroth R. L. 2006. Genotype and environment determine allocation to and costs of resistance in quaking aspen. Oecologia. 148: 293-303.

Palokangas, P., and Neuvonen, S. 1992. Differences between species and instars of Phratora leaf beetles (Coleoptera, Chrysomelidae) in the probability of being preyed on. Annales Zoologici Fennici. 29: 273-278.

Pasteels, J. M., Rowell-Rahier, M., Braekman, J. C., and Dupont, A. 1983. Salicin from host plant as precursor of salicylaldehyde in defensive secretion of chrysomeline larvae. Physiological Entomology. 8: 307-314.

Pasteels, J. M., and Gregorre, J.-C. 1984. Selective predation on chemically defended chrysomelid larvae. A conditioning process. Journal of Chemical Ecology. 12: 16931700. 
Peacock, L., Herrick, S., and Brain, P. 1999. Spatio-temporal dynamics of willow beetle (Phratora vulgatissima) in short-rotation coppice willows grown as monocultures or a genetically diverse mixture. Agricultural and Forest Entomology, 1: 287-296.

Peacock, L., and Herrick, S. 2000. Responses of the willow beetle Phratora vulgatissima to genetically and spatial diverse Salix spp. plantations. Journal of Applied Ecology. 37: 821-831.

Peacock, L., Harris, J., and Powers, S. 2004. Effects of host variety on blue willow beetle Phratora vulgatissima performance. Annals of Applied Biology. 144: 45-52.

R Development Core Team. 2010. R: A language and environment for statistical computing. R foundation for statistical computing. Vienna, Austria, http://www.R-project.org.

Rank N. E., and Smiley, T. S. 1994. Host-plant effects on Parasyrphus melanderi (Diptera: Syrphidae) feeding on a willow leaf beetle Chrysomela aenicollis (Coleoptera: Chrysomelidae). Ecological Entomology. 19: 31-38.

Risch, S. J. 1981. Insect herbivore abundance in tropical monocultures and polycultures: an experimental test of two hypotheses. Ecology. 62: 1325-1340.

Root, R. B. 1973. Organization of a plant-arthropod association in simple and diverse habitats: the fauna of collards (Brassica oleracea). Ecological Monographs. 43: 95124.

Rose, U. S. R., Manukian, A., Heath, R. R., and Tumlinson, J. H. 1996. Volatile Semiochemicals released from undamaged cotton leaves. Plant Physiology. 111: 487495.

Schoonhoven, L. M., van Loon, J. J. A., and Dicke M. 2005. Insect-Plant Biology, Oxford University Press. Oxford. UK.

Shen, C. S., and BACH, C. E. 1997. Genetic variation in resistance and tolerance to insect herbivory in Salix cordata. Ecological Entomology. 22: 335-342. 
Southwood, T. R. E., Brown, V. K., and Reader, P. M. 1979. The relationships of plant and insect diversities in succession. Biological Journal of the Linnean Society. 12: 327348.

Stevens, M. T., and Lindroth, R. L. 2005. Induced resistance in the indeterminate growth of aspen (Populus tremuloides). Oecologia. 145: 298-306.

Stevens, M. T., Waller, D. M., and Lindroth, R. L. 2007, Resistance and tolerance in Populus tremuloides: genetic variation, costs and environmental dependency. Evolutionary Ecology. 21: 829-847.

Smiley, T. S., Horn, J. M., and Rank, N. E. 1985. Ecological effects of salicin at three trophic levels: New problems from old adaptions. Science. 229: 649-651.

TAKABAYAshi, J., and Dicke, M. 1996. Plant-carnivore mutualism through herbivore-induced carnivore attractants. Trends in Plant Science. 1: 109-113.

Teragushi, S., Stenzel, J., Sedlacek, J., and Deininger, R. 1981. Arthropod-grass communities: comparison of communities in Ohio and Alaska. Journal of Biogeography. 8: 53-65.

Tholl, D., Boland, W., Hansel, A., Loreto, F., Röse, U. S. R., and Schnitzler J.-P. 2006. Practical approaches to plant volatile analyses. The Plant Journal. 45: 540-560.

Van den Dool, H., and Kratz, P. D. 1963. A generalization of the retention index system including linear temperature programmed gas-liquid partition chromatography. Journal of Chromatography. 11: 463-471.

Venables, W. N., and Ripley, B. D. 2002. Modern applied statistics with S, fourth ed. Springer, New York. 
Whitham, T.G., Bailey, J. K., Schweitzer, J. A., Shuster, S. M., Bangert, R. K., LeRoy, C. J., Lonsdorf, E., Allan, G. J., DiFazio, S. P., Potts, B. M., Fischer, D. G., Gehring, C. A., Lindroth, R. L., Marks, J., Hart, S. C., Wimp, G. M., and Wooley, S. C. 2006. A framework for community and ecosystem genetics: from genes to ecosystems. Nature Reviews Genetics. 7: 510-523.

Zvereva, E. L., and Rank, N. E. 2004. Fly parasitoid Megaselia opacicornis uses defensive secretions of the leaf beetle Chrysomela lapponica to locate its host. Oecologia. 140: 516-522. 


\section{APPENDIX}

Table A1: Results of generalized linear models (quasipoisson distributed) for quantity differences of herbivoreinduced plant volatiles between full-sib families and between spring and summer (independent from the fullsib families). Bold font indicates significant $P$-values.

\begin{tabular}{|c|c|c|c|c|c|c|c|c|}
\hline \multirow[b]{2}{*}{ Compound } & & \multirow[b]{2}{*}{$\mathrm{N}$} & \multicolumn{3}{|c|}{ Full-sib family difference } & \multicolumn{3}{|c|}{ Spring-summer difference } \\
\hline & & & Df & $F$-value & $P$-value & Df & $F$-value & $P$-value \\
\hline \multirow[t]{2}{*}{ Ocimene } & spring & 28 & 6 & 1.7159 & 0.1666 & & & \\
\hline & summer & 28 & 6 & 0.6954 & 0.6561 & 1 & 13.507 & 0.0005 \\
\hline \multirow[t]{2}{*}{ (Z)-3-Hexenyl acetate } & spring & 28 & 6 & 0.8043 & 0.5778 & & & \\
\hline & summer & 28 & 6 & 0.5808 & 0.7415 & 1 & 25.862 & $<0.0001$ \\
\hline \multirow[t]{2}{*}{ 6-Methyl-5-hepten-2-one } & spring & 28 & 6 & 1.3869 & 0.2657 & & & \\
\hline & summer & 28 & 6 & 1.0727 & 0.4097 & 1 & 47.954 & $<0.0001$ \\
\hline \multirow[t]{2}{*}{ Methyl salicylate } & spring & 28 & 6 & 2.1619 & 0.0885 & & & \\
\hline & summer & 28 & 6 & 2.6613 & 0.0443 & 1 & 6.383 & 0.0145 \\
\hline \multirow[t]{2}{*}{$\beta$-Caryophyllene } & spring & 28 & 6 & 0.8836 & 0.5240 & & & \\
\hline & summer & 28 & 6 & 2.0039 & 0.1106 & 1 & 4.824 & 0.0324 \\
\hline \multirow[t]{2}{*}{$\alpha$-Humulene } & spring & 28 & 6 & 0.7065 & 0.6479 & & & \\
\hline & summer & 28 & 6 & 1.5220 & 0.2195 & 1 & 9.842 & 0.0028 \\
\hline \multirow[t]{2}{*}{ Nerolidol } & spring & 28 & 6 & 1.6327 & 0.1876 & & & \\
\hline & summer & 28 & 6 & 1.0449 & 0.4252 & 1 & 6.399 & 0.0144 \\
\hline
\end{tabular}


Table A2: Densities of leaf beetles, their larvae and predatory arthropods in spring and summer 2009 (arithmetic means \pm standard error).

\begin{tabular}{|c|c|c|c|c|c|}
\hline & & $\sum$ & mean & \pm & $\mathrm{SE}$ \\
\hline \multirow[t]{2}{*}{ Leaf beetle eggs } & spring & 199 & 0.6 & \pm & 0.21 \\
\hline & summer & 2899 & 8.9 & \pm & 1.93 \\
\hline \multirow[t]{2}{*}{ Leaf beetle larvae } & spring & 3443 & 10.6 & \pm & 2.68 \\
\hline & summer & 1763 & 5.4 & \pm & 1.54 \\
\hline \multirow[t]{2}{*}{ Leaf beetles } & spring & 323 & 1.0 & \pm & 0.12 \\
\hline & summer & 616 & 1.9 & \pm & 0.30 \\
\hline \multirow[t]{2}{*}{ Phratora sp. } & spring & 250 & 0.8 & \pm & 0.12 \\
\hline & summer & 585 & 1.8 & \pm & 0.29 \\
\hline \multirow[t]{2}{*}{ Crepidodera sp. } & spring & 66 & 0.2 & \pm & 0.04 \\
\hline & summer & 28 & 0.1 & \pm & 0.02 \\
\hline \multirow[t]{2}{*}{ Predatory arthropods } & spring & 199 & 0.6 & \pm & 0.06 \\
\hline & summer & 334 & 1.0 & \pm & 0.08 \\
\hline \multirow[t]{2}{*}{ Coccinellidae } & spring & 111 & 0.3 & \pm & 0.05 \\
\hline & summer & 104 & 0.3 & \pm & 0.05 \\
\hline \multirow[t]{2}{*}{ Cantharidae } & spring & 45 & 0.1 & \pm & 0.02 \\
\hline & summer & 15 & 0.0 & \pm & 0.02 \\
\hline \multirow[t]{2}{*}{ Spiders } & spring & 24 & 0.1 & \pm & 0.02 \\
\hline & summer & 212 & 0.7 & \pm & 0.06 \\
\hline
\end{tabular}




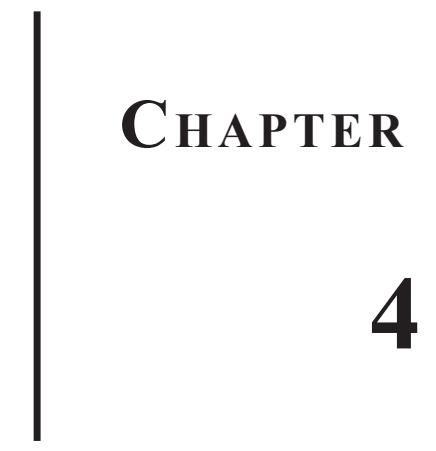

\section{The Allomone of Leaf Beetle Larvae (Salicylaldehyde) attracts Experienced Harmonia axyridis and other Predators}

Maximilian von Fragstein, Teja Tscharntke, Stefan Schütz 


\section{ABSTRACT}

Infochemical cues emitted by herbivore prey or herbivore-infested plants are often used by specialist and generalist predatory arthropods to find and locate their prey. We studied in a field experiment whether salicylaldehyde, released as a defense compound (allomone) by leaf beetle larvae can attract generalist predators. The generalist coccinellid beetle Harmonia axyridis and the cantharid beetles Cantharis pellucida and Rhagonycha sp. were highly attracted by an experimentally dispenser releasing salicylaldehyde. Similarly to the beetles the scorpionflys (Panorpidae) were highly attracted to salicylaldehyde.

Laboratory olfactometer tests with experienced $H$. axyridis imagines confirmed the results of the field study, as they were also attracted by salicylaldehyde. Naïve imagines, however, were deterred by salicylaldehyde. These results indicate that the sensory capability to perceive volatiles from prey can differ according to prior experience.

In conclusion, salicylaldehyde of leaf beetle larvae is not only an allomone for generalist predators, but can also attract experienced generalist predators using salicylaldehyde as kairomone.

Key Words: generalist predators, salicylaldhyde, allomone, Harmonia axyridis, Chantharis pellucida 


\section{INTRODUCTION}

Generalist predators are important for pest control in agriculturally and forestry systems and their efficiency are often shaped by semiochemicals such as pheromones and allomones released by insects, and herbivore induced plant volatiles (Dicke and Vet, 1998, Dicke and Baldwin, 2010). It is known that in trophic systems with strong chemical defense mechanisms specialist predators and parasitoids can overcome the defense mechanisms of herbivorous insects, using their semiochemicals for host finding and location. This is documented for many parasitoids (Rutledge, 1996, Quicke, 1997) and predatory true bugs (Weissbecker et al., 2000), solitary and social wasps (Hendrichs et al., 1994, Jander, 1998), predatory beetles such as clerid beetles of the genus Thanasimus (Erbilgin and Raffa, 2001) and aphidophagous Coccinellidae (Raymond et al., 2000). Harmonia axyridis imagines are known to locate their prey by means of olfactory as well as visual cues (Obata, 1986, Verheggen et al., 2007).

In our tritrophic system consisting of Populus tremula, salicin-sequestering Chrysomelinae and their predators only specialist predators are attracted by the beetle's larvae allomone, salicylaldehyde. Salicylaldehyde is sequestered by leaf beetle larvae feeding on willow and poplar, which are chemically defended by phenolic glucosides, especially salicin and its derivatives (Pasteels et al., 1983, Smiley et al., 1985, Köpf et al., 1998, Tremonia et al., 2001). Specialist predators, such as phorid flies (Zvereva and Rank, 2004), syrphid flies (Smiley, 1991, Rank and Smiley, 1994, Köpf et al., 1997, Gross et al., 2004), the sawfly Tenthredo olivacea (Pasteels and Gregoire, 1984) and a potter wasp from the genus Symmorphus (Smiley, 1991, Sears et al., 2001) are attracted by salicylaldehyde, which is used as a kairomone for host finding. However, salicylaldehyde acts as a repellent against several generalist predators such as ants (Wallace and Blum, 1969, Kearsley and Whitham, 1992, Hilker and Schulz, 1994), ladybird beetle imagines and larvae (Denno et al., 1990, Smiley, 1991, Cha et al., 2009), a praying mantis (Cha et al., 2009), and spiders (Palokangas and Neuvonen, 1992). Moreover, salicylaldehyde provides antimicrobial defense for leaf beetle larvae against bacteria (Gross et al., 2002, 2008).

Because of the strong chemical defense and the specialization of its plant feeders, the trophic system consisting poplars and willows (Salicaceae), salicin-sequestering leaf beetles (Chrysomelinae) and their natural enemies represents an interesting case for the chemical 
ecology of tritrophic interactions.

To the best of our knowledge, there are no published results on olfactory responses of generalist predators such as soldier beetles and lady bird beetles to salicylaldehyde. The aim of this study was to determine whether there are attractant or deterrent effects of salicyladehyde to generalist predatory beetles. Additional we ask whether there are differences between experienced and naïve predators.

\section{MATERIAL AND METHODS}

\section{Field bioassays}

We used funnel traps modified from those described by Ruther et al. (2000) and Tolasch et al. (2007). Two transparent plexiglass sheets $(12 \mathrm{~cm}$ height $\times 14 \mathrm{~cm}$ width) were arranged crosswise over a 120-mm powder funnel. These sheets were used as baffle. Baffle and powder funnel were connected to a $250 \mathrm{ml}$ polyethylene collection bottle. As dispensers we used $0.2 \mathrm{ml}$ PCR tubes (Thermo-Tube ${ }^{\mathrm{TM}}$, Peqlab, Erlangen, Germany). Dispensers were prepared as described in Tolasch et al. (2007), and each tube was filled with $5 \mathrm{mg}$ salicylaldehyde (99 \%, CAS: 17754-90-4, Aldrich, Steinheim, Germany). Dispensers were mounted on a

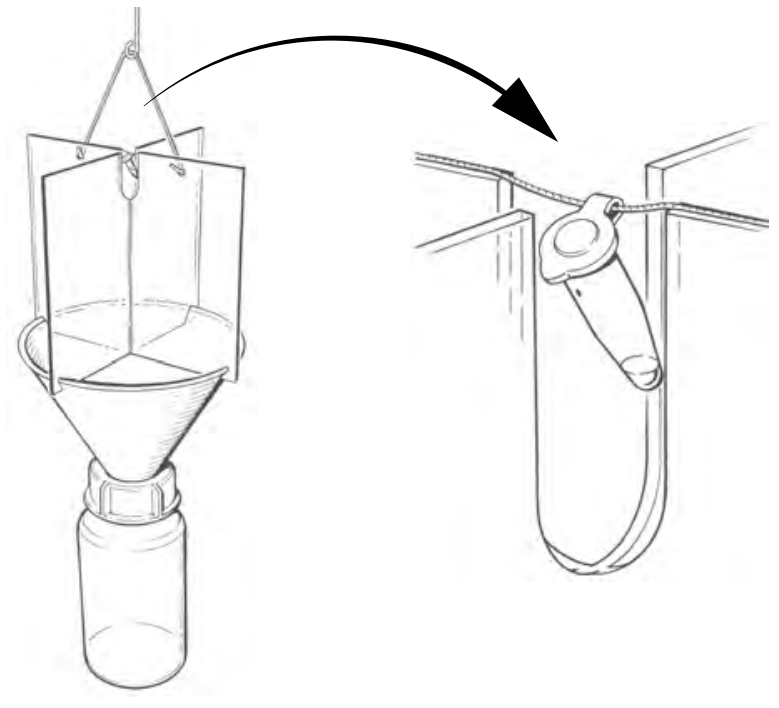

Figure 1: Funnel trap used for field experiments. Detail of the mounted salicylaldehyde dispenser. (Tolasch et al., 2007, drawing by B. Schmid, University of Hohenheim) thread in a gap at the top between the plastic sheets (Fig. 1). The collecting bottles were filled with brine $(100 \mathrm{ml})$ to preserve the insects and minimize the possible attraction of insects to the already captured individuals.

The field bioassays were performed from beginning of May to end of August 2009 and from end of May to end of August 2010 in an area with a young seral stage in the vicinity of Göttingen (Lower Saxony, Germany) near Lutterberg 
$\left(51^{\circ} 37^{\prime} \mathrm{N} 9^{\circ} 64^{\prime} \mathrm{O}\right)$. The study is located beneath a high-tension line, the reason why the trees were cut at regular intervals. Predominant tree species were Populus tremula, Betula sp. and Salix caprea. Trees varied in their height between one and four meter. The P. tremula trees had a high infestation with poplar leaf beetles (Chrysomela populi) and their larvae.

A total of 8 traps were grouped into 4 sets, each set containing a baited trap and a non-baited control. Traps were suspended approximately $1.5-2 \mathrm{~m}$ above the ground. The distance between traps within one set was about $5 \mathrm{~m}$, whereas the distances between the sets were ca. $50-100 \mathrm{~m}$. Traps were controlled weekly, captured beetles were removed, and the brine was replaced. Determination was done in the laboratory and collected beetles were identified to species level using Freude et al. (1967, 1979).

\section{Laboratory bioassays}

Olfactometer bioassays were conducted with Harmonia axyridis imagines collected in nature (experienced) and imagines emerged from pupae in the laboratory (naïve). Both (imagines and pupae) were collected on an experimental field with Vicia faba of the Reinshof near Göttingen $\left(51^{\circ} 29^{\prime} \mathrm{N} 9^{\circ} 55^{\prime} \mathrm{O}\right)$. Beetles and pupae were reared in the laboratory at $20^{\circ} \mathrm{C}$ with a natural day and night rhythm. After emerging adults were reared at $20^{\circ} \mathrm{C}$ for few days and were fed with pieces of the yellow mealworm Tenebrio molitor.

The reaction of $H$. axyridis to salicylaldehyde stimuli was tested in a static four-chamberolfactometer as described in Steidle and Schöller (1997) and Collatz et al. (2009). We did not discriminate between females and males, because both sexes predate on insects in the same way. The olfactometer experiments were carried out with a $10^{-3}$ concentration $(\mathrm{w} / \mathrm{w})$ of saliylaldehyde in order to achieve physiological meaningful concentrations. Dilutions of synthetic salicylaldehyde standards were prepared in paraffin oil (Uvasol ${ }^{\circledR}$, spectrosc. qual., high visc., Merck, Darmstadt, Germany). Ca. $100 \mu$ of standard dilution or paraffin oil as control were dropped on $2 \mathrm{~cm}^{2}$ filter paper pieces (Schleicher \& Schuell, Dassel, Germany). One chamber of the olfactometer was loaded with a Petri dish containing a filter paper soaked with ca. $100 \mu 1$ salicylaldehyde dilution. The opposite chamber contained a Petri dish with a filter paper soaked with ca. $100 \mu \mathrm{l}$ paraffin oil as control. The other two chambers remained empty as transition zones. The olfactometer was illuminated from above using red light. At 
the beginning of each experiment, a beetle was placed in the center of the walking arena. The walking and resting positions of the beetles were recorded for $600 \mathrm{~s}$ by using the computer software "The Observer 2.0" (Noldus, Wageningen, The Netherlands, 1990). After each test all chambers and the walking arena were cleaned with ethanol (70\%). In order to avoid biased results due to side preferences of beetles the position of the olfactometer was rotated clockwise. Bioassays with naïve beetles were performed when beetles were $2-4$ days old. The age of field collected beetles was unknown. Naïve beetles were freshly collected from rearing jars.

\section{Statistical analyses}

Statistical analyses were carried out using the software R, Version 2.11.1 (R Development Core Team, 2010). Data were tested for normality with the Shapiro-Wilk's test. If required, data were log-transformed to meet the assumption of normality of residuals. With regard to the field bioassays we fitted linear mixed-effects models ("lme"-function in package "nlme", Pinheiro and Bates, 2000) using maximum likelihood with the salicylaldehyde - control treatment as fixed factor. To account for non-independence of different sampling dates and the traps, we used the following sequence of random effects: sampling date and trap. The residuals were inspected for constant variance and normality to account for heteroscedasticity (Pinheiro and Bates, 2000).

We analyzed the duration time of beetles spent in the test and control fields in the olfactometer experiments using Wilcoxon-matched pairs test.

\section{RESULTS}

\section{Field bioassays}

In the field bioassays, a total of 34 Coccinellidae were caught with the salicylaldehyde baited traps and five beetles were caught in the non-baited control traps in the two years (Fig. 2). The most abundant species of coccinellid beetles was Harmonia axyridis in salicylaldehyde baited traps. A total number of 88 Cantharidae were determined in the baited traps, whereas in non- 
baited controls only three cantharid beetles were found. We identified Cantharis pellucida (50) and Rhagonycha sp. (36) as most abundant species. In the salicylaldehyde baited traps, Over both seasons 91 Panorpidae were caught in the salicylaldhyde baited traps and only 12 in control traps. Results separated for each of the two years are shown in Table 1. All results, combined data as well as the data of the single years, show highly significant differences between salicylaldehyde baited and non-baited control traps (Tab. 1, Fig. 2).

\section{Laboratory bioassays}

Table 1: Number of specimens of predatory beetles and scorpionflies caught during the vegetation period of 2009 and 2010. Results of linear-mixed effects models for predatory arthropods caught in salicylaldehydebaited and non-baited traps. $\mathrm{SA}=$ salicylaldehyde, con $=$ control, numDF $=$ numerator degrees of freedom, denDF $=$ denominator degrees of freedom. Bold font indicates significant $P$-values.

\begin{tabular}{lcccccrr}
\hline Family/Species & Year & SA $[\Sigma]$ & con $[\Sigma]$ & num DF & den DF & $F$-value & $P$-value \\
\hline Cantharidae & 2009 & 57 & 3 & 1 & 44 & 10.28 & $\mathbf{0 . 0 0 2 5}$ \\
& 2010 & 31 & 2 & 1 & 51 & 21.75 & $<\mathbf{0 . 0 0 0 1}$ \\
Cantharis pellucida & 2009 & 39 & 1 & 1 & 44 & 5.25 & $\mathbf{0 . 0 2 6 8}$ \\
& 2010 & 11 & 0 & 1 & 51 & 6.84 & $\mathbf{0 . 0 1 1 7}$ \\
Rhagonycha sp. & 2009 & 16 & 2 & 1 & 44 & 6.32 & $\mathbf{0 . 0 1 5 7}$ \\
& 2010 & 20 & 2 & 1 & 51 & 10.07 & $\mathbf{0 . 0 0 2 6}$ \\
Coccinellidae & 2009 & 18 & 3 & 1 & 44 & 9.72 & $\mathbf{0 . 0 0 3 2}$ \\
& 2010 & 16 & 0 & 1 & 51 & 12.72 & $\mathbf{0 . 0 0 0 8}$ \\
Harmonia axyridis & 2009 & 14 & 2 & 1 & 44 & 9.28 & $\mathbf{0 . 0 0 3 9}$ \\
Panorpidae & 2010 & 14 & 0 & 1 & 51 & 10.06 & $\mathbf{0 . 0 0 2 6}$ \\
& 2009 & 46 & 7 & 1 & 44 & 6.64 & $\mathbf{0 . 0 1 3 4}$ \\
& 2010 & 45 & 5 & 1 & 51 & 5.81 & $\mathbf{0 . 0 1 9 6}$ \\
\hline
\end{tabular}

Experienced Harmonia axyridis adults caught in nature showed a significant preference to salicylaldehyde in the olfactometer test (Fig. 3). In contrast, the naivve specimens of H. axyridis were significantly deterred by salicylaldehyde (Fig. 3). 

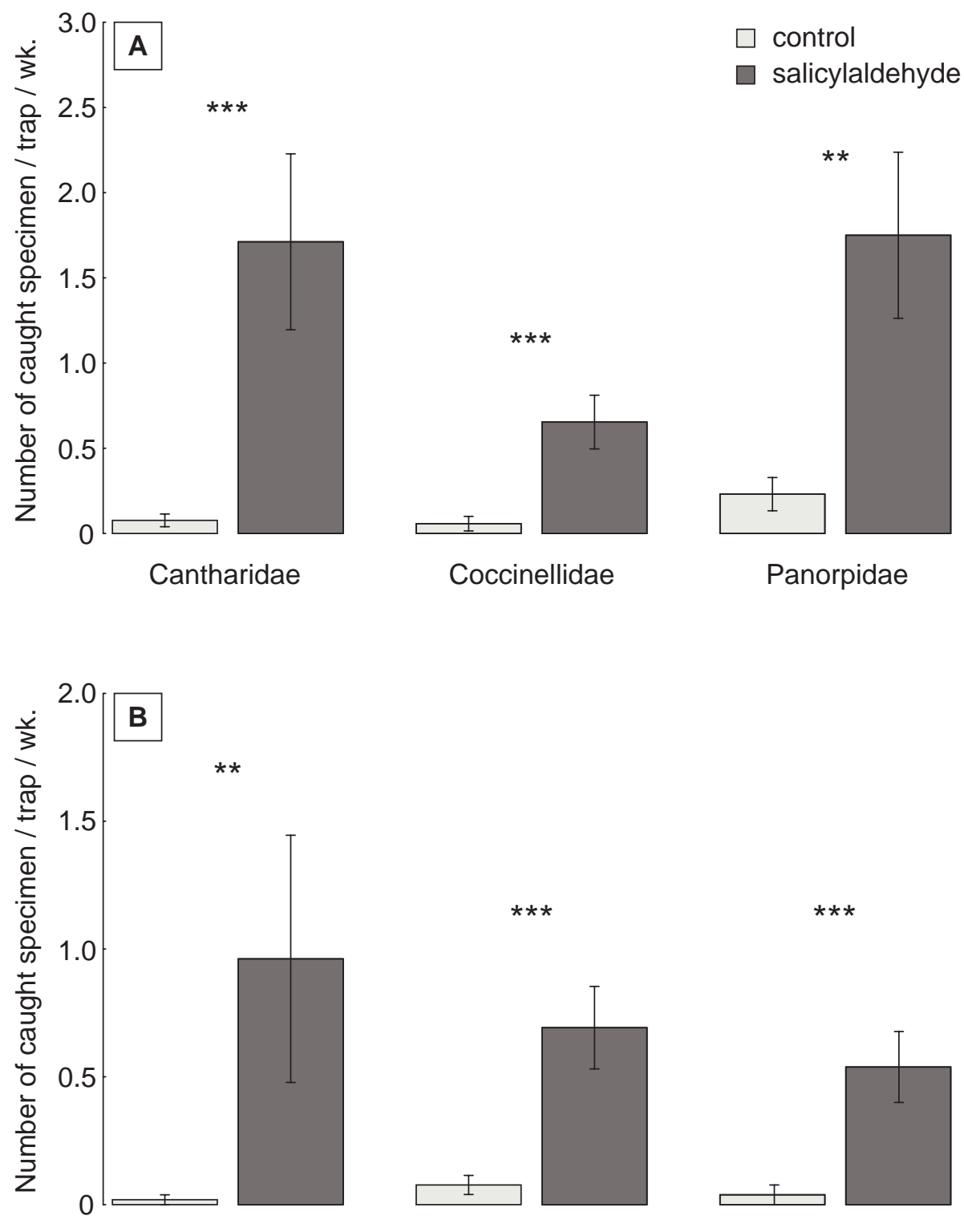

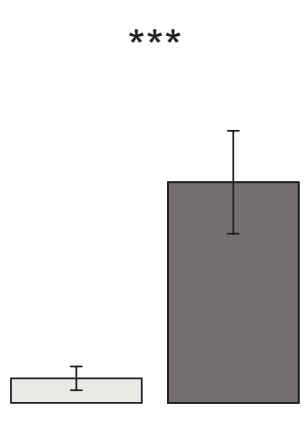

Rhagonycha sp.

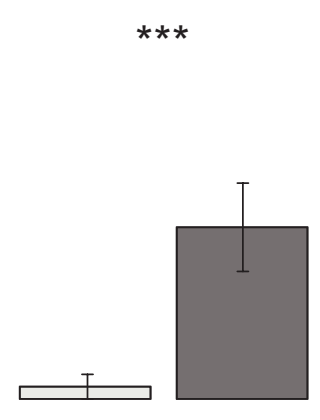

Harmonia axyridis

Figure 2: Weekly trap catches of different families (A) and the most abundant species (B) of generalist predators in response to the synthetic salicylaldehyde. Graphs show the combined data from 2009 and 2010. Mean \pm standard error are given. ${ }^{* *} P<0.01, * * * P<0.001$ (Linear Mixed Effects Model). 


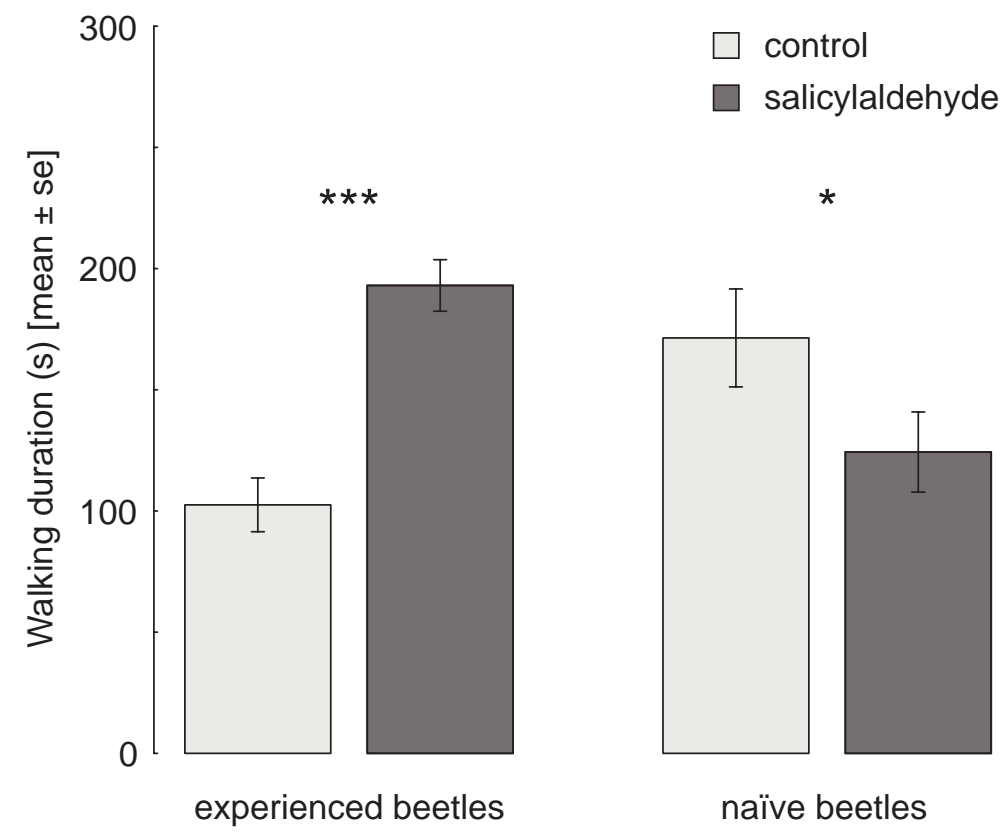

Figure 3: Walking duration time (mean \pm standard error) of experienced and naïve Harmonia axyridis in the odor fields of an olfactometer. Experienced beetles $\mathrm{N}=21$, naïve beetles $\mathrm{N}=20$. $* * \mathrm{P}<0.01$, *** $\mathrm{P}<0.001$ (Wilcoxonmatched pairs test).

\section{DISCUSSION}

In this study, we investigated the response of generalist predator beetles to salicylaldehyde, the defense compound of leaf beetle larvae feeding on willow and poplar. Salicylaldehyde is sequestered from salicin, a phenolic glycoside that serves as feeding deterrent against generalist herbivores. Our results indicate that generalist predators were attracted by salicylaldehyde. This is in contrast to previous laboratory studies, where salicylaldehyde is described to deter generalist predators such as ants (Wallace and Blum, 1969, Kearsley and Whitham, 1992, Hilker and Schulz, 1994), spiders (Palokangas and Neuvonen, 1992), lady bird beetles (Denno et al., 1990, Smiley, 1991, Cha et al., 2009), as well as praying mantis (Cha et al., 2009).

The results of the field study and the laboratory experiment show an attraction of experienced Harmonia axyridis adults by salicylaldehyde. These results are in contrast to the study of Denno et al. (1990) and Smiley (1991). Both reported a repellent effect of salicylaldehyde 
to native lady bird beetles. However, our laboratory study with naïve $H$. axyridis showed a repellent effect of salicylaldehyde. This result supports the finding of Cha et al. (2009), who also proved the deterrence of salicylaldehyde with regard to $H$. axyridis larvae. Our results indicate that $H$. axyridis imagines seem to have a learning ability as Dejean et al. (2003) and Boivin et al. (2010) proved for lady bird beetle larvae. Schöller and Prozell (2002) described that the generalist egg parasite Trichogramma evanescens is able to learn the scent of possible hosts. They showed that experienced females response significantly to the main component of the sex pheromone of two Lepidoptera host species.

We suggest that the adults made an experience with salicylaldehyde as an indicator of prey availability. As additional ability H. axyridis have to overcome the defense system of salicinusing leaf beetle larvae. Like most other aphidophagous coccinellid beetles, $H$. axyridis is not a specialist predator. They also accept different lepidopteran and two chrysomelid species as prey (Tedders and Schaefer, 1994, Hodek and Honek, 1996, Koch et al., 2003). Koch et al. (2003) described the ability of $H$. axyridis to overcome the the defense of Danaus plexippus (Lepidotera) larvae. These larvae sequester cardenolides from their host plants that provide protection against predators (Seiber et al, 1980). One of the leaf beetle species that is reported to be hunted by $H$. axyridis is Chrysomela vigintipunctata that feeds on salicin rich willows and sequester salicylaldehyde in the defensive secretion (Soetens et al., 1998).

In our field study we found an attraction of soldier beetles Cantharis pellucida and beetles of the genus Rhagonycha to baited traps. To the best of our knowledge, there are no studies with Cantharidae analyzing olfactory attraction of defense substances of the host or of herbivoreinduced plant volatiles. Cantharid adults were observed being carnivorous preying on aphids and other invertebrates (Sunderland et al., 1987) as well as being phytophagous consuming plant material (Gordon and Woodford, 1994). Traugott (2003) described adults of different Cantharis species mainly feeding on nectar, pollen and honeydew.

We did also not expect that Panorpa specimens were significantly more abundant in salicylaldehyde baited than in non-baited control traps. There is little evidence that Panorpa is an active predator of insects and their larvae, because they are mainly known to be scavengers, feeding on arthropod carrion (Thornhill, 1980). Therefore we assume that the Panorpa specimens were not attracted by the saliclyladhyde but by the scent of arthropod 
carrion in our funnel traps.

The results reported in this study indicate the potential of salicylaldehyde as an attractant for experienced generalist predators with respect to pest control of salicin-using leaf beetles and their larvae. These leaf beetles of the genera Chrysomela, especially C. populi and C. tremulae and Phratora sp. are reported to be the most important defoliating pests in young short rotation plantations in Central Europe (Sinreich, 1955, Augustin et al., 1993, Gruppe et al., 1999). Due to the increasing demand for renewable energy, short-rotation forestry with its highly productive Salix and Populus species becomes increasingly important as a potential energy source. Therefore, current ecological research should examine the biological control of such defoliating insect pests in more detail, e.g. the learning ability of H. axyridis imagines and larvae. Further, there may also be responses of $H$. axyridis and Cantharis pellucida to herbivore-induced volatiles and synergistic effects with salicylaldehyde that are still unknown.

\section{ACKNOWLEDGEMENTS}

Many thanks for conducting the olfactometer tests to Thorald Eck, for lending the funnel traps to T. Tolasch, and C. Scherber for statistical advice. We thank the forester's lodge Landwehrhagen and the forester Mr. Wilke for providing the experimental site. The study was funded by the "Functional Biodiversity research" project of the Ministry of Science and Culture of Lower Saxony (MWK, "Niedersächsisches Vorab"). 


\section{REFERENCES}

Augustin, S., Courtin, C., and Delplanque, A. 1993. Poplar clones effect on development, mortality, and fecundity of Chrysomela (= Melasoma) populi L. and Chrysomela tremulae F. (Col., Chrysomelidae). Journal of Applied Entomology. 116: 39-49.

Boivin, G., Rogfer, C., Coderre, D., and Wajnberg, E. 2010. Leraning affects prey selection in larvae of a generalist coccinellid predator. Entomologia Experimentalis et Applicata. 165: 48-55.

Cha, D. H., Hochwender, C. G., Bosecker, E. M., Tucker, R. E., Kaufman, A. D., Fritz, R. S., and Sмyтн, R. R. 2009. Do exotic generalist predators alter host plant preference of a native willow beetle? Agricultural and Forest Entomology. 11: 175-184.

Collatz, J., Tolasch, T., and Steidle, J. L. M. 2009. Mate finding in the parasitic wasp Cephalonomia tarsalis (Ashmead): More than one way to a female's heart. Journal of Chemical Ecology. 35: 761-768.

Dejean, A., Gibernau, M., Lauga, J., and Orivel, J. 2003. Coccinellid learning during capture of alternative prey. Journal of Insect Behaviour. 16: 859-864.

Denno, R. F., Larsson, S., and Olmstead, K. L. 1990. Role of enemy-free space and plant quality in host-plant selection by willow beetles. Ecology. 71: 124-137

Dicke M., and BALDwin, I. T. 2010. The evolutionary context for herbivore-induced plant volatiles: beyond the "cry for help". Trends in Plant Science. 15: 167-175.

Dicke M., and Vet, L. E. M. 1998. Plant-carnivore interactions: Evolutionary and ecological consequences for plant, herbivore and carnivore, pp. 483-520, in H. Olff, V. K. Brown, and R. H. Drents (eds.). Herbivores: Between Plants and Predators. Blackwell Science, Oxford, UK. 
ERBILGIN, N., and RAFFA, K. F. 2001. Kairomonal range of generalist predators in specialized habitats: responses to multiple phloeophagous species emitting pheromones vs. host odors. Entomologia Experimentalis et Applicata. 99: 205-210.

Freude, H., Harde, K. W., and Lohse, G. A. 1979. Die Käfer Mitteleuropas, Band 6, Goecke and Evers, Krefeld, Germany.

Freude, H., Harde, K. W., and Lohse, G. A. 1967. Die Käfer Mitteleuropas, Band 7, Goecke and Evers, Krefeld, Germany.

Gordon, S. C., and Woodford, J. A. T. 1994. Cantharid beetle damage to Rubus plants in eastern Scotland. Journal of Horticultural Science and Biotechnology. 69: 727-730.

Gross, J., Fatouros, N. E., Neuvonen, S., and Hilker, M. 2004. The importance of specialist natural enemies for Chrysomela lapponica in pioneering a new host plant. Ecological Entomology. 29: 584-593.

GrupPe, A., Fusseder, M., and SCHOPF, R. 1999. Short rotation plantations of aspen and balsam poplar on former arable land in Germany: defoliating insects and leaf constituents. Forest Ecology and Management. 121: 113-122.

Hendrichs, J., Katsoyannos, B. I., Wornoayporn, V., and Hendrichs, M. A. 1994. Odormediated foraging by yellowjacket wasps (Hymenoptera: Vespidae): predation on leks of pheromone-calling Mediterranean fruit fly males (Diptera: Tephritidae). Oecologia. 99: 88-94.

Hilker, M., and Schulz, S. 1994. Composition of larval secretion of Chrysomela lapponica (Coleoptera, Chrysomelidae) and its dependence on host plant. Journal of Chemical Ecology. 5: 1075-1093.

Hodek, I., and Honěk, A. 1996. Ecology of Coccinellidae. Kluwer Academic Publishers, Dordrecht, The Netherlands. 464 pp. 
JANDER, R. 1998. Olfactory learning of fruit odors in the eastern yellow jacket, Vespula maculifrons (Hymenoptera: Vespidae). Journal of Insect Behavior. 11: 879-888.

Kearsley, M. J. C., and Whitham, T. G. 1992. Guns and butter: a no cost defense against predation for Chrysomela confluens. Oecologia. 92: 556-562.

Koch, R. L., Hutchinson, W., Venette, R., and Heimpel, G. 2003. Susceptibility of immature monarch butterfly, Danaus plexippus (Lepidoptera : Nymphalidae : Danainae), to predation by Harmonia axyridis (Coleoptera : Coccinellidae). Biological Control. 28: 265-270.

Köpf, A., Rank, N. E., Roininen, H., and Tahvanainen; J. 1997. Defensive larval secretions of leaf beetles attract a specialist predator Parasyrphus nigritarsis. Ecological Entomology. 22: 176-183.

Köpf, A., Rank, N. E., Roininen, H., Julkunen-Tittto, R., Pasteels, J. M., and Tahvanainen; J. 1998. Phylogeny and the evolution of host plant use and sequestration in the willow leaf beetle genus Phratora (Coleoptera: Chrysomelidae). Evolution. 52: 517-528.

OватА, S. 1986. Mechanisms of prey finding in the aphidophagous ladybird beetle, Harmonia axyridis [Coleoptera, Coccinellidae]. Entomophaga. 31: 303-311.

Palokangas, P., and Neuvonen, S. 1992. Differences between species and instars of leaf beetles in the probability to be preyed on. Annales Zoologici Fennici. 29: 273-278.

Pasteels, J. M., Rowhell-Rahier, M., Braekmann, J. C., and Dupont, A. 1983. Salicin from host plant as precursor of salicylaldehyde in defensive secretion of Chrysomelinae larvae. Physiological Entomology. 8: 307-314.

Pasteels, J. M., and Gregoire J.-C. 1984. Selective predation on chemically defended chrysomelid larvae. A conditioning process. Journal of Chemical Ecology. 12: 16931700 . 
Pinheiro, J. C., and Bates, D. M. 2000. Mixed-effects models in S and S-PLUS. Springer, New York.

Rank N. E., and Smiley, T. S. 1994. Host-plant effects on Parasyrphus melanderi (Diptera: Syrphidae) feeding on a willow leaf beetle Chrysomela aenicollis (Coleoptera: Chrysomelidae). Ecological Entomology. 19: 31-38.

Ruther, J., Reinecke, A., Thiemann, K., Tolasch, T., Francke, W., and Hilker, M. 2000. Mate finding in the forest cockchafer, Melolontha hippocastani, mediated by volatiles from plants and females. Physiological Entomology. 25: 172-179 .

Rutledge, C. E. 1996. A survey if identified kairomones and synomones used by insects to locate and accept their hosts. Chemoecology. 7: 121-131.

SCHÖLlER, M., and Prozell, S. 2002. Response of Trichogramma evanescens to the main sex pheromone component of Ephestia spp. and Plodia interpunctella, (Z,E)-9,12-tetradecadenyl acetat (ZETA). Journal of Stored Products Research. 38: 177-184.

Sears, A. L. W., Smiley, J. T., Hilker, M., Müller, F., and Rank, N. E. 2001. Nesting behavior and prey use in two geographically separated populations of the specialist wasp Symmorphus cristatus (Vespidae: Eumeninae). American Midland Naturalist. 145: 233-246.

Seiber, J. N., Tuskes, P. M., Brower, L. P., and Nelson, C. J. 1980. Pharmacodynamics of some individual Milkweed cardenolides fed to larvae of the monarch butterfly (Danaus plexippus L.). Journal of Chemical Ecology. 6: 321-339.

SinReICH, A., 1955. Pappelschädlinge und -krankheiten in Österreich in den Jahren 1951 1954. Anzeiger für Schädlingskunde. 28: 1-5.

Smiley, T. S., Horn, J. M., and RANK, N. E. 1985. Ecological effects of salicin at three trophic levels: New problems from old adaptions. Science. 229: 649-651. 
Soetens, P., Pasteels, J. M., Daloze, D., and Kaisin, M. 1998. Host plant influence on the composition of the defensive secretion of Chrysomela vigintipunctata larvae (Coleoptera: Chrysomelidae). Biochemical Systematics and Ecology. 26: 703-712.

Steidle, J. L. M., and SchölleR, M. 1997. Olfactory host location and learning in the granary weevil parasitoid Lariophagus distinguendus (Hymenoptera: Pteromalidae). Journal of Insect Behaviour. 10: 331-342.

Sunderland, K. D., Crook, N. E., Stacey, D. L., and Fuller, B. J. 1987. A study of feeding by polyphagous predators on cereal aphids using Elisa and gut dissection. Journal of Applied Ecology. 24: 907-933.

Tedders, W. L., and Schaefer, P. W. 1994. Release and establishment of Harmonia axyridis (Coleoptera, Coccinellidae) in the Southeastern United States. Entomological News. 105: 228-243.

Thornhill, R. 1980. Competition and coexistence among Panorpa scorpionflies (Mecoptera: Panorpidae). Ecological Monographs. 50: 179-197.

Tolasch, T. Fragstein, M. v., and Steidle, J. L. M. 2007. Sex Pheromone of Elater ferugineus L. (Coleoptera: Elateridae). Journal of Chemical Ecology. 33: 2156-2166.

Tremonia, A., Hsiao, T. H., Pasteels, J. M., and Milinkovitch, M. C. 2001. Feeding specialization and host-derived chemical defense in Chrysomeline leaf beetles did not lead to an evolutionary dead end. Proceedings of the National Academy of Science. 98: 3909-3914.

Wallace, J. B., and Blum, M. S. 1969. Refined defensive mechanisms in Chrysomela scripta. Annals of the Entomological Society of America. 62: 503-506.

Weissbecker, B., van Loon, J. J. A., Posthumus, M. A., Bouwmeester, H. J., and Dicke, M. 2000. Identification of volatile potato sesquiterpenoids and their olfactory detection by the two-spotted sinkbug Pericellus bioculatus. Journal of Chemical Ecology. 26: 1433-1445. 
Whitman, D. W., and Eller, F. J. 1992. Orientation of Microplitis croceipes (Hymenoptera: Braconidae) to green leaf volatiles: dose response curves. Journal of Chemical Ecology. 18: 1743-1753.

Zvereva, E. L., and Rank, N. E. 2004. Fly parasitoid Megaselia opacicornis uses defensive secretions of the leaf beetle Chrysomela lapponica to locate its host. Oecologia. 140: 516-522. 


\section{Chapter}

\section{5}

\section{Porous Defense in a Tritrophic System:}

\section{Odor Perception Reflects Prey Specialization of Potter Wasps (Hymenoptera: Eumeninae)}

Maximilian von Fragstein, Gerrit Holighaus, Teja Tscharntke, Stefan Schütz

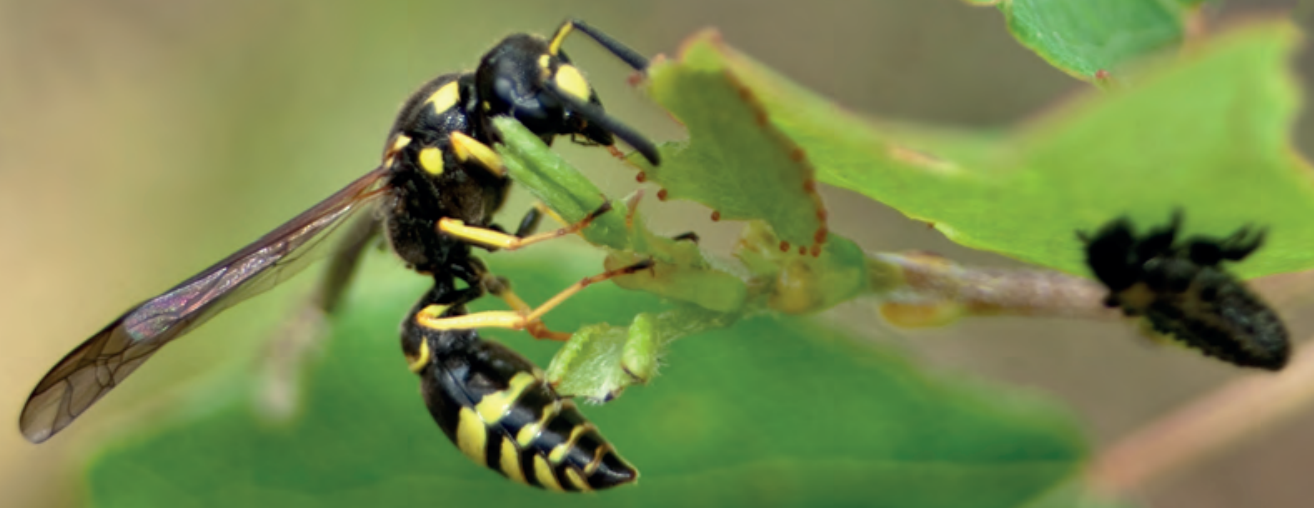




\section{ABSTRACT}

Predatory arthropods are attracted to infochemicals emitted by their herbivore prey or by herbivore-infested plants. We studied such a tritrophic system measuring the olfactoric responses of three potter wasp species (Symmorphus murarius, Symmorphus gracilis, Discoelius zonalis, Hymenoptera: Eumeninae), which differ in resource-use specialization, to herbivore-induced plant volatiles (HIPVs) emitted by aspen (Populus tremula) and saliclylaldehyde, sequestered as a defence compound by Chrysomela leaf beetle larvae. Electroantennographic recordings (GC-MS/EAG and EAG) exhibited differences in perception of HIPVs between the three wasp species. The highly specialized S. murarius (specialist on Chrysomela) was more sensitive to salicylaldehyde than the less specialized S. gracilis, feeding on leaf beetles and weevils, whereas $D$. zonalis, feeding on a range of microlepidopteran prey, did not respond at all. These results indicate that the sensory capability to perceive volatiles from prey and HIPVs can differ greatly according to the wasp species and its degree of resource specialization.

Key Words: electrophysiology, salicylaldehyde, Symmorphus murarius, Symmorphus gracilis, Discoelius zonalis, Populus tremula, herbivore-induced plant volatiles, HIPVs, (Z)-3-hexen-1-ol, Chrysomelinae 


\section{INTRODUCTION}

Carnivorous enemies of herbivores exploit of several olfactoric strategies to sucessfully localize their prey. The use of plant volatiles, herbivore-induced plant volatiles (HIPVs) released by infested plants or directly of volatiles released by their prey such as pheromones and even allomones for the location of prey is known from many predatory insects (Dicke, 2009). In this way, such infochemicals often shape multitrophic interactions (Takabayashi and Dicke, 1996; Dicke and Baldwin, 2010). The use of infochemicals and especially HIPVs is known for a range of carnivores including parasites (Dougherty et al., 1999), parasitoids (Rutledge, 1996; Quicke, 1997) and predators such as predatory beetles (Herms et al., 1991; Yoneya et al., 2009), true bugs (Weissbecker et al., 2000) and wasps. The latter include solitary and eusocial species as Pompilidae (Punzo and Ludwig, 2005), Sphecidae (Anton and Gnatzy, 1998) and Vespidae (Aldrich et al., 1985; Hendrichs et al., 1994; Jander, 1998). To the best of our knowledge, no studies have been carried out on infochemical use by potter wasps (Eumeninae).

Females of solitary potter wasps prey upon insect larvae for provisioning their nests with food for their offspring. Most Eumeninae species prey on Lepidoptera larvae. Discoelius zonalis hunts on microlepidopteran larvae, wich in turn are herbivores of several plant species (Blüthgen, 1961). Other eumenid species forage for coleopteran larvae such as chrysomelids and curculionids (Blüthgen, 1961; Evans, 1966). Among those, Symmorphus species show different prey specializations on herbivores of Salicaceae (Populus and Salix). The highly specialized S. murarius exclusively hunts for Chrysomelinae leaf beetle larvae, whereas the less specialized S. gracilis accepts Chrysomelinae larvae and larvae of Curculionidae, especially of the genus Cionus (Blüthgen, 1961; Gathmann and Tscharntke, 1999; Budriene, 2003). S. murarius and D. zonalis are very rare in Central Europe, whereas S. gracilis is the most common species.

As an effective defence strategy, leaf beetle larvae feeding on Salicaceae sequester phenolic glucosides, especially salicin and its derivatives and transform it into salicylaldehyde (Pasteels et al., 1983; Smiley et al., 1985; Köpf et al., 1998; Burse et al., 2009). This salicylaldehyde is an effective deterrent and provides protection against several generalist arthropod predators 
such as ants (Wallace and Blum, 1969; Hilker and Schulz 1994), ladybird beetles (Denno et al., 1990; Smiley, 1991) and spiders (Palokangas and Neuvonen, 1992). In contrast, specialist predators adapted to the defence system are inviolable, and use salicylaldehyde as a kairomone for host finding. Those are phorid flies (Zvereva and Rank 2003, 2004), syrphid flies (Rank and Smiley, 1994; Köpf et al., 1997; Gross et al., 2004) and the sawfly Tenthredo olivacea (Pasteels and Gregoire, 1984).

Because of these differences in prey specialisation, our tritrophic model system consisting of Populus tremula, salicin-sequestering Chrysomelinae, and their predators, the potter wasps S. muraurius and S. gracilis, provide an interesting case to investigate how infochemicals shape the interactions in a comparative approach (Fig. 1).

The aim of this study was to determine whether there are differences in odor perception of S. murarius, S. gracilis, and D. zonalis to distinct HIPVs and salicylaldehyde, the allomone of the beetle larvae.

The questions adressed were:

1) Do the three wasp species perceive HIPVs?

2) Is the specialization degree of the three wasps to salicin-sequestering larve reflected in perception performance of salicyaldehyde?

3) In eumenid wasps brood provisioning is provided only by females. Do the males also detect plant odor and salicylaldehyde?

To answer these questions, GC-MS/EAD experiments were carried out to examine perception of HIPVs of Populus tremula by females of S. murarius, S. gracilis and D. zonalis. Comparative EAG dose-response experiments wer conducted to scrutinize the perception of salicylaldehyde, and selected HIPVs. 
highly specialized

S. murarius

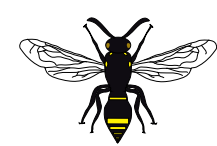

less specialized

S. gracilis

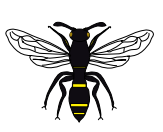

not specialized

D. zonalis

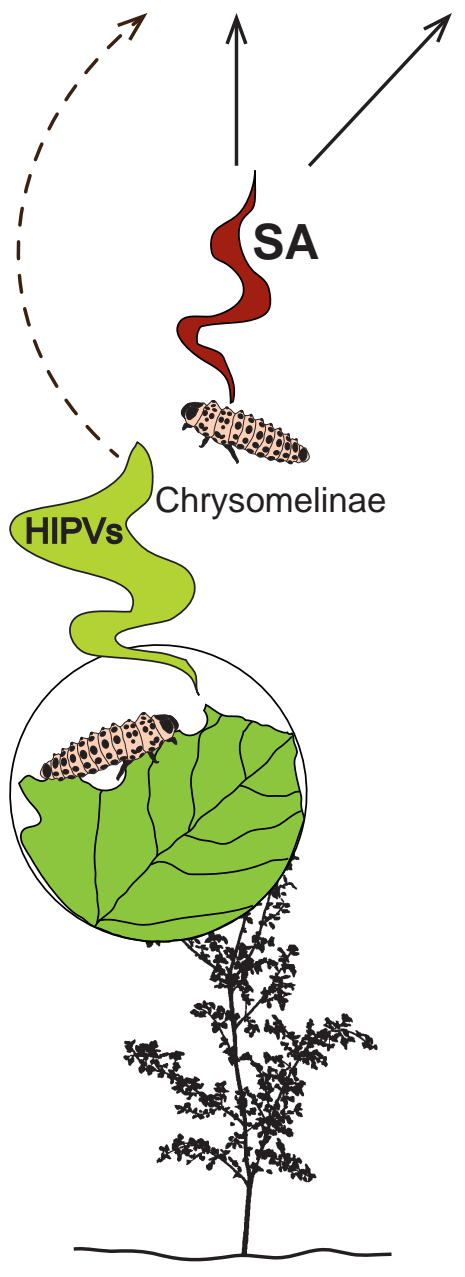

Salicaceae

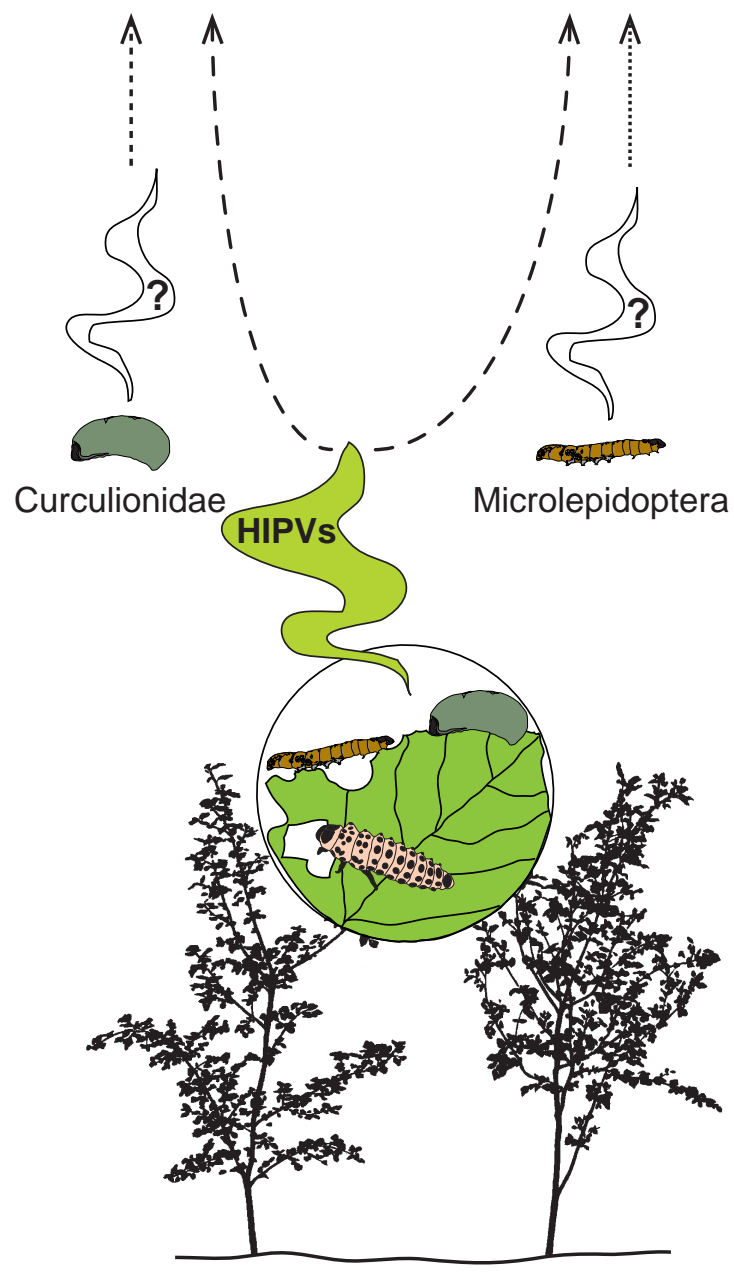

Salicaceae, Vitaceae, Urticaceae, a.o.

Figure 1: Schematic drawing of the tritrophic systems of Salicaceae, salicin-using leaf beetle larvae, and females of the potter wasps Symmorphus murarius, S. gracilis, and Discoelius zonalis. HIPVs = Herbivore-induced plant volatiles; SA = Salicylaldehyde. (Drawing of trees by W. Tambour, University of Göttingen). 


\section{MATERIAL AND METHODS}

\section{Insect Sampling}

Specimens of the genus Symmorphus (S. murarius and S. gracilis) were obtained from artificial trap-nests consisting of plastic tubes of $15 \mathrm{~cm}$ diameter filled with reed internodes (Phragmites australis) placed in the field from April to September 2008 in the vicinity of Göttingen, Lower Saxony, Germany. In total, 396 trap nests were installed. Additional specimens of D. zonalis were obtained from numerous trap-nests placed 2009 near Baderitz (Sornzig-Ablaß), Saxonia, Germany. During winter 2008 and 2009, all traps were opened in the laboratory and examined for occupied reed internodes (Gathmann and Tscharntke, 1999). All occupied reeds were stored at $2-6{ }^{\circ} \mathrm{C}$ in a climate chamber until eclosion of adult individuals in early spring. In total only six $S$. murarius (3 females and 3 males), 55 S. gracilis (20 females and 25 males), and one D. zonalis (male) hatched in 2009. In 2010, another 22 D. zonalis (12 females and 10 males) hatched. Number of hatched individuals reflects the commonness of the respective species. Wasps were identified to species level using the identification keys of Blüthgen (1961) and Schmid-Egger (1994).

\section{Volatile Sampling and Extracts}

Volatiles were collected from naturally herbivore-infested eight year old poplar trees (Populus tremula) on an experimental field in July 2008. The trees were part of a biodiversity experiment carried out in 2008 as described by Kleemann et al. (2010). Volatiles were sampled on a charcoal trap (CLSA-Filter, Daumazan sur Arize, France) using a modified push-pull headspace collection system (Tholl et al., 2006) directly on the trees. Always about 50 leaves of a branch were enclosed in a plastic roasting bag (Melitta GmbH, Minden, Germany). Air was circulated through the trap by a miniature pump (Fürgut, Aichstetten, Germany) at a flow of $0.81 \mathrm{~min}^{-1}$. The sampling time was $2 \mathrm{hr}$. Adsorbed volatiles were eluted with $100 \mu 1$ of dichloromethane/methanol (2:1). The solvents used were of analytical quality (Suprasolv quality, Merck/VWR, Darmstadt, Germany). After elution, samples were stored in an ultralow temperature freezer at $-80^{\circ} \mathrm{C}$. 


\section{Chemicals}

The following authentic standards were obtained with given purity from commercial sources: 6-methyl-5-hepten-2-one (96\%, CAS: 110-93-0, Fluka, Germany), (Z)-3-hexen-1-ol (98\%, CAS: 928-96-1, Merck-Suchardt, Hohenbrunn, Germany), (Z)-3-hexenyl acetate (98\%, CAS: 3681-71-8, Aldrich, Germany), linalool (97\%, CAS: 78-70-6, Merck, Germany), (E/Z)linalool oxide (97\%, CAS: 60047-17-8, Acros, Germany), methyl salicylate (99\%, CAS: 11936-8, Sigma-Aldrich, Germany), $\beta$-caryophyllene (98.5\% CAS: 87-44-5, Sigma-Aldrich, Germany), nonanal (98\%, CAS: 124-19-6, Merck, Germany), ocimene (mixture 70\% (Z)ocimene $+25 \%$ limonene, 98\%, CAS: 13877-91-3, Fluka, Germany), and salicylaldehyde (99\%, CAS: 17754-90-4, Aldrich, Steinheim, Germany).

\section{GC-MS/EAD System and Data Analyses}

Volatile samples were analyzed with a coupled GC-MS/EAD system (Weissbecker et al., 2004) consisting of a gas chromatograph Agilent type 6890 connected to a type 5973 quadrupole mass spectrometer (both Palo Alto, USA) with electron ionisation (EI, 70 $\mathrm{eV}$ ), connected to an "olfactory detector port" (ODP-2, Gerstel, Mülheim, Germany) and custom made antennae holder equipped with an EAG-amplifier (Dr. Koch, University of Kaiserslautern). Two column types in a similar setup, a HP-INNOWax (Agilent, 30 m, 0.25 mm ID, $0.25 \mu \mathrm{m}$ coating thickness, polyethyleneglycol), and a HP-5ms (Agilent, $30 \mathrm{~m}$, $0.25 \mathrm{~mm} \mathrm{ID}$, and $0.25 \mu \mathrm{m}$ film thickness, phenylmethylsiloxane) were used to validate the composition of the extracts. An aliquot of $1 \mu \mathrm{l}$ was injected into the injector held at $250^{\circ} \mathrm{C}$. The oven temperature program was $50^{\circ} \mathrm{C}$ held for $1.5 \mathrm{~min}$, followed by an increase of 7.50 ${ }^{\circ} \mathrm{C} / \mathrm{min}$ to $200^{\circ} \mathrm{C}$, remaining at $200^{\circ} \mathrm{C}$ for $5 \mathrm{~min}$. Helium (purity $99.999 \%$ ) was used as the carrier gas $(1 \mathrm{ml} / \mathrm{min})$. The effluent from the column was splitted (1:1) into two pieces of deactivated capillary using a Graphpack 3D/2 flow splitter (Gerstel, Mülheim, Germany). One capillary $(1 \mathrm{~m} \times 0.1 \mathrm{~mm}$ i.d.) led to the mass spectrometer, the other $(1 \mathrm{~m} \times 0.15 \mathrm{~mm}$ i.d.) to an "olfactory detector port" (ODP-2, Gerstel). Volatiles were guided through the capillary into the EAD-interface and were mixed with humidified air $\left(23^{\circ} \mathrm{C}, 80 \% \mathrm{RH}\right)$ with a flow rate of $400 \mathrm{ml} / \mathrm{min}$.

Excised antennae of both sexes of the three potter wasp species were placed into an antenna 
holder (Färbert et al., 1997), where both antenna ends contacted an electrolyte solution for providing electrical contact to a pair of $\mathrm{Ag} / \mathrm{AgCl}$ electrodes. We used an amplification factor of 100 for the EAD potentials generated by high-impedance amplifier (input impedance $100 \mathrm{M} \Omega$; Prof. Koch, Kaiserslautern, Germany). After digitization (35900E A/D converter, Agilent) the signals were recorded with the GC ChemStation software (D.02.00.275, Agilent Technologies). For identification of the constituents, mass spectra and GC linear retention indices (van den Dool and Kratz, 1963) were compared to those of authentic standards and those of the mass spectral databases Wiley 9 combined with NIST '08 (McLafferty \& Hoboken, 2009).

\section{Electroantennographic Recordings}

Dose-response experiments were conducted with antenna of females and males of the three eumenid species using an EAG setup as described in Weissbecker et al. (2004). The series were carried out by manually injecting the synthetic volatile standards upstream the dissected antenna into a stream with synthetic air. To guarantee standard conditions stimuli were supplied every $120 \mathrm{~s}$. Dilutions of synthetic standards were prepared of (Z)-3-hexen-1ol, nonanal, and salicylaldehyde in paraffin oil (Uvasol ${ }^{\circledR}$, spectrosc. qual., high visc., Merck, Darmstadt, Germany) in doses from $10^{-5}, 10^{-4}, 10^{-3}$, and $10^{-2}(\mathrm{w} / \mathrm{w})$ in order to calculate a dose-response curve. Ca. $100 \mu \mathrm{l}$ of standard dilution or paraffin oil as a control were dropped on $2 \mathrm{~cm}^{2}$ filter paper pieces (Schleicher \& Schuell, Dassel, Germany). A soaked filter paper was inserted into a $10 \mathrm{ml}$ glass syringe (Poulten \& Graf GmbH, Wertheim, Germany). A typical stimulus was supplied by puffing $5 \mathrm{ml}$ of air over the antenna (Schütz et al., 1997) and repeated once for each concentration and control. The EAG response for each dilution and control was recorded for S. murarius, S. gracilis and D. zonalis.

\section{Statistical Analyses}

Statistical analyses were carried out using the software R, Version 2.10.0 (R Development Core Team, 2010). We subtracted the mV-response to the initial paraffin control from all obtained compound responses. Thus we obtained data for four doses to describe a doseresponse relationship. We refrained from normalizing the EAG response data. To analyze the EAG response we used a non-linear regression approach using the software package "drc" 
generally designed for the analysis of multiple dose-response curves (Ritz and Streibig, 2005). We fitted dose-response curves with three-, four- and five-parameter logisitic nonlinear models. To select the minimal adequate model we used the one with the lowest Akaike's Information Criterion (AIC) (Burnham and Anderson, 2002). Sensitivity parameters have been calculated for comparison between species and compounds. We selected the $\mathrm{ED}_{10}$ (effective dose evoking $10 \%$ of the total response), as an estimate value of the odor detection threshold. The limit of detection according to IUPAC definitions (IUPAC Compendium of Chemical Terminology, $2^{\text {nd }}$ edition 1997) has been calculated for blank measures of selected antennae. $\mathrm{ED}_{10}$ was always above those values. Additionally we calculated the $\mathrm{ED}_{50}$, which characterizes the point of steepest slope of the curve, and calculated the detection range $\left(\mathrm{ED}_{50}\right.$ $-\mathrm{ED}_{10}$ ) (see van Giessen et al., 1994). An overview of the use of non-linear curve fitting and interpretation of calculated sensitivity parameters in insect chemoreception is given by van Giessen et al. (1994) and Jordan (2009). To calculate differences between paraffin oil control and the lowest concentration of synthetic compounds we used a two sample t-test.

Differences between responses of females and males to the $10^{-3}$ concentration were considered significant at a $P$-value $<0.05$ (ANOVA F-test). Data were tested for normality with the Shapiro-Wilk's test. If required, data were log-transformed to meet the assumptions of homogeneity of variance and normality of residuals of the statistical models. 


\section{RESULTS}

\section{GC-MS/EAD Recordings}

The three species showed antennal responses to different compounds of poplar volatile extracts, i.e. alcohols, aldehydes, ketones, (acyclic) monoterpenes, and sesquiterpenes. Reproducable antennal responses of all three wasp species could be verified for (Z)-3hexen-1-ol, (Z)-3-hexenyl acetate, 6-methyl-5-hepten-2-one, (E/Z)-linalool oxide and $\beta$-caryophyllene. Methyl salicylate was perceived by the two Symmorphus species only. Linalool evoked antennal responses in S. murarius and D. zonalis, ocimene exclusively in S. gracilis (Table 1).

Table 1: Electroantennogam activity from antennae of Symmorphus murarius, S. gracilis, and Discoelius zonalis to different compounds in plant volatile extracts from Populus tremula leaves.

\begin{tabular}{|c|c|c|c|}
\hline Compound & S.murarius & S. gracilis & D. zonalis \\
\hline 6-methyl-5-hepten-2-one & ++ & + & +++ \\
\hline (Z)-3-Hexen-1-ol & ++ & + & ++ \\
\hline (Z)-3-Hexenyl acetate & ++ & + & ++ \\
\hline Linalool & ++ & - & ++ \\
\hline$(E / Z)$-Linalool oxide ${ }^{a}$ & + & + & + \\
\hline Methyl salicylate & ++ & + & - \\
\hline$\beta$-Caryophyllene & + & + & + \\
\hline Nonanal * & NA & + & - \\
\hline Ocimene $^{\text {a }}$ & - & + & - \\
\hline
\end{tabular}

a: Stereochemistry not determined. * was not present in all extracts. Response categories: 0-0.5 $\mathrm{mV}(-), 0.5-5 \mathrm{mV}(+), 5-15 \mathrm{mV}(++), 15-25 \mathrm{mV}(+++)$

\section{Electroantennographic Experiments}

Antennae of all three eumenid wasps responded to (Z)-3-hexen-1-ol resulting in a similar detection threshold $\left(\mathrm{ED}_{10}\right)$. S. murarius had the broadest detection range for this plant volatile and among those tested it was the only one perceived by D. zonalis (Table 2, Fig. 2). Both Symmorphus species perceived nonanal and had a similar detection threshold, whereof $S$. gracilis showed the broadest detection range. The antennae of $S$. murarius females were exceedingly sensitive to salicylaldehyde (Fig. 2 and Appendix Table A1). The detection 
Table 2: Estimated sensitivity parameters derived from fitted dose-response curves of electroantennogram activities from antennae of Symmorphus murarius, S. gracilis, and Discoelius zonalis to different concentrations of salicylaldehyde, nonanal and (Z)-3-hexen-1-ol. ED10 = detection threshold, ED50 = detection half response, ED50 - ED10 = detection range. S. murarius $\mathrm{N}=3$, S. gracilis $\mathrm{N}=11$, D. zonalis $\mathrm{N}=8$. conc $=$ concentration. $\mathrm{SE}=$ standard error.

\begin{tabular}{|c|c|c|c|c|c|c|}
\hline \multirow{4}{*}{$\begin{array}{l}\text { Compound } \\
\text { Salicylaldehyde }\end{array}$} & \multirow{4}{*}{$\begin{array}{l}\text { Species } \\
\text { S. murarius }\end{array}$} & \multirow{2}{*}{\multicolumn{2}{|c|}{$\begin{array}{l}\text { Threshold } \\
\text { ED10 }\end{array}$}} & \multirow{2}{*}{\multicolumn{2}{|c|}{$\begin{array}{l}\text { Half reponse } \\
\text { ED50 }\end{array}$}} & \multirow{3}{*}{$\begin{array}{l}\text { Detection range } \\
\text { ED50 ED10 } \\
\text { log10 conc. } \pm \text { SE }\end{array}$} \\
\hline & & & & & & \\
\hline & & \multicolumn{2}{|c|}{$\log 10$ conc. $\pm \mathrm{SE}$} & \multicolumn{2}{|c|}{$\log 10$ conc. $\pm \mathrm{SE}$} & \\
\hline & & $-7.6 \pm$ & 0.8 & $-5.3 \pm$ & 0.5 & 2.3 \\
\hline & S. gracilis & $-2.7 \pm$ & 0.8 & $-1.3 \pm$ & 0.9 & 1.4 \\
\hline & D. zonalis & \multicolumn{2}{|c|}{ no response } & \multicolumn{2}{|c|}{ no response } & no response \\
\hline \multirow[t]{3}{*}{ Nonanal } & S. murarius & $-4.4 \pm$ & 0.4 & $-2.7 \pm$ & 1.3 & 1.8 \\
\hline & S. gracilis & $-4.8 \pm$ & 0.5 & $-1.5 \pm$ & 0.7 & 3.3 \\
\hline & D. zonalis & \multicolumn{2}{|c|}{ no response } & \multicolumn{2}{|c|}{ no response } & no response \\
\hline \multirow[t]{3}{*}{ (Z)-3-hexen-1-ol } & S. murarius & $-3.6 \pm$ & 0.3 & $-1.7 \pm$ & 0.6 & 1.9 \\
\hline & S. gracilis & $-3.6 \pm$ & 0.1 & $-2.6 \pm$ & 0.5 & 1.0 \\
\hline & D. zonalis & $-3.2 \pm$ & 0.5 & $-1.6 \pm$ & 0.7 & 1.6 \\
\hline
\end{tabular}

threshold $\left(\mathrm{ED}_{10}\right)$ of salicylaldehyde is about 3 magnitudes lower compared to nonanal and 4 magnitudes lower compared to (Z)-3-hexen-1-ol (Table 2). The analyses of sensitivity parameters revealed that $S$. murarius was much more sensitive to salicylaldehyde than S. gracilis (i.e. about 5 magnitudes lower $\mathrm{ED}_{10}$, and 4 magnitudes lower $\mathrm{ED}_{50}$ ), consequently it also showed a broader detection range $\left(\mathrm{ED}_{50}-\mathrm{ED}_{10}\right)$ (Table 2). S. gracilis perceived salicylaldehyde, but antennae were less sensitive to it than to the other two compounds. There was a significant difference between paraffin oil controls and the lowest concentration tested $\left(10^{-5}\right)$ of salicylaldehyde for $S$. murarius only $(\mathrm{df}=4, t$-value $=-6.7246, P$-value $=0.0025)$. In most cases, the females had a higher sensitivity to the three tested compounds than the males, albeit not always being significant. Nevertheless, all substances were perceived by the male wasps (Table 3). 

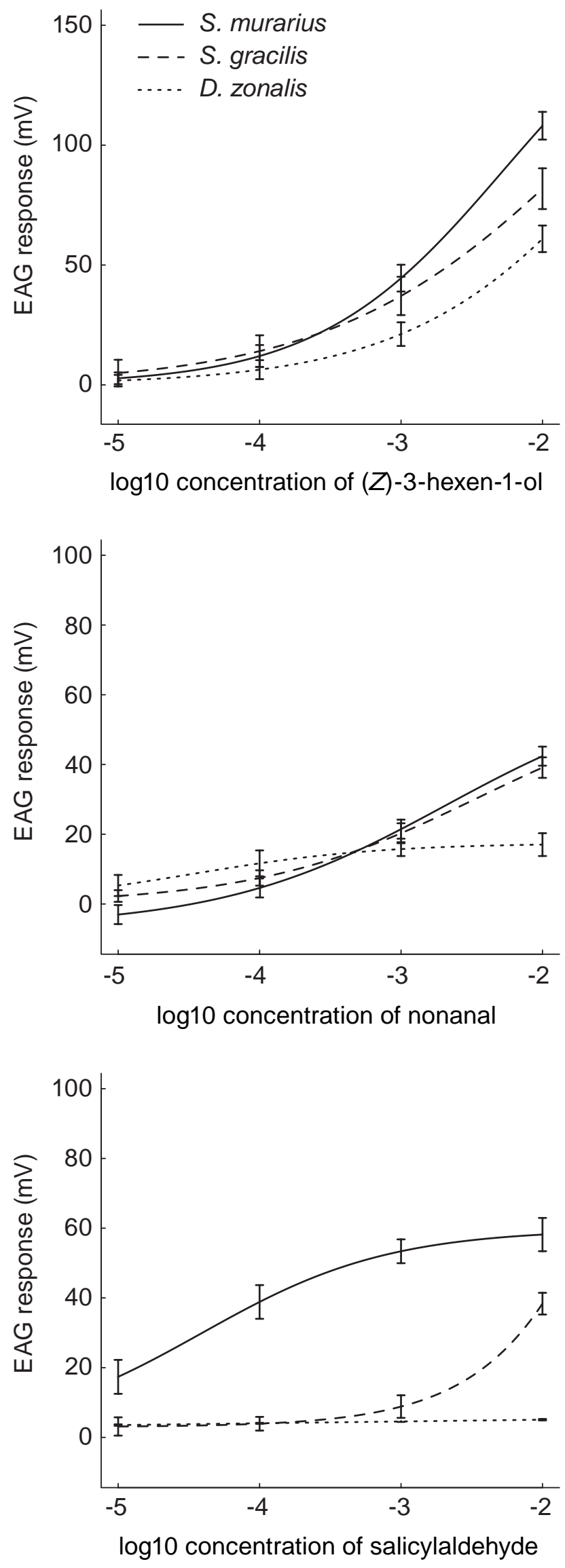

Figure 2: Dose-response curves (EAG) of females of the three potter wasp species Symmorphus murarius, S. gracilis, and Discoelius zonalis. Error bars show the SE of the fitted logistic curves. Mean and SE values of measured antennal response is depicted in Table 2. Doses are shown as log10 concentrations in paraffin (w/w). Responses are absolute amplified values [mV]. S. murarius $\mathrm{N}=3$, S. gracilis $\mathrm{N}=11, D$. zonalis $\mathrm{N}=8$. 
Table 3: EAG response comparison of females and males of Symmorphus murarius, S. gracilis, and Discoelius zonalis to a 10-3 concentration of salicylaldehyde, nonanal, and (Z)-3-hexen-1-ol. Data are given with mean and standard errors (SE). n.s. $=P>0.05$, * $=P<0.05$, ** $=P<0.01$.

\begin{tabular}{|c|c|c|c|c|c|c|c|c|c|c|c|c|c|c|}
\hline \multirow[b]{2}{*}{ Species } & \multirow[b]{2}{*}{ Sex } & \multirow[b]{2}{*}{$\mathrm{n}$} & \multicolumn{4}{|c|}{ Salicylaldehyde } & \multicolumn{3}{|c|}{ Nonanal } & & \multicolumn{4}{|c|}{ (Z)-3-hexen-1-ol } \\
\hline & & & mean & & SE & & mean & & SE & & mean & & SE & \\
\hline \multirow[t]{2}{*}{ S. murarius } & qq+ & 3 & 50.00 & \pm & 5.99 & \multirow{2}{*}{$* *$} & 21.45 & \pm & 2.72 & & 44.00 & \pm & 5.33 & \\
\hline & $\hat{\sigma} \sigma^{\lambda}$ & 3 & 19.54 & \pm & 0.84 & & 7.97 & \pm & 2.76 & & 18.56 & \pm & 10.72 & \\
\hline \multirow[t]{2}{*}{ S. gracilis } & 우우 & 11 & 11.77 & \pm & 2.31 & \multirow{2}{*}{ n.s. } & 22.45 & \pm & 3.44 & & 39.34 & \pm & 7.87 & \multirow{2}{*}{ s. } \\
\hline & $\widehat{\partial}$ & 5 & 11.84 & \pm & 2.44 & & 9.14 & \pm & 2.22 & & 34.62 & \pm & 6.86 & \\
\hline \multirow[t]{2}{*}{ D. zonalis } & 우우 & 8 & 6.78 & \pm & 1.95 & \multirow{2}{*}{ n.s. } & 13.20 & \pm & 3.93 & \multirow{2}{*}{ n.s. } & 24.28 & \pm & 3.62 & \multirow{2}{*}{ n.s. } \\
\hline & $\hat{\partial} \hat{\sigma}$ & 3 & 2.41 & \pm & 1.90 & & 12.24 & \pm & 1.12 & & 15.37 & \pm & 3.61 & \\
\hline
\end{tabular}

\section{DISCUSSION}

Our results show that the potter wasps S. murarius, S. gracilis and D. zonalis perceive terpenoids, green leaf volatiles and aromatic compounds, major classes of HIPVs. S. murarius antennae were much more sensitive to salicylaldehyde than S. gracilis, whereas D. zonalis was not able to detect salicylaldehyde at all. We assume that this reflects degree of prey specialization of these species. Symmorphus species are specialists of salicin-sequestering Chrysomelinae (Blüthgen, 1961; Rank, 1994). S. murarius, showing strongest olfactory sensitivity to salicylaldehyde, exclusively hunts salicin-sequestering Chrysomela larvae, whereas S gracilis hunts also Cionus larvae (Curculionidae) (Blüthgen, 1961; Gathmann and Tscharntke, 1999; Budriene, 2003). Salicin sequestration is not known in Curculionidae. Depending on salicin content of Salicaceae hosts, most species of the genus Chrysomela sequester salicin into salicylaldehyde (Pasteels et al., 1990; Termonia et al., 2001). Salicylaldehyde is an effective deterrent and provides protection against several generalist arthropod predators (Denno et al., 1990; Hilker and Schulz 1994) except Symmorphus species. These specialists have adapted and overcome the defence of Chrysomelinae. We suggest that Symmorphus species use the allomone salicylaldehyde as a kairomone for host finding. All European Symmorphus species (S. allobrogus, S. angustatus, S. bifasciatus, S. connexus, S. crassicornis, S. cristatus) including S. gracilis and S. murarius were found to 
prey primarily salicin-sequestering Chrysomelinae larvae (Blüthgen, 1961; Gathmann and Tscharntke, 1999; Budriene, 2003). Exceptions are S. gracilis and S. connexus, additionally hunting for larvae of Microlepidoptera and Curculionidae. D. zonalis is a generalist preying larvae of different Microlepidoptera species. They neither prey on Chrysomela leaf beetles, nor is anything reported about salicylaldehyde in the defence of Microlepidoptera larvae. Therefore, we suspect that $D$. zonalis has no antennal receptors, sensitive to salicylaldehyde. The North American potter wasp species Symmorphus cristatus is also a specialist of salicinsequestering leaf beetle larvae (Rank, 1994; Sears et al., 2001) and Sears et al. (2001) were the first who, suspected that Symmorphus cristatus use salicylaldehyde, the allomone of their prey, for host finding. To the best of our knowledge, our study is the first proving that Symmorphus wasps, specialized predators of salicin-sequestering leaf beetle larvae, perceive salicylaldehyde.

All three wasp species showed a similar perception ability to plant volatiles considered as herbivore induced. Among those, green leave volatiles (GLV), such as (Z)-3-hexen-1-ol and (Z)-3-hexenyl acetate as well as terpenoids, as 6-methyl-5-hepten-2-one, (E/Z)-linalool oxide and $\beta$-caryophyllene are perceived by all three species. In contrast nonanal is hardly perceived by $D$. zonalis. The aromatic methyl salicylate evoked, just like salicylaldehyde, antennal responses only in both Symmorphus species. The chemical structure is very similar to salicylaldehyde and it could be possible that both compounds activate the same olfactoric receptor. This could explain why D. zonalis does not perceive methyl salicylate, albeit it is considered as a HIPV (Dickens, 1999; de Boer and Dicke, 2004; Dicke, 2009). Antennal activity and behavioral attractiveness of HIPVs for carnivorous arthropods has been shown in numerous studies (Turlings et al., 1990; Dicke and Vet, 1998; Dickens, 1999; Steidle and van Loon, 2003; Dicke and Baldwin, 2010) and it is assumed that this is a widespread and advantageous way to locate their prey (Dicke, 2009). Eusocial wasps, Vespula maculifrons, Polistes arizonesis and Mischocyttarus flavitarsis (Vespidae) have been discussed to use host plant chemicals as foraging kairomones (Aldrich et al., 1985; Cornelius, 1993; Geitzenauer and Bernays, 1996). Only few studies of predators concerning HIPVs applied electroantennographical methods. Stinkbugs, (Pentatomidae, Heteroptera), predators of Leptinotarsa decemlineata, evoke antennal responses to HIPVs produced by 
potato herbivory (Dickens, 1999; Weissbecker et al., 2000).

Males of all three eumenid wasp species perceive salicylaldehyde, nonanal and (Z)-3hexen-1-ol in most cases similar to females. However, Symmorphus males hardly responded to nonanal. S. gracilis males had a comparably high sensitivity to salicylaldehyde as the females, albeit not participating in nest provisioning. Males could be observed in the field flying around Chrysomela larvae-infested poplar trees searching and waiting for females. It could be speculated, that males use salicylaldehyde alone or in combination with HIPVs, such as (Z)-3-hexen-1-ol as a sexual kairomone. Sexual kairomone use is known for the cockchafers Melolontha melolontha and M. hippocastani (Reinecke et al., 2002; Ruther et al., 2002).

Our results showed that $S$. murarius and $S$. gracilis perceive the defence compound salicylaldehyde from salicin-sequestering leaf beetle larvae (Chrysomelinae) and further odor compounds released by $P$. tremula trees, among them many HIPVs. In contrast, the little specialised species $D$. zonalis detected only HIPVs and showed no perception ability to salicylaldehde. We conclude that salicylaldehyde is a major kairomone for host finding in those Symmorphus species, preying on salicin-sequestering Chrysomelinae, yet to be confirmed in behavioural studies.

\section{ACKNOWLEDGEMENTS}

Many thanks for support to S. Schiele, K. Schmon and S. Zieger for dissecting trap nests, C. Scherber for statistical advice and B. Weissbecker for support with GC-MS and EAGtechniques. We thank J. L. M. Steidle for valuable comments on an earlier draft of the manuscript. The study was funded by the "Functional Biodiversity Research" project of the Ministry of Science and Culture of Lower Saxony (MWK, „Niedersächsisches Vorab“). 


\section{REFERENCES}

Aldrich, J. R., Kochansky, J. P., and Sexton, J. D. 1984. Chemical attraction of the eastern yellowjacket, Vespula maculifrons (Hymenoptera: Vespidae). Experientia. 41: 420422.

Anton, S. and Gnatzy, W. 1998. Prey specificity and the importance of close-range chemical cues in prey recognition in the digger wasp, Liris niger. Journal of Insect Behavior. 11: 671-690.

Blüthgen, P. 1961. Die Faltenwespen Mitteleuropas (Hymenoptera, Diploptera). Abhandlungen der deutschen Akademie der Wissenschaften zu Berlin, AkademieVerlag, Berlin, Germany.

Budriene, A. 2003. Prey of Symmorphus wasps (Hymenoptera: Eumeninae) in Lithuania. Acta Zoologica Lituanica. 13: 306-310.

Burnham, K. P. and Anderson, D. R. 2002. Model selection and multimodel interference. A practical information-theoretic approach. Springer Science \& Business Media, New York.

Burse, A., Frick, S., Discher, S., Tolzin-Banasch, K., Kirsch, R., Strauss, A., Kunert, M., and Boland, W. 2009. Always being well prepared for defense: The production of deterrents by juvenile Chrysomelina beetles (Chrysomelidae). Phytochemistry. 70: 1899-1909.

Connelius, M. L. 1993. Influence of caterpillar-feeding on the foraging behavior of the paper wasp Mischocyttarus flavitarsis (Hymenoptera: Vespidae). Journal of Insect Behavior. 6: 771-781.

De Boer J. G. and Dicke, M. 2004. The role of methyl salicylate in prey searching behavior of the predatory mite Phytoseiulus persimilis. Journal of Chemical Ecology. 30: 255271. 
Denno, R. F., Larsson, S., and Olmstead, K. L. 1990. Role of enemy-free space and plant quality in host-plant selection by willow beetles. Ecology. 71: 124-137.

Dicke M. and Baldwin, I. T. 2010. The evolutionary context for herbivore-induced plant volatiles: beyond the “cry for help”. Trends in Plant Science. 15: 167-175.

Dicke M., van Loon, J. J. A., and Soler, R. 2009. Chemical complexity of volatiles from plants induced by multiple attack. Nature Chemical Biology. 5: 317-324.

Dicke M. and Vet, L. E. M. 1998. Plant-carnivore interactions: Evolutionary and ecological consequences for plant, herbivore and carnivore, pp. 483-520, in H Olff, V. K. Brown, and R. H. Drents (eds.). Herbivores: Between Plants and Predators. Blackwell Science, Oxford, UK.

Dickens, J. C. 1999. Predator-prey interactions: olfactory adaptions of generalist and specialist predators. Agricultural and Forest Entomology. 1: 47-54.

Dougherty, M. J., Guerin, P. M., Ward, R. D., and Hamilton, J. G. C. 1999. Behavioral and electrophysiological responses of the phlebotomine sandfly Lutzomyia longipalpis (Diptera: Psychodidae) when exposed to canid host odor kairomones. Physiological Entomology. 24: 251-262.

Evans, H. E. 1966. The Behavior Patterns of Solitary Wasps. Annual Reviews of Entomology. 11: 123-154.

Färbert, P., Koch, U. T. Färbert, A., Staten, R. S., and Cardé, R. T. 1997. Pheromone concentration measured with electroantennogram in cotton fields treated for mating disruption of Pectoniphora gossypiella (Lepidoptera: Gelechiidae). Environmental Entomology. 25: 567-590.

Gathmann, A. and Tscharntke, T. 1999. Landschafts-Bewertung mit Bienen und Wespen in Nisthilfen: Artenspektrum, Interaktionen und Bestimmungsschlüssel Naturschutz und Landschaftspflege Baden-Württemberg. 73: 277-305. 
Geitzenauer, H. L. and Bernays, E. A. 1996. Plant effects on prey choice by a vespid wasp, Polistes arizonensis. Ecological Entomology. 21: 227-234.

Gouinguené, S., Pickett, J. A., Wadhams, L. J., Birkett, M. A., and Turlings, T. C. J. 2005. Antennal electrophysiological responses of three parasitic wasps to caterpillar-induced volatiles from maize (Zea mays mays), cotton (Gossypium herbaceum), and cowpea (Vigna ungiculata). Journal of Chemical Ecology. 31: 1023-1038.

Gross, J., Fatouros, N. E., Neuvonen, S., and Hilker, M. 2004. The importance of specialist natural enemies for Chrysomela lapponica in pioneering a new host plant. Ecological Entomology. 29: 584-593.

Hendrichs, J., Katsoyannos, B. I., Wornoayporn, V., and Hendrichs, M. A. 1994. Odormediated foraging by yellowjacket wasps (Hymenoptera: Vespidae): predation on leks of pheromone-calling Mediterranean fruit fly males (Diptera: Tephritidae). Oecologia. 99: 88-94.

Herms, D. A., HaAck, R. A., and Ayres, B. D. 1991. Variation in semiochemical mediated prey-predator interaction: Ips pini (Scolytidae) AND Thanasimus dubius (Cleridae). Journal of Chemical Ecology. 17: 515-524.

Hilker, M. and Schulz, S. 1994. Composition of larval secretion of Chrysomela lapponica (Coleoptera, Chrysomelidae) and its dependence on host plant. Journal of Chemical Ecology. 5: 1075-1093.

JANDER, R. 1998. Olfactory learning of fruit odors in the eastern yellow jacket, Vespula maculifrons (Hymenoptera: Vespidae). Journal of Insect Behavior. 11: 879-888.

Jordan, M. D., Anderson, A., Begum, D., Carraher, C., Authier, A., Marshall, S. D., Kiely, A., Gatehouse, L. N., Greenwood, D. R., Christie, D. L., and others. 2009. Odorant receptors from the light brown apple moth (Epiphyas postvittana) recognize important volatile compounds produced by plants. Chemical Senses. 34: 383-394. 
Kleemann, F., Fragstein, M. v., Vornam, B., Müller, A., Leuschner, C., Holzschuh, A., Tscharntke, T., Finkeldey, R., and Polle, A. 2011. Relating genetic variation of ecologically important tree traits to associated organisms in full-sib aspen families. European Journal of Forest Research. 130: 707-716.

Köpf, A., Rank, N. E., Roininen, H., and Tahvanainen; J. 1997. Defensive larval secretions of leaf beetles attract a specialist predator Parasyrphus nigritarsis. Ecological Entomology. 22: 176-183.

Köpf, A., Rank, N. E., Roininen, H., Julkunen-Tittto, R., Pasteels, J. M., and Tahvanainen; J. 1998. Phylogeny and the evolution of host plant use and sequestration in the willow leaf beetle genus Phratora (Coleoptera: Chrysomelidae). Evolution. 52: 517-528.

McLafferty, F. W. and Hoboken, N. J. 2009. Registry of Mass Spectral Data combined with NIST / EPA / NIH database 2008. Wiley-Blackwell.

McNaught, A. D. and Wilkinson, A. 1997. IUPAC Compendium of chemical terminology, second edition. Royal Society of Chemistry, Cambridge, UK.

Palokangas; P. and Neuvonen, S. 1992. Differences between species and instars of leaf beetles in the probability to be preyed on. Annales Zoologici Fennici. 29: 273-278.

Pasteels, J. M., and Gregorre J.-C. 1984. Selective predation on chemically defended chrysomelid larvae. A conditioning process. Journal of Chemical Ecology. 12: 16931700 .

Pasteels, J. M., Rowhell-Rahier, M., Braekmann, J. C., and Dupont, A. 1983. Salicin from host plant as precursor of salicylaldehyde in defensive secretion of Chrysomelinae larvae. Physiological Entomology. 8: 307-314.

Punzo, F. and Ludwig, L. 2005. Behavioral responses of Pepsis thisbe (Hymenoptera: Pompilidae) to chemosensory cues associated with host spiders. Journal of Insect Behavior. 18: 757-766. 
Quicke, D. L. J. 1997. Parasitic wasps. Chapman Hall, London.

R Development Core Team. 2010. R: A language and environment for statistical computing. R foundation for statistical computing. Vienna, Austria, http://www.R-project.org.

RAnK, N. E. 1994. Host-plant effects on larval survival of a salicin-using leaf beetle Chrysomela aenicollis Schaeffer (Coleoptera: Chrysomelidae). Oecologia. 97: 342353.

Rank, N. E. and Smiley, T. S. 1994. Host-plant effects on Parasyrphus melanderi (Diptera: Syrphidae) feeding on a willow leaf beetle Chrysomela aenicollis (Coleoptera: Chrysomelidae). Ecological Entomology. 19: 31-38.

Reinecke, A., Ruther, J., and Hilker, M. 2002. The scent of food and defense: green leaf volatiles and toluquinone as sex attractant mediate mate finding in the European cockchafer Melolontha melolontha. Ecology Letters. 5: 257-263.

Ritz, C., and Streibig, J. C. 2008. Nonlinear regression with R. Springer, New York.

Ruther, J., Reinecke, A., and Hilker, M. 2002. Plant volatiles in the sexual communication of Melolontha hippocastani: response towards time-dependent bouquets and novel function of (Z)-3-hexen-1-ol as a sexual kairomone. Ecological Entomology. 27: 7683.

Rutledge, C. E. 1996. A survey if identified kairomones and synomones used by insects to locate and accept their hosts. Chemoecology. 7: 121-131.

Schmid-EgGer, C. 1994. Bestimmungschlüssel für die deutchen Arten der solitären Faltenwespen (Hymenoptera: Eumeninae). Deutscher Jugendbund für Naturbeobachtung, Hamburg, Deutschland. 
Smid, H. M., van Loon, J. J. A., Posthumus, M. A., and Vet, L. E. M. 2002. GC-EAGanalysis of volatiles from Brussels sprouts plants damaged by two species of Pieris caterpillar: olfactory receptive range of a specialist and a generalist parasitoid was species. Chemoecology. 12: 169-176.

Schütz, S., Weissbecker, B., Klein, A., and Hummel, H. E. 1997. Host plant selection of the Colorado potato beetle as influenced by damage induced volatiles of the potato plant. Naturwissenschaften. 84: 212-217.

Sears, A. L. W., Smiley, J. T., Hilker, M., Müller, F., and Rank, N. E. 2001. Nesting behavior and prey use in two geographically separated populations of the specialist wasp Symmorphus cristatus (Vespidae: Eumeninae). American Midland Naturalist. 145: 233-246.

Smiley, T. S., Horn, J. M., and Rank, N. E. 1985. Ecological effects of salicin at three trophic levels: New problems from old adaptions. Science. 229: 649-651.

SMILEY, K. S. 1991. Aggregation benefits in a willow leaf beetle along an elevational gradient, pp. 148-160. In: Hall, C. A. Doyle-Jones, V., and Widawski, B. (eds). Natural history of eastern California and high-altitude research, University of California. White Mountain Research Station Symposium. The regents of the University of California, Los Angeles, USA.

Steidle, J. L. M. and van Loon, J. J. A. 2003. Dietary specialization and infochemical use in carnivorous arthropods: testing a concept. Entomologia Experimentalis et Applicata. 108: $133-148$.

Takabayashi, J. and Dicke, M. 1996. Plant-carnivore mutualism through herbivore-induced carnivore attractants. Trends in Plant Science. 1: 109-113.

Tholl, D., Boland, W., Hansel, A., Loreto, F., Röse, U. S. R., and Schnitzler J.-P. 2006. Practical approaches to plant volatile analyses. The Plant Journal. 45: 540-560. 
Turlings, T. C. J., Tumlinson, J. H., and Lewis, W. J. 1990. Exploiting of herbivore-induced plant odors by host seeking parasitic wasps. Science. 250: 1251-1253.

VAn Den Dool, H. and Kratz, P. D. 1963. A generalization of the retention index system including linear temperature programmed gas-liquid partition chromatography. Journal of Chromatography. 11: 463-471.

Van Giessen, W. A., Fescemyer, H. W., Burrows, P. M., Peterson, J. K., and Barnett, O. W. 1994. Quantification of electroantennogram responses of the primary rhinaria of Acyrthosiphon pisum (Harris) to C 4-C 8 primary alcohols and aldehydes. Journal of Chemical Ecology. 20: 909-927.

Wallace, J. B. and Blum, M. S. 1969. Refined defensive mechanisms in Chrysomela scripta. Annals of the Entomological Society of America. 62: 503-506.

Weissbecker, B., van Loon, J. J. A., Posthumus, M. A., Bouwmeester, H. J., and Dicke, M. 2000. Identification of volatile potato sesquiterpenoids and their olfactory detection by the two-spotted sinkbug Pericellus bioculatus. Journal of Chemical Ecology. 26: 1433-1445.

Weissbecker, B., Holighaus, G., and Schütz, S. 2004. Gas chromatography with mass spectrometric and electroantennographic detection: analysis of wood odorants by direct coupling of insect olfaction and mass spectrometry. Journal of Chromatography A. 1056: 209-216.

Yoneya, K., Kugimiya, S., and TaKabayashi, J. 2009. Can herbivore-induced plant volatiles inform predatory insect about the most suitable stage of its prey? Physiological Entomology. 34: 379-386.

Zvereva, E. L. and Rank, N. E. 2003. Host plant effects on parasitoid attack on the leaf beetle Chrysomela lapponica. Oecologia. 135: 258-267. 
Zvereva, E. L. and Rank, N. E. 2004. Fly parasitoid Megaselia opacicornis uses defensive secretions of the leaf beetle Chrysomela lapponica to locate its host. Oecologia. 140: 516-522. 


\section{APPENDIX}

Table A1: Non-normalized values of electroantennogram activities from antennae of Symmorphus murarius, S. gracilis, and Discoelius zonalis to different concentrations of salicylaldehyde, nonanal and (Z)-3-hexen-1ol. Data are given with mean and standard errors (SE). S. murarius $\mathrm{N}=3$, S. gracilis $\mathrm{N}=11$, D. zonalis $\mathrm{N}=8$.

\begin{tabular}{|c|c|c|c|c|c|c|c|c|c|c|}
\hline \multirow[b]{2}{*}{ Compound } & \multirow[b]{2}{*}{ Concentration } & \multicolumn{3}{|c|}{ S. murarius } & \multicolumn{3}{|c|}{ S. gracilis } & \multicolumn{3}{|c|}{ D. zonalis } \\
\hline & & mean & \pm & SE & mean & \pm & SE & mean & \pm & SE \\
\hline \multirow[t]{4}{*}{ Salicylaldehyde } & $10^{\wedge}-5$ & 16.30 & \pm & 1.91 & 1.63 & \pm & 1.77 & 1.90 & \pm & 1.58 \\
\hline & $10^{\wedge}-4$ & 41.01 & \pm & 4.56 & 6.17 & \pm & 1.86 & 2.50 & \pm & 2.10 \\
\hline & $10^{\wedge}-3$ & 50.00 & \pm & 5.99 & 11.77 & \pm & 2.31 & 6.78 & \pm & 1.95 \\
\hline & $10^{\wedge}-2$ & 60.14 & \pm & 6.18 & 41.24 & \pm & 5.31 & 4.09 & \pm & 5.39 \\
\hline \multirow[t]{4}{*}{ Nonanal } & $10^{\wedge}-5$ & -3.03 & \pm & 1.96 & -0.27 & \pm & 1.20 & 4.09 & \pm & 2.64 \\
\hline & $10^{\wedge}-4$ & 4.60 & \pm & 1.15 & 10.44 & \pm & 2.19 & 12.75 & \pm & 2.52 \\
\hline & $10^{\wedge}-3$ & 21.45 & \pm & 2.72 & 22.45 & \pm & 3.44 & 13.20 & \pm & 3.93 \\
\hline & $10^{\wedge}-2$ & 42.39 & \pm & 4.15 & 42.74 & \pm & 4.31 & 17.84 & \pm & 2.40 \\
\hline \multirow[t]{4}{*}{ (Z)-3-hexen-1-ol } & $10^{\wedge}-5$ & 0.04 & \pm & 1.35 & 7.23 & \pm & 2.38 & 7.12 & \pm & 2.20 \\
\hline & $10^{\wedge}-4$ & 13.80 & \pm & 2.20 & 11.84 & \pm & 2.21 & 4.19 & \pm & 1.79 \\
\hline & $10^{\wedge}-3$ & 44.00 & \pm & 5.33 & 39.34 & \pm & 7.87 & 24.28 & \pm & 3.62 \\
\hline & $10^{\wedge}-2$ & 108.19 & \pm & 10.50 & 94.62 & \pm & 17.27 & 68.12 & \pm & 7.82 \\
\hline
\end{tabular}




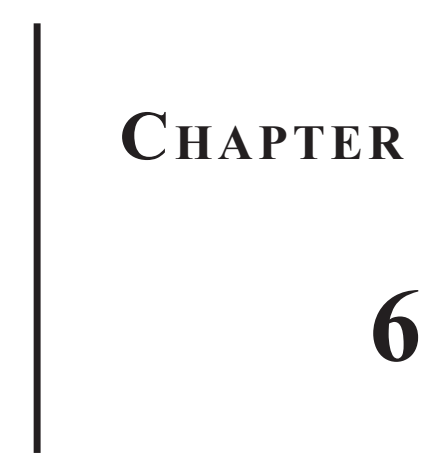

\section{Synthesis}

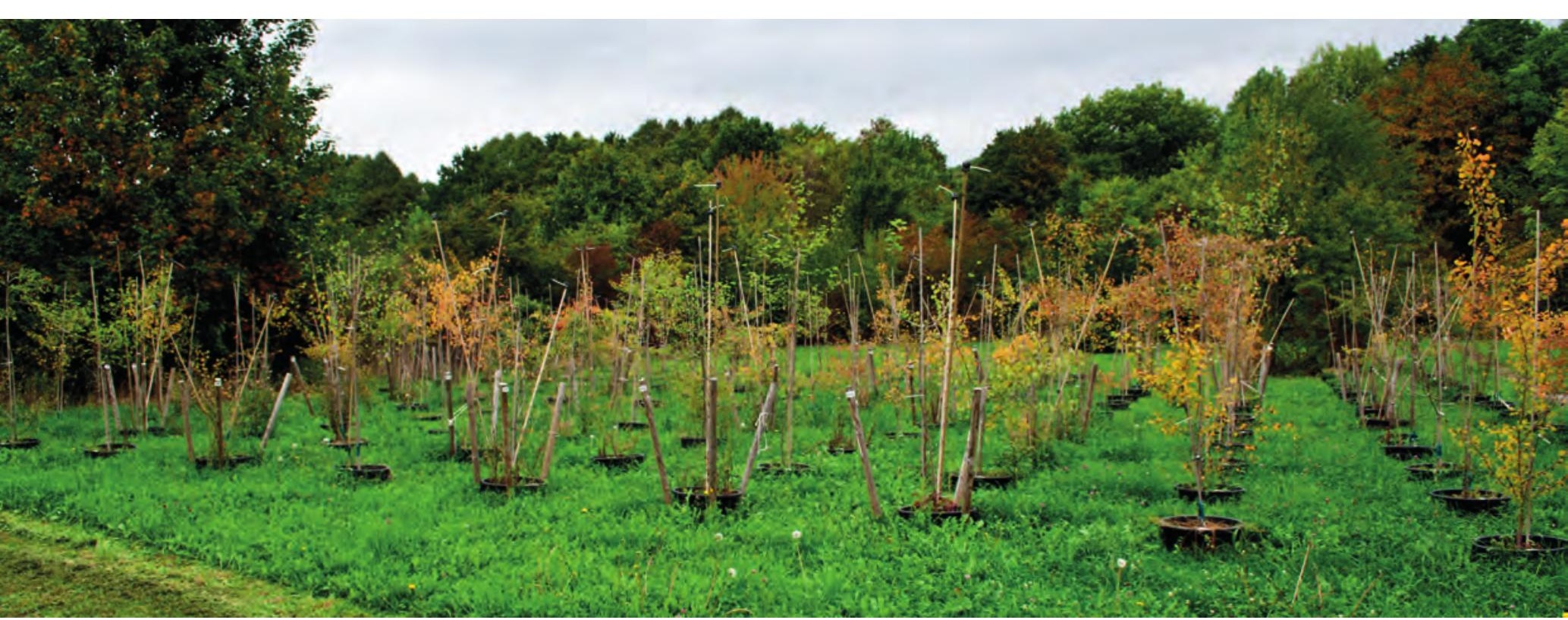




\section{SYNTHESIS}

Research on interactions of willows and poplars with herbivorous insects focuses mostly on the role of leaf chemical ecology using Salix clones or Populus hybrids, whereas less is known from real-world tritrophic interactions on genetically different Populus tremula trees.

In this thesis we used field observations to identify the community composition and abundance of herbivorous insects and predatory arthropods of seven closely related aspen (P. tremula) full-sib families. As observational studies are often criticized by lacking control and manipulation of possible confounding variables, we analyzed different morphological and chemical tree traits and used experimental methods (e.g. electroantennography) to investigate tritrophic interactions between poplar trees, chewing herbivores and their natural enemies (Fig. 1).

In our study the variation of neutral molecular genetic markers (nuclear microsatellites) was higher within each family than between the families. It was not possible to relate the different phenotypic characteristics and ecological traits (e.g. herbivore load) to the genetic variation based on molecular markers, because of the small number (only five) of neutral markers.

On the first trophic level we investigated aspen (P. tremula) of seven full-sib families. They differed in morphological traits such as leaf number, tree height and biomass production as well as in phenolic defensive compounds and other phytochemical leaf traits, whereas there were no differences in leaf toughness and herbivore-induced plant volatiles. The biomass production was closely related to the variation in plant morphological traits (e.g. leaf number, leaf area, etc.), but not to leaf chemistry. This is in contrast to the recent literature where the trade-off between chemical defence and growth is frequently discussed. Costs for increased defence can reduce plant growth (Simms and Rausher, 1987), whereas a decrease of defence can reduce fitness and growth if herbivores are present (Philippe and Bohlmann, 2007). In general, high levels of functional trait variations could be related to ecosystem stability in other studies (Lecerf and Chauvet, 2008). 
Are there differences in plant traits between the $\mathrm{P}$. tremula full-sib families? 1st \& 2nd trophic level

signifcant variations in morphological, phenological and chemical traits! generalist herbivores negatively affected by phenolic compunds! no trade-off: growth resistance!

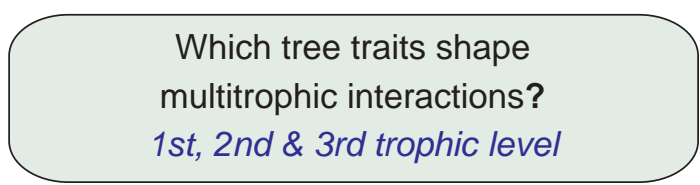

\begin{tabular}{lcc|} 
tree height & herbivores & predators \\
leaf number & $(0 /-)$ & $(0)$ \\
leaf toughness & $(-/$ ) $)$ & $(0)$ \\
HIPVs & $(0 / 0)$ & $(0)$ \\
herbivores & & $(+)$ \\
\hline
\end{tabular}

\section{chapter 3}

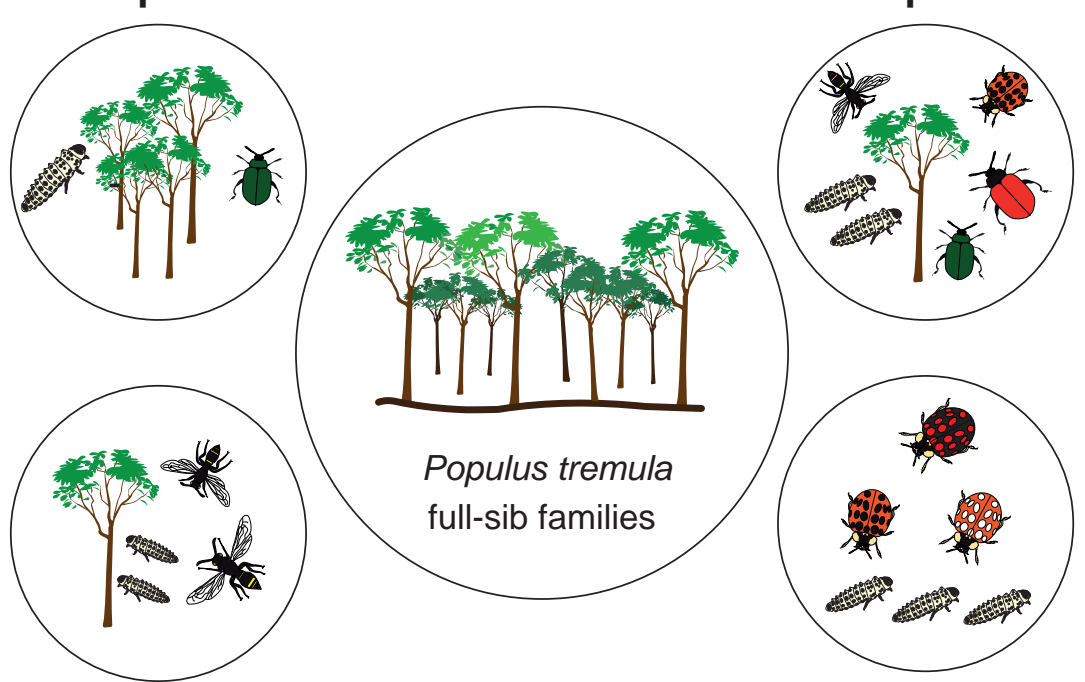

chapter 4

chapter 5

How do generalist predatory beetles respond to SA? 2nd \& 3rd trophic level

able to percieve HIPVs and SA?

1st, 2nd \& 3rd trophic level

predatory wasps reverse general defence signal to the contrary - prey specialisation degree reflects HIPVs and SA olfaction abilities!

Figure 1: Scheme of the study objectives with the main questions of each chapter of the thesis (green rectangle) and the most important results (orange rectangle). HIPVs = herbivore-induced plant volatiles, SA $=$ salicylaldehyde,$(+)=$ positive effect, $(-)=$ negative effect, $(0)=$ no effect. Chapter $3:(+/+)$ the first part within the bracket $=$ influence on leaf beetle adults, the second part $=$ influence on leaf beetle larvae.

In both observational studies (chapter 2 \& 3) specialised leaf beetles from the genera Phratora and Chrysomela and their larvae were the most abundant specimen of the second trophic level (chewing herbivores). Their abundances on the trees were influenced by morphological 
traits such as tree height, leaf number, total leaf area, and leaf toughness as well as by chemical traits (phenolic compounds). Our analyses indicate that the phenolic compounds had the strongest effect on the herbivores (chapter 2) (Fig. 2). These results are in line with the recent literature (Lindroth and Bloomer, 1991, Matsuki and MacLean, 1994, Hemming and Lindroth, 1995, Peacock et al., 1999, Boeckler et al., 2011). Additionally we observed a spatio-temporal shift of herbivores and predators within our field site (chapter 3 ). This spatial distribution across the poplar field site suggested colonization from adjacent hedges, because in spring leaf beetles were most abundant in the field half close to the hedges. In contrast, highest abundances in summer were found in the second half of the field, presumably due to avoidance of tree leaves with induced responses to high beetle density in spring.

The most abundant predatory arthropods in the second experimental field (2009) were generalist predators such as coccinellid and cantharid beetles and spiders (third trophic level). Only few specialised predators such as Symmorphus gracilis (Hymenoptera, Eumenidae) could be observed. The analyses revealed that predatory arthropods were positively affected by the abundance of the leaf beetles, their larvae and eggs. Moreover, we could show that the generalistic coccinellid and cantharid beetles used salicylaldehyde as attractant. Our results further suggest that Harmonia axyridis imagines are able to learn to use salicylaldehyde as an attractant. This is in contrast to the recent literature as salicylaldehyde sequestered from salicin and its derivatives is known to provide protection for leaf beetle larvae against generalist predators (Wallace and Blum, 1969, Smiley, 1991, Palokangas and Neuvonen, 1992).

Similar to the generalist predators in our study the defence effect of salicylaldehyde was ineffective against specialist predators (Pasteels and Gregoire, 1984, Smiley and Rank, 1986, Rank and Smiley, 1994, Zvereva and Rank, 2003). This indicates that specialist predatory eumenid wasps are able to perceive salicylaldehyde and herbivore-induced plant volatiles and that the olfaction ability reflects the degree of prey specialisation of different wasp species. Our results suggest the use of infochemicals for host location and finding by eumenid wasp species (Fig. 2). 


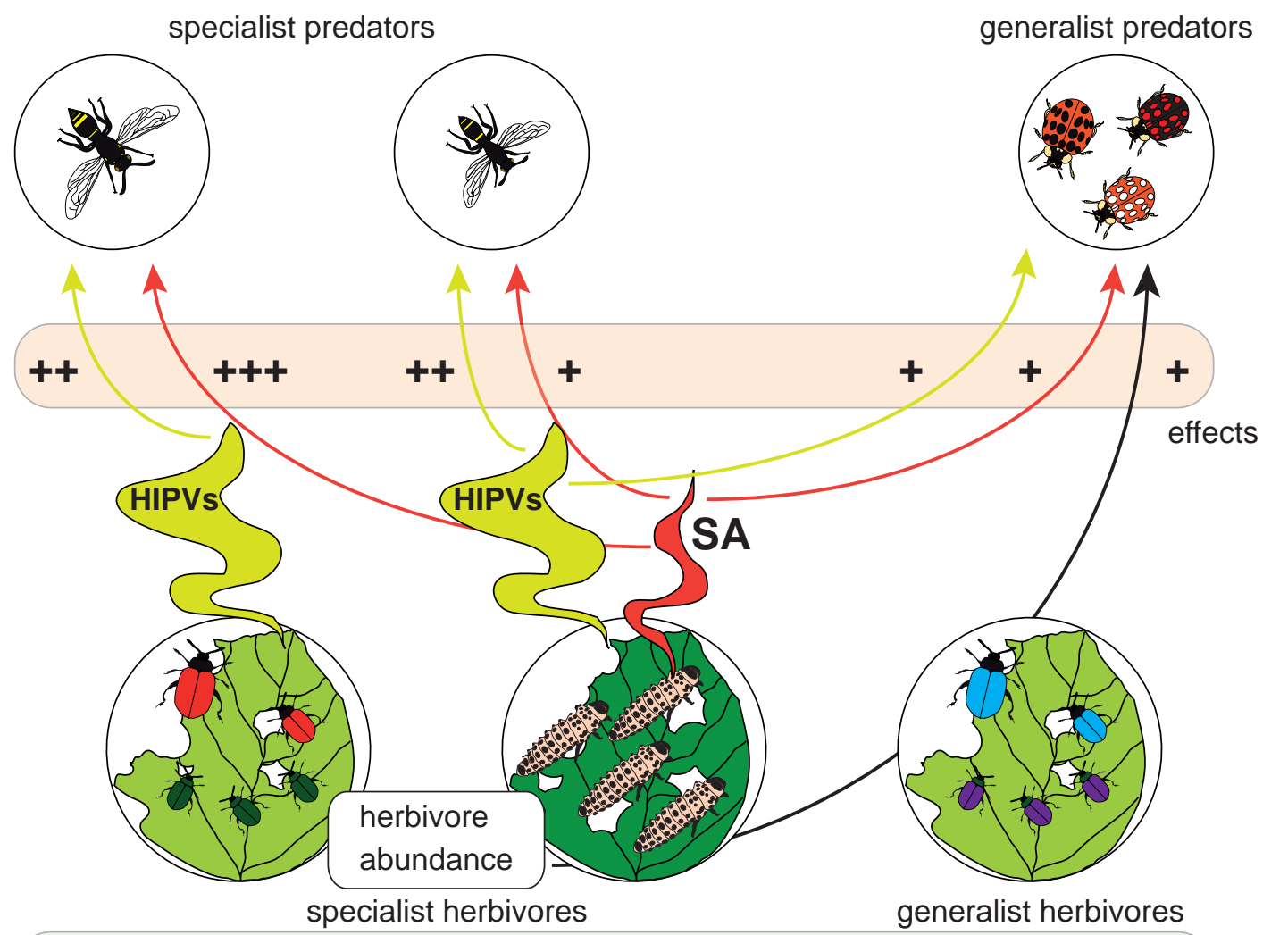

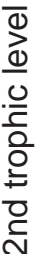

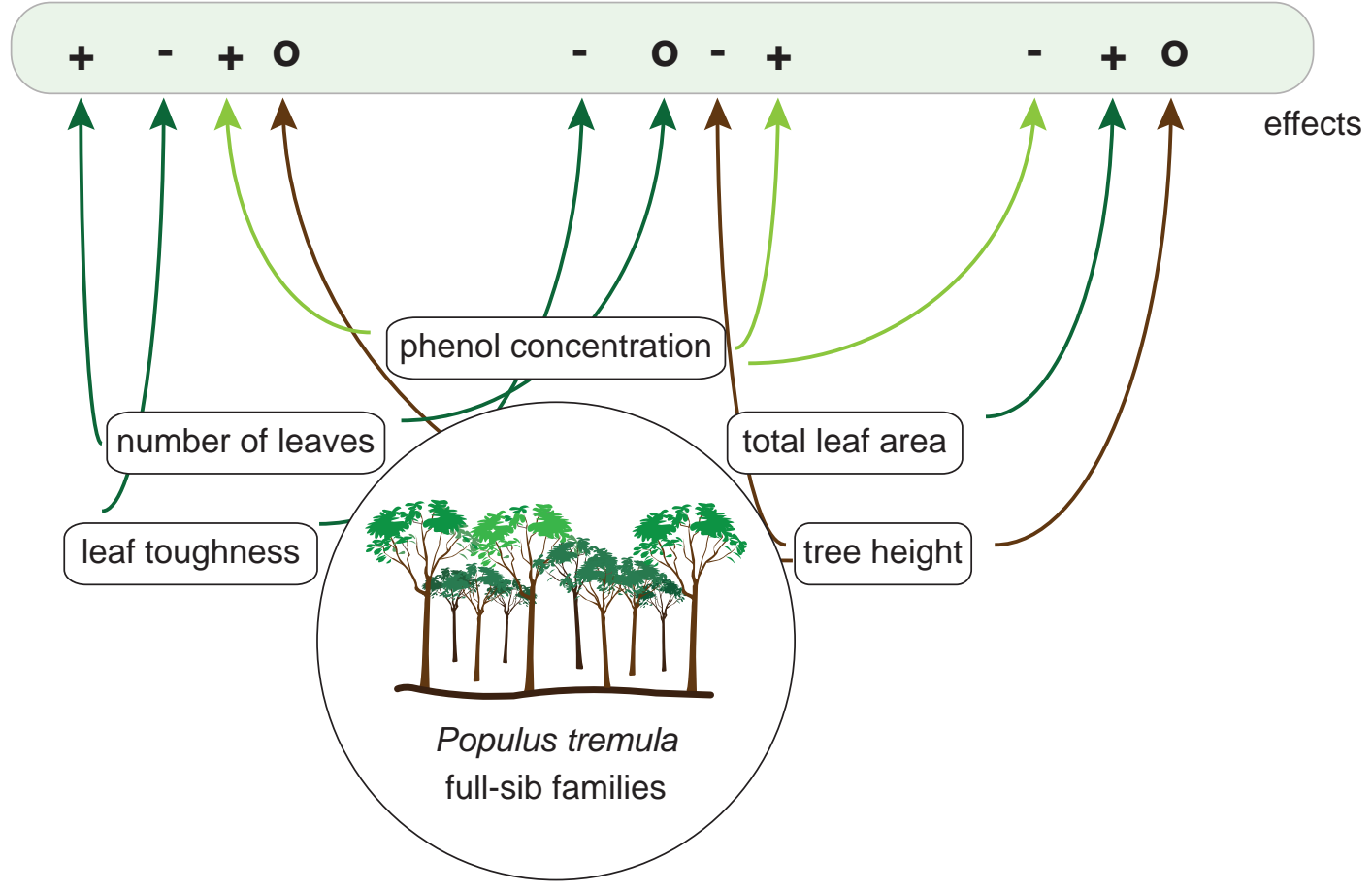

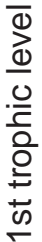

Figure 2: Synthesis of the results of the thesis. HIPVs $=$ herbivore-induced plant volatiles, $\mathrm{SA}=$ salicylaldehyde, $(+)=$ positive effect, $(-)=$ negative effect, $(0)=$ no effect. Specialist predatory wasps: $(+),(++)$ and $(+++)=$ differences in olfaction ability reflects the degree of prey specialisation of different specialized wasp species. 
Overall we conclude that direct and indirect effects shape aspen-insect interactions. Aspen influence herbivorous insects directly via plant morphological, chemical and genetic traits as well as indirectly via their spatial distribution and via temporal aspects. Predators are likewise directly influenced by aspen via emitted herbivore-induced plant volatiles and indirectly via herbivore abundances on the trees. Furthermore, infochemicals emitted by their prey affect generalist and specialist predators in the tritrophic system consisting of Populus tremula, specialist leaf beetles, their larvae and their predators. 


\section{REFERENCES}

Boeckler, G. A., Gershenzon, J., and Unsicker, S. B. 2011. Phenolic glycosides of the Salicaceae and their role as anti-herbivore defenses. Phytochemistry. doi: 10.1016/j. phytochem.2011.01.038.

Hemming, J. D. C., and Lindroth R. L. 1995. Intraspecific variation in aspen phytochemistry: effects on performance of gypsy moth and forest tent caterpillars. Oecologia. 103: 7988.

LeCERF, A., and CHAUvet, E. 2008. Intraspecific variability in leaf traits strongly affects alder leaf decomposition in stream. Basic and Applied Ecology. 9: 598-605.

Lindroth, R. L., and Bloomer, M. S. 1991. Biochemical ecology of the forest tent caterpillar: responses to dietary protein and phenolic glycosides. Oecologia. 86: 408-413.

MAtSUKi, M., and MACLEAN JR., S. M. 1994. Effects of different leaf traits on growth rates of insect herbivores on willows. Oecologia. 100: 141-152.

Palokangas, P., and Neuvonen, S. 1992. Differences between species and instars of leaf beetles in the probability to be preyed on. Annales Zoologici Fennici. 29: 273-278.

Pasteels, J. M., and Gregoire J.-C. 1984. Selective predation on chemically defended chrysomelid larvae. A conditioning process. Journal of Chemical Ecology. 12: 16931700.

Peacock, L., Herrick, S., and Brain, P. 1999. Spatio-temporal dynamics of willow beetle (Phratora vulgatissima) in short-rotation coppice willows grown as monocultures or a genetically diverse mixture. Agricultural and Forest Entomology. 1: 287-296.

Philippe, R. N., and Bohlmann, J. 2007. Poplar defense against insect herbivores. Canadian Journal of Botany. 85: 1111-1126. 
Rank N. E., and Smiley, T. S. 1994. Host-plant effects on Parasyrphus melanderi (Diptera: Syrphidae) feeding on a willow leaf beetle Chrysomela aenicollis (Coleoptera: Chrysomelidae). Ecological Entomology. 19: 31-38.

Simms, E. L., and Rausher, M. D. 1987. Costs and benefits of plant-resistance to herbivory. American Naturalist. 130: 570-581.

Smiley K. S., and Rank, N. E. 1986. Predator protection versus rapid growth in a montane leaf beetle. Oecologia. 70: 106-112.

SmiLey, K. S. 1991. Aggregation benefits in a willow leaf beetle along an elevational gradient, pp. 148-160. In: Hall, C. A. Doyle-Jones, V., and Widawski, B. (eds). Natural history of eastern California and high-altitude research, University of California. White Mountain Research Station Symposium. The regents of the University of California, Los Angeles, USA.

Wallace, J. B., and Blum, M. S. 1969. Refined defensive mechanisms in Chrysomela scripta. Annals of the Entomological Society of America. 62: 503-506.

ZvereVA, E. L., and RANK, N. E. 2004. Fly parasitoid Megaselia opacicornis uses defensive secretions of the leaf beetle Chrysomela lapponica to locate its host. Oecologia. 140: 516-522. 


\section{SuMMARY}

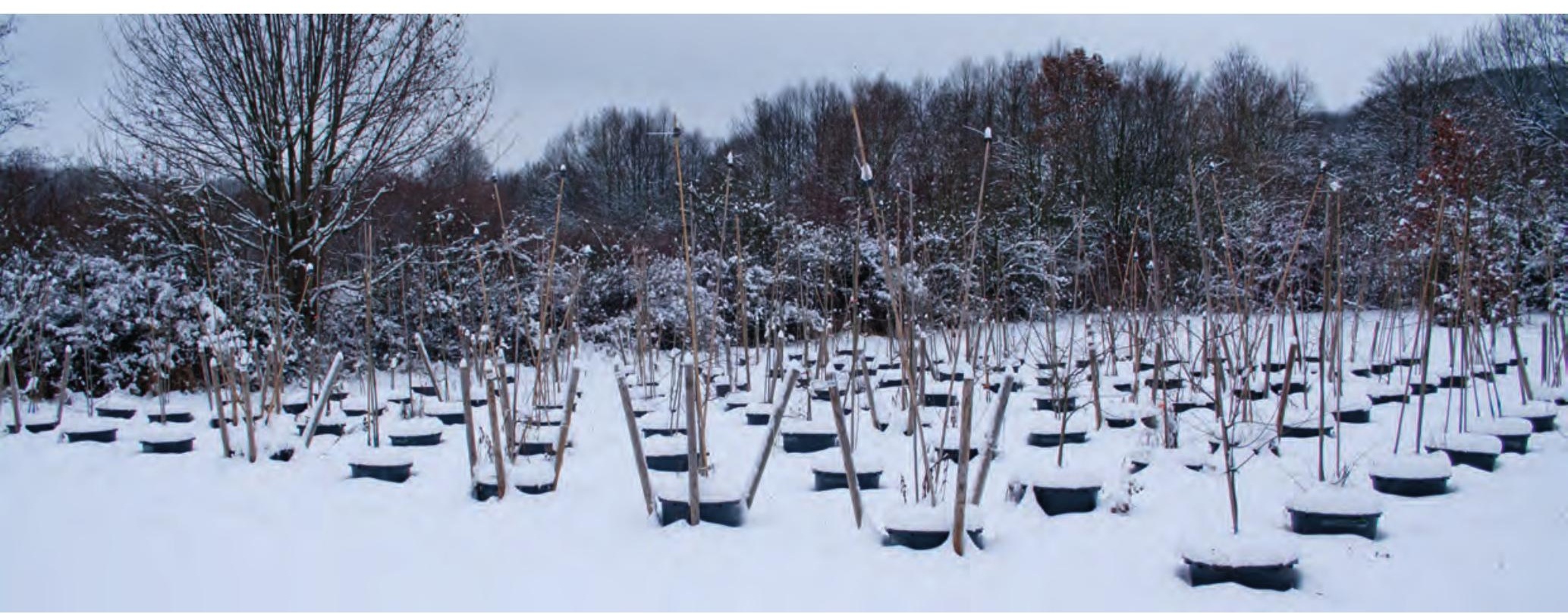




\section{SUMMARY}

A drastic increase of global energy consumption is expected for the following years. Due to the increasing demand for renewable energy, much of the current research focuses on short-rotation forestry with high productive Salix and Populus species as a potential energy source. In this context the European aspen (Populus tremula) gained importance for biomass production, because of its ability to reach considerable growth rates even on poor soils and under unfavourable habitat conditions. The European aspen is a pioneer species and is one of the most widespread tree species in boreal and temperate forests. On natural sites aspen create habitats for a rich arthropod community including many endangered species. Current knowledge in plant-insect interactions of willows and poplars is based on studies, which are mostly concentrated on only two trophic levels and differences in leaf chemistry affecting phytophagous insects.

The aim of the first part of this thesis was to characterize the differences between closely related aspen (P. tremula) full-sib families and to examine the influence of their morphological and chemical traits on herbivorous insects and their natural enemies in real-world multitrophic interactions. Thereto two common garden experiments were established with closely related aspen full-sib families (6 - $51 \%$ genetic distance).

As hypothesized the aspen full-sib families differed in morphological traits such as tree height and leaf number as well as in leaf chemical traits such as phenolic glycosides. In the first common garden experiment a negative relationship was found between phenolic glycosides and chewing herbivorous insects (e.g. Phratora vulgatissima). In the second common garden experiment specialist leaf beetles and their larvae were influenced by different morphological tree traits. The imagines were positively related to the number of leaves (i.e. the resource abundance), whereas leaf beetle larvae were negatively related to tree height, which is in contrast to Lawton's plant size hypothesis. Herbivore-induced plant volatiles differed between spring and summer, but did not change with aspen genetics or herbivore load. Generalist predatory arthropods were indirectly affected by genetic aspen differences as their abundance closely followed the abundance of leaf beetle adults and larvae. They were also positively directly related to emitted herbivore-induced plant volatiles. In addition, after the colonization of one half of the experimental field in spring our results revealed a 
spatio-temporal shift to the second field half in summer, presumably due to avoidance of tree leaves with induced responses because of the spring infestation.

The second part of the thesis is based on the knowledge that predatory arthropods often use infochemical cues for host finding and host location and that multitrophic interactions are often shaped by such infochemicals. The aim of the two studies of the second part was to investigate the olfaction ability of generalist and specialist predatory insects of volatiles emitted by their prey and the prey's host plants and the effects of these volatiles to the predators. This was tested with a field study and laboratory experiments (olfactometer tests and elctroantennography (EAG)). In contrast to recent studies our results showed that generalist predatory beetles such as Harmonia axyridis were attracted by salicylaldehyde, the defense compound of salicin-using leaf beetle larvae. The results further suggest that H. axyridis imagines can learn to use salicylaldehyde as an attractant.

The results of EAG experiments indicate that specialist predatory eumenid wasps are able to perceive salicylaldehyde and herbivore-induced plant volatiles and that the olfaction ability reflects the degree of prey specialisation of the different wasp species.

We conclude that direct and indirect effects shape aspen-insect interactions. Aspen influence herbivorous insects directly via plant morphological, chemical and genetic traits as well as indirectly via their spatial distribution and temporal changes. Predators are likewise directly influenced by aspen via emitted herbivore-induced plant volatiles and indirectly via herbivore abundances on the trees. Furthermore, infochemicals emitted by their prey affect generalist and specialist predators in the tritrophic system consisting of Populus tremula, specialist leaf beetles, their larvae and their predators. 


\section{ZUSAMMENFASSUNG}

Für die kommenden Jahre wird ein dramatischer Anstieg des weltweiten Energieverbrauches erwartet. Aufgrund des wachsenden Bedarfs an erneuerbarer Energie richtet sich das Interesse der aktuellen Forschung auf Kurzumtriebsplantagen mit schnell wachsenden und ertragreichen Salix (Weiden) und Populus (Pappeln) Arten als mögliche Energiequelle. In diesem Zusammenhang erlangt die Europäische Zitterpappel (Populus tremula) an Bedeutung, da sie im Stande ist höhere Erträge auf nährstoffarmen Böden und unter ungünstigen klimatischen Bedingungen zu erbringen. Die Europäische Zitterpappel ist eine Pionier-Art und eine der am weitesten verbreiteten Baumart in borealen und gemäßigten Wäldern. In natürlichen Vorkommen bilden Zitterpappeln Habitate für zahlreiche Insekten. Darunter befinden sich auch eine Vielzahl an gefährdeten Arten. Die meisten Studien über Insekten-Pflanzen Interaktionen an Pappel und Weiden konzentrieren sich auf nur zwei trophische Ebenen. Diese Studien untersuchen vor allem den Einfluss von Unterschieden der chemischen Blattinhaltsstoffe auf pflanzenfressende Insekten.

Die vorliegende Arbeit wurde in zwei Teile untergliedert. Ziel des ersten Teils der Arbeit war es Unterschiede in der Morphologie und der emittierten Blattduftstoffe zwischen nah verwanden Zitterpappel Kreuzungen zu charakterisieren. Ein weiteres Ziel war es herauszufinden, inwiefern die morphologischen und chemischen Merkmale der Bäume pflanzenfressende Insekten und deren natürliche Gegenspieler in „natürlichen multitrophischen Interaktionen“ beeinflussen. Für die Untersuchungen wurden zwei verschiedene Freilandversuche etabliert, in denen eng verwandte Zitterpappel Kreuzungen (mit einer genetischen Distanz zwischen $6-51 \%$ ) gepflanzt wurden Zitterpappeln.

Wie erwartet unterschieden sich die Zitterpappeln der verschiedenen Kreuzungen in ihren morphologischen Merkmalen wie z.B. Baum-Höhe, Blattanzahl, etc. und in chemischen Merkmalen wie phenolischen Glykosiden. Im ersten der beiden Freilandversuche wurde ein negativer Zusammenhang zwischen phenolischen Glykosiden und pflanzenfressenden Insekten (z.B.: Phratora vulgatissima) festgestellt. Im zweiten Freilandversuch wurde herausgefunden, dass spezialisierte Blattkäfer und ihre Larven durch unterschiedliche morphologische Baummerkmale beeinflusst werden. Die Abundnaz der Imagines war positiv mit der Anzahl der Blätter pro Baum (Ressource Abundanz) korreliert, wohingegen 
ein negativer Zusammenhang zwischen der Baum-Höhe und Blattkäfer Larven gefunden wurde, Dieses Ergebnis steht im Gegensatz zur Pflanzen-Größe Hypothese nach Lawton. Durch Herbivoren induzierte Pflanzen Volatilen unterschieden sich in der Abgabemenge zwischen Frühling und Sommer. Es konnten aber weder Unterschiede zwischen den verschiedenen Kreuzungen noch durch verschiedene Herbivoren Abundanz festgestellt werden. Generalistische räuberische Arthropoden wurden indirekt durch genetische Unterschiede der Zitterpappeln (Kreuzungen) beeinflusst, indem ihre Anzahl positiv mit der Zahl der Herbivoren korreliert ist. Auch wurde festgestellt, dass es einen positiven Zusammenhang zwischen abgegebenen Herbivoren induzierten Pflanzen Volatilen und räuberischen Arthropoden gibt. Zusätzlich zeigten unsere Ergebnisse, dass es auf der Fläche eine räumlich-zeitliche Veränderung des Befalls der Bäume gab. Die im Frühjahr befallenen Bäume wurden von der zweiten Generation von Blattkäfern im Sommer gemieden, da diese vermutlich durch den Befall der ersten Blattkäfer Generation induzierte Resistenzen in den Blättern aufwiesen.

Der zweite Teil der vorliegenden Arbeit basiert auf dem Wissen, dass räuberische Arthropoden oft sogenannte „Infochemikalien“ als Signale nutzen um ihre Beute zu lokalisieren und zu finden. Diese Infochemikalien formen häufig multitrophische Interaktionen. Das Ziel der zwei Studien des zweiten Teils der vorliegenden Arbeit war die Untersuchung der olfaktorischen Reaktion von generalistischen und spezialisierten Prädatoren auf Volatilen die von ihrer Beute abgegeben werden und von Volatilen die von den Wirtbäumen der Beute abgegeben werden. Die Studien wurden in einem Freilandversuch und in Laborexperimenten (Olfaktometer Test und Elektroantennographie (EAG)) durchgeführt.

Im Gegensatz zu anderen Studien zeigten die Ergebnisse, dass generalistische räubereische Käfer wie z.B. Harmonia axyridis von Salicylaldehyd, der Abwehr Substanz Salicin sequestrierender Käferlarven, angezogen wurden. Dieses Ergebnis lässt vermuten, dass $H$. axyridis Imagines in der Lage sind zu lernen Salicylaldehyd als Lockstoff zu nutzen.

Die Ergebnisse der EAG Experimente indizieren, dass spezialisierte räuberische Lehmwespen (Eumeninae) in der Lage sind Salicylaldehyd und von Herbivoren induzierte Pflanzen Volatilen wahrzunehmen. Des Weiteren spiegelte die olfaktorische Wahrnehmungsfähigkeit den Grad der Beute-Spezialisierung der drei verschiedenen Wespen Arten wieder. 
Zusammenfassend konnte gezeigt werden, dass direkte und indirekte Effekte die Interaktionen zwischen Zitterpappeln und Insekten beeinflussen und formen. Zitterpappeln beeinflussen pflanzenfressende Insekten sowohl direkt durch morphologische, chemische und genetische Merkmale als auch indirekt durch räumliche Verbreitung und zeitliche Veränderungen (induzierte Resistenz). Ähnlich sind Prädatoren von Zitterpappeln direkt durch Herbivoren induzierte Pflanzen Volatilen und indirekt durch die Anzahl von Herbivoren auf den Bäumen beeinflusst. Darüber hinaus beeinflussen Infochemikalien, abgegeben von Beutetieren, generalistische und spezialisierte Prädatoren in dem tritrophischen System bestehend aus Populus tremula, spezialisierten Blattkäfern, deren Larven und ihren Prädatoren. 


\section{ACKNowledgements}

I sincerely thank my supervisor Prof. Dr. Teja Tscharntke for giving me the opportunity to independently work on my thesis, for his critical advice, guidance and constructive support on the manuscripts of this thesis.

I kindly thank Prof. Dr. Stefan Schütz for his support and providing access to the research facilities of the Department of Forest Zoology and Forest Conservation, where many experiments of this thesis were performed.

Furthermore I thank Prof. Dr. Johannes Steidle for his support and for being part of my thesis committee.

I am grateful to Prof. Dr. Andrea Polle for the coordination of the Göttingen Poplar Diversity Project. Funding was granted by the Ministry of Science and Culture of Lower Saxony and the „Niedersächsisches Vorab“.

I especially want to thank Dr. Christoph Scherber for his priceless help concerning statistical analyses, his patience and spending his valuable time.

With Gerrit Holighaus I had a short, cold and nice winter field season. He was very helpful during all the time of the thesis with constructive feedback and discussions. Also he became a close and reliable friend. Thank you very much also for the funny and painful racing bicycle tours together with Jan.

I really want to thank my two roommates Björn Klatt and Georg "Horscht” Everwand for the great and funny time together. I am also very grateful to my dear colleagues and friends for their help, discussions, inspiration, support, and for having a great time in Göttingen, especially Laura Rose, Jan Seelig, Yann Clough, Jochen Fründ, Andreas Flohre, Suse Schiele, Janna Groenveld, Maria Vlaic, Elisabeth Eilers, Susanne Jahn, Kristin Krewenka, Bernhard Weissbecker, Jutta Gilles and the rest of the Agroecology and Forest Zoology groups.

Finally I deeply thank my parents, for their everlasting support, encouragement, interest, trust and enthusiasm.

A very heartfelt thank goes to my partner Barbara Scheid, who was very encouraging, caring and helping all the time, especially in the last weeks with her help correcting the manuscripts. 


\section{Curriculum Vitae}

\section{Paul-Albin Maximilian von Fragstein und Niemsdorff}

geboren am 21.03.1981 in Stuttgart

\section{Promotion}

2008 - 2011 bei Prof. Dr. Teja Tscharntke am Fachgebiet Agrarökologie, Georg-August-Universität Göttingen

„Tritrophic interacations between Populus tremula, leaf beetles and their natural enemies - from the field to the laboratory"

$2007-2008$

bei Prof. Dr. Johannes L. M. Steidle am Fachgebiet Tierökologie, Universität Hohenheim

„Pheromone glands of click beetles (Coleoptera, Elateridae): Morphology, evolution and systematic significance"

\section{Studium}

$2001-2006$

Biologie an der Universität Hohenheim, Stuttgart,

Schwerpunkte: Zoologie, Tierökologie, Pflanzenphysiologie, Limnologie

Diplomarbeit: „Sexualpheromone bei Schnellkäfern (Elateridae)“ (Note 1,0)

\section{Schulbildung}

$1991-2000 \quad$ Friedrichs Gymnasium, Kassel 


\section{Publications}

Fragstein, M. v., Tscharntke, T., and Schütz, S. 2011. The allomone of leaf beetle larvae (salicylaldehyde) attracts experienced Harmonia axyridis and other predators. (submitted to Biological Control).

Fragstein, M. v., and TscharntKe, T. 2011. Variable responses of leaf beetle adults and larvae and their predators to morphological and genetic differences in Populus tremula trees. (submitted to Agricultural and Forest Entomology).

Fragstein, M. v., Holighaus, G., Tscharntke, T., and Schütz, S. 2011. Porous defense in a tritrophic system: odor perception reflects prey specialisation of potter wasps (Hymenoptera: Eumeninae). (submitted to Journal of Chemical Ecology).

Holighaus, G., Fragstein, M. v., and Schütz, S. 2011. Eight-Carbon volatiles characterize sporphore developmental stage of Fomes fomentarius - Repellent or/and attractant to fungivorous Bolitophagus reticulatus. (in prep).

Holighaus, G., Angeli, S., Fragstein, M. v., and Schütz, S. 2011. Pheromonal function of defensive secretions in Bolitophagus reticulatus (Col., Tenebrionidae). (in prep).

Kleemann, F., Fragstein, M. v., Vornam, B., Müller, A., Leuschner, C., Holzschuh, A., Tscharntke, T., Finkeldey, R., and Polle, A. 2010. Relating genetic variation of ecologically important tree traits to associated organisms in full-sib aspen families. European Journal of Forest Research. 130: 707-716.

Tolasch, T., Fragstein, M. v., and Steidle, J. L. M. 2010. Sex Pheromone of Agriotes acuminatus (Stephens, 1830) (Coleoptera: Elateridae). Journal of Chemical Ecology. 36: 314-318. 
Fragstein, M. v., Tolasch, T., and Steidle, J. L. M. 2008. Pheromondrüsen bei Schnellkäferarten der Gattung Athous (Coleoptera, Elateridae). Mitteilungen der Deutschen Gesellschaft für allgemeine und angewandte Entomologie. 16: 201-204.

Tolasch, T., Fragstein, M. v., and Steidle, J. L. M. 2007. Sex Pheromone of Elater ferrugineus L. (Coleoptera: Elateridae). Journal of Chemical Ecology. 33: 2156-2166. 